$-1-$

ARGONNE NATIONAL LABORATORY

P. O. Box 299

Lemont, Illinois

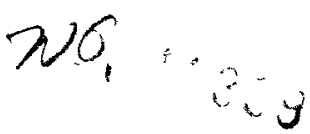

\title{
PHOTOCHEMISTRY OF URANYL COMPOUNDS
}

by

Eugene Rabinowitch

Information Division

January 1954

This paper will be published as part of The Chemistry of Uranium, Part II, National Nuclear Energy Series, Division VIII. It is issued at this time to permit review and comment prior to publication and to make the information available to other Atomic Energy Commis sion laboratories promptly.

Operated by The University of Chicago under

Contract W-31-109-eng-38 


\section{DISCLAIMER}

This report was prepared as an account of work sponsored by an agency of the United States Government. Neither the United States Government nor any agency Thereof, nor any of their employees, makes any warranty, express or implied, or assumes any legal liability or responsibility for the accuracy, completeness, or usefulness of any information, apparatus, product, or process disclosed, or represents that its use would not infringe privately owned rights. Reference herein to any specific commercial product, process, or service by trade name, trademark, manufacturer, or otherwise does not necessarily constitute or imply its endorsement, recommendation, or favoring by the United States Government or any agency thereof. The views and opinions of authors expressed herein do not necessarily state or reflect those of the United States Government or any agency thereof. 


\section{DISCLAIMER}

Portions of this document may be illegible in electronic image products. Images are produced from the best available original document. 


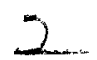

TABLE OF CONTENTS

Page

1. Photochemical Reactions of Uranyl Ions with Inorganic

Compounds......................... 4

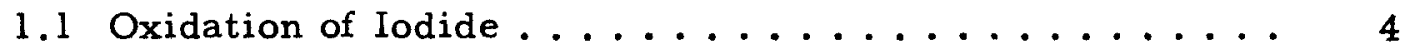

1.2 Oxidation of Other Inorganic Reductants .......... 17

1.3 Uranyl-sensitized Oxidation of Water by Bromate .... 18

2. Photochemical Reactions of Uranyl Ions with Organic

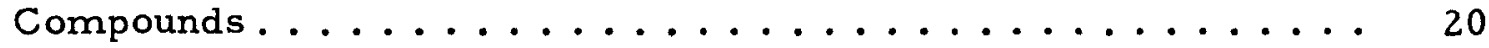

2.1 Monobasic Aliphatic Acids............... 20

2.2 Dibasic Aliphatic Acids ............... 37

3. Substituted Aliphatic Acids ................... 77

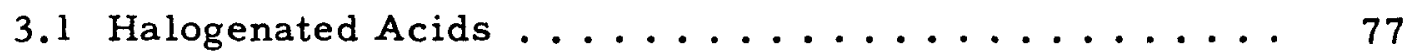

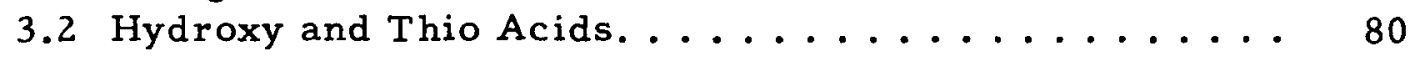

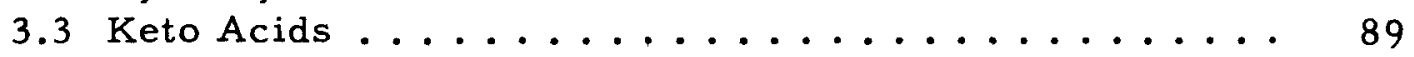

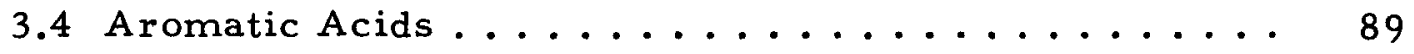




\section{3 \\ PHOTOCHEMISTRY OF URANYL COMPOUNDS}

\section{INT R ODUCTION}

Photochemistry of uranyl compounds is one of the most extensively studied and also the most confused chapters of photochemistry. One of the reasons may be that the primary photochemical reactions are slow, giving time for many different secondary thermal reactions to develop. Another reason is that much of the study in this field has been done by insufficiently precise methods. Mechanisms often were suggested to fit a given set of observations without considering whether they could be reconciled with the other sets available in the literature.

In the presentation below, some attempts have been made to establish correlations between the different studies, but much of it is tenuous and many contradictions remain unresolved. Much of the field calls for renewed experimental investigation with better research tools and more precise analysis of the results.

To understand the slow rate of photochemical reactions of uranyl ions in visible light, it must be borne in mind that the average mola $r$ absorption coefficient of non-complexed uranyl ions in the region 400-500 $\mathrm{m} \mu$ (the absorption is negligible $>500 \mathrm{~m} \mu$ ) is of the order of 5 liters mole $\mathrm{cm}^{-1}$ only (cf. Figure 2.3). Consequently, to obtain $50 \%$ absorption over a light path of $1 \mathrm{~cm}$, the $\mathrm{UO}_{2}^{++}$concentration must be of the order of $0.06 \mathrm{~mole} / \mathrm{liter}$.

If a solution of this concentration, $1 \mathrm{~cm}$ deep, is exposed to a light flux of $\mathrm{n}$ einstein/( $\left.\mathrm{sec} 1000 \mathrm{~cm}^{2}\right)$ and undergoes a photochemical reaction with a quantum yield of 1 , it will need $0.06 / \mathrm{n} \mathrm{sec}$ for half-transformation if the absorption remains constant (sensitized reaction), and somewhat less than twice this time if the absorption declines with the progress of the reaction (direct photochemical reactions of $\mathrm{UO}_{2}^{+}$, e.g., oxidation-reductions with $\mathrm{UO}_{2}^{++}$as oxidant). The half-decomposition time for direct reaction is therefore

$$
\begin{array}{llll}
\text { about } 6 \times 10^{3} \mathrm{sec} & \text { for } & \mathrm{n}=10^{-5}\left[6 \times 10^{15} \text { quanta } /\left(\sec \mathrm{cm}^{2}\right)\right] \\
\text { about } 6 \times 10^{4} \mathrm{sec} & \text { for } & \mathrm{n}=10^{-6}\left[6 \times 10^{14} \text { quanta } /\left(\sec \mathrm{cm}^{2}\right)\right] \\
\text { about } 6 \times 10^{5} \mathrm{sec} & \text { for } & \mathrm{n}=10^{-7}\left[6 \times 10^{13} \text { quanta } /\left(\sec \mathrm{cm}^{2}\right)\right]
\end{array}
$$

Diffuse daylight (illumination of the order of 10,000 lux) corresponds to about $10^{14}$ quanta/ $\left(\mathrm{sec} \mathrm{cm}^{2}\right)$ in the region $\lambda<500 \mathrm{~m} \mu$. A one $\mathrm{cm}$ layer of $0.06 \mathrm{M}$ uranyl solution, exposed to such light, and reacting with a quantum yield of 1 , will consequently require about five days of continuous illumination for halfdecomposition. In other words, an average $\mathrm{UO}_{2}^{++}$ion will absorb, under these conditions, only one quantum every 5 days. 


$$
4
$$

Many uranyl reactions, particularly those with organic acids, proceed, however, mainly or exclusively by light absorption in uranyl-anion complexes, which may absorb considerably more strongly than the free ions (cf. Chap. 2).

Remarkably enough, it seems that in several cases excitation of a complex $\mathrm{UO}_{2}^{++} \mathrm{A}^{-}$is insufficient to cause a reaction of $\mathrm{UO}_{2}^{++}$with $\mathrm{A}^{-}$without a further encounter, $\left[\mathrm{UO}_{2}^{++} \mathrm{A}^{-}\right] *+\mathrm{A}^{-}$.

\section{PHOTOCHEMICAL REACTIONS OF URANYL IONS WITH INORGANIC COMPOUNDS}

Uranyl ions can serve in light either as oxidants, or as sensitizers for oxidation by other oxidants, particularly molecular oxygen "autoxidation"). The results of photochemical experiments in which air was not rigorously excluded often are ambiguous because of the superimposition of these two phenomena.

The best-known photochemical reactions of uranyl ions are those with organic compounds, such as formic acid, oxalic acid, and other fatty acids. Among reactions with inorganic reductants, only that with iodide has been investigated quantitatively, and even this reaction has been studied only with very crude techniques.

1.1 Oxidation of Iodide - Luther and Michie (1908) stated that uranyl salts "slowly precipitate iodine from potassium iodide solutions." This observation probably was made in the presence of light and air, and, most likely, refers to uranyl-sensitized photochemical autoxidation of iodide. Baur (1910), starting from a theory of the photogalvanic effect (Becquerel effect) in oxidationreduction systems, predicted that in the absence of air, light will cause a reversible shift of the oxidation-reduction equilibrium of the couples uranyl ion-uranous ion and iodine-iodide ion; he expected this shift to produce a strong photogalvanic effect. Trumpler (1915) tried to detect the latter, but found only a very weak change of galvanic potential in light. He used a solution $0.1 \mathrm{M}$ in $\mathrm{UO}_{2} \mathrm{SO}_{4}, 0.02 \mathrm{~N}$ in $\mathrm{I}_{2}, 0.04 \mathrm{~N}$ in $\mathrm{KI}$ and $1 \mathrm{~N}$ in $\mathrm{H}_{2} \mathrm{SO}_{4}$. It will be noted that it contained a considerable proportion of iodine, and we will see below that the photochemical reaction of uranyl ions with iodide ions stops with the formation of a small amount of free iodine. This may explain Trumpler's negative results.

That uranyl ions do react in light with iodide, even in the absence of air, was first observed, also in Baur's laboratory, by Hatt (1918). He noted that the liberation of iodine ceased after only a few per cent of the available iodide was oxidized. The final "photostationary" concentration of iodine depended on the intensity of illumination, $L$, but increased much slower than proportionally with it. 
5

Let us assume that the reaction in light is a reversible oxidationreduction:

$$
\mathrm{U}(\mathrm{VI})+2 \mathrm{I}^{-} \frac{\text { light }}{\text { dark (and light }} \text { ?) } \mathrm{U}(\mathrm{IV})+\mathrm{I}_{2}
$$

The normal redox potential of the iodine-iodide couple is $-\underline{0.535}$ volt and is independent of $\mathrm{pH}$. The empirical uranyl-uranous potentials are variable and difficult to interpret because of complex formation, and probably also because of intermediate formation of $U(V)$ ions (cf. Chap. ), but from the the rmodynamic data for the free ions $\mathrm{UO}_{2}^{++}$and $\mathrm{U}^{+4}$, (cf. Chap. ), we calculate $E_{0}^{\prime}=-\underline{0.48}+4 \times 0.03(\mathrm{pH})$ volt.

Iodine molecules are thus somewhat stronger oxidants than uranyl ions at all practically significant $\mathrm{pH}$ values; it is therefore plausible that reaction (1) should proceed in the dark from the right to the left.

If this back reaction occurred in the simple way indicated in reaction (1) [ and not, for example, via the intermediate formation of $U(V)$ ], and if all $\mathrm{U}(\mathrm{IV})$ present in the illuminated solutions was due to the photochemical reduction of $\mathrm{U}(\mathrm{VI})$ (making the concentrations $\left[\mathrm{I}_{2}\right]$ and $[\mathrm{U}(\mathrm{IV})]$ identical), the rate of the back reaction would be

$$
-\frac{d[U(I V)]}{d t}=\text { const. } x[U(I V)]\left[I_{2}\right]=\text { const. } x[U(I V)]^{2}
$$

Assuming, further, that $\mathrm{U}(\mathrm{VI})$ is present in large excess (so that the concentration [U(VI)] is not markedly depleted in light) and that the concentration of $\left[\mathrm{I}^{-}\right]$is high enough to permit all excited $\mathrm{UO}_{2}^{++}$ions to react with $\mathrm{I}^{-}$during the excitation period, the rate of the forward reaction in (1) must be, independently of the concentration $\left[\mathrm{I}^{-}\right]$:

$$
+\frac{d[U(I V)]}{d t}=\text { const. } \times L
$$

where $L$ is the rate of light absorption, which is proportional to the intensity of incident light.

We then have for the photostationary state (designated by an asterisk):

$$
[\mathrm{U}(\mathrm{IV})]^{*}=\left[\mathrm{I}_{2}\right]^{*}=\text { const. } x \sqrt{\mathrm{L}}
$$

Hatt's results indicated that $\left[I_{2}\right] *$ is proportional to a power of $L$ even lower than $1 / 2$; using the empirical formula $\left[\mathrm{I}_{2}\right]^{*}=$ const. $\times \mathrm{L}^{1 /} \mathrm{x}$, he obtained values of $\underline{x}$ between 3.6 and 7 . Baur suggested that such a high value of $\underline{x}$ can be explained by a high order of the back reaction. He attempted to make the latter plausible by assuming a very complicated mechanism for this reaction, 
involving intermediary formation of the ions $U(\mathrm{~V})$, their dismutation, and a final reaction involving five ions. We do not need to discuss this implausible mechanism, since it was abandoned in the next paper from Baur's laboratory. This publication, by Ouellet (1931), contained the somewhat more precise determinations of the photostationary state shown in Table 4.1.

Table 4.1

PHOTOSTATIONARY STATE IN URANYL IODIDE SOLUTIONS (after Ouellet, 1931)

$50 \mathrm{cc} 0.1 \mathrm{~N} \mathrm{UO}_{2} \mathrm{SO}_{4} ;[\mathrm{KI}]=$ about $0.01 \mathrm{~N} ;$ no $\mathrm{O}_{2}$, No $\mathrm{I}_{2}$ formed in the dark after several days.

\begin{tabular}{|l|c|c|c|}
\hline Light & $\begin{array}{c}\text { Intensity } \\
\text { (in 1000 lux) }\end{array}$ & {$\left[\mathrm{I}_{2}\right]^{*}$ obs. (a) } & {$\left[\mathrm{I}_{2}\right]^{*}$ calc. (Eq. 5) } \\
\hline A rtificial & 1.8 & 9.7 & -- \\
& 7.5 & 12.7 & -- \\
& 11 & 14.6 & -- \\
Sun (Series 1) & 170 & 24.8 & 25 \\
& 360 & 33.2 & 34 \\
& 660 & 40.7 & 40 \\
& 900 & 41.0 & 42 \\
Sun (Series 2) & 170 & 27.5 & 30 \\
& 360 & 36 & 39 \\
& 660 & 53 & 55 \\
& 900 & 57 & 59 \\
Sun (Series 3) & 465 & 49 & -- \\
& 870 & 54 & -- \\
Sun (Series 4) & 445 & 35.4 & -- \\
& 850 & 41.5 & - \\
\hline
\end{tabular}

${ }^{\text {(a) }}\left[\mathrm{I}_{2}\right]^{*}$ expressed in cc of $4 \times 10^{-4} \mathrm{~N} \mathrm{Na}_{2} \mathrm{~S}_{2} \mathrm{O}_{3}$ needed for titration of the solution after illumination.

The "calculated" $\left[I_{2}\right]^{*}$ values in Table 4.1 were derived from an empirical equation:

$$
\left[I_{2}\right]^{*}=\frac{L}{A+B L} \text {, }
$$


with the constants

$$
\begin{aligned}
& A=3400, B=0.020 \text { in series } 1 ; \\
& A=3400, B=0.0113 \text { in series } 2
\end{aligned}
$$

Ouellet proceeded to show that an equation of type (5) can be derived from Baur's quaint theory of photochemistry as "molecular electrochemistry." According to this theory, light causes a "polarization" of the absorbing molecule, and the charges on the two "poles" are removed by reactions with cathodic and anodic "depolarizers" present in solution. For example, the reactions in the uranyl iodide solution were represented by Baur as follows:

$$
\begin{aligned}
& \mathrm{U}(\mathrm{VI}) \stackrel{\text { light }}{\longrightarrow}[\mathrm{U}(\mathrm{VI})] \pm \pm \text { (polarization) }
\end{aligned}
$$

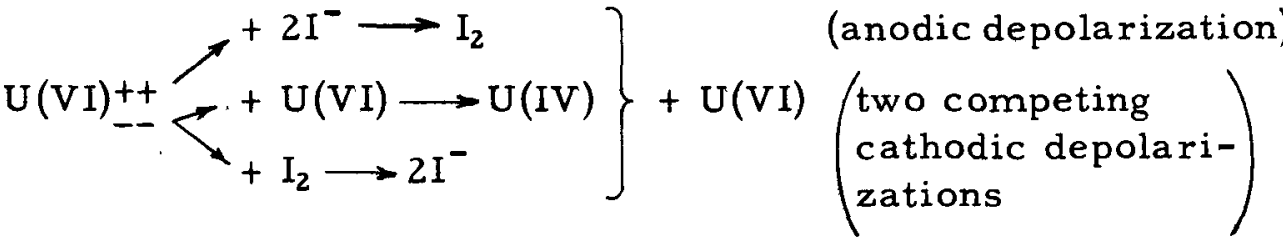

Reaction (6d) represents "depolarization" by one of the reaction products (iodine) and, as such, should cause "self-inhibition" of the forward reaction $(6 b, c)$. This "negative auto-catalysis" accounts, according to Baur and Ouellet, for the second term in the denominator of (5), and thus for the rapid "light saturation" of reaction (1).

Replacing "molecular electrolysis" by the usual photochemical concepts, one could imitate reaction system $(6 \mathrm{a}-\mathrm{d})$ by assuming that light absorbed by $\mathrm{UO}_{2}^{++}$ions can sensitize the back reaction between $\mathrm{U}(\mathrm{IV})$ and $\mathrm{I}_{2}$. However, a simpler and more natural assumption, which leads to a similar result, is that with increasing concentration of iodine, more and more light is absorbed by the latter (instead of by the uranyl ions) and that under these conditions the back reaction in (1) becomes predominantly photochemical:

$$
\mathrm{I}_{2} \stackrel{\text { light }}{\longrightarrow} \mathrm{I}_{2} \text { * }(\text { or } \mathrm{I}+\mathrm{I}) \stackrel{+\mathrm{U}(\mathrm{IV})}{\longrightarrow} \mathrm{U}(\mathrm{VI})+2 \mathrm{I}^{-}
$$

One is at first tempted to suggest that the dark back reaction in (1) may be so slow that even in moderate light (1) will be practically entirely a photochemical reaction. Hatt has, in fact, observed that preilluminated systems containing uranyl ions, iodide and photochemically formed iodide can be left in the dark for several days without losing entirely the brown color they have acquired in light. However, kinetic analysis shows that a combination of two opposing purely photochemical reactions would lead to a photostationary state which is independent of light intensity. The amount of light absorbed by iodine in a mixture containing uranyl ions as competing absorbers is:

$$
\mathrm{L}_{\mathrm{I}_{2}}^{\mathrm{abs}}=\frac{\bar{\alpha}_{\mathrm{I}_{2}}\left[\mathrm{I}_{2}\right] \mathrm{L}_{\text {total }}^{\mathrm{abs}}}{\bar{\alpha}_{\mathrm{I}_{2}}\left[\mathrm{I}_{2}\right]+\bar{\alpha}_{\mathrm{UO}_{2}^{++}}\left[\mathrm{UO}_{2}^{++}\right]}
$$


where the $\bar{\alpha}$ 's are the average absorption coefficients of the two colored species for the light used. Since we assumed $\mathrm{UO}_{2}^{++}$to be present in excess, and $\left[\mathrm{UO}_{2}^{++}\right]$therefore to be practically constant, we have, for the photostationary state:

$$
\mathrm{L}_{\mathrm{I}_{2}}^{\mathrm{abs}} * \frac{\left[\mathrm{I}_{2}\right]^{*} \mathrm{~L}_{\text {total }}^{\text {abs }}}{\mathrm{K}+\left[\mathrm{I}_{2}\right]^{*}}
$$

where

$$
\mathrm{K}=\frac{\bar{\alpha}_{\mathrm{UO}_{2}^{+}+}\left[\mathrm{UO}_{2}^{+}\right]}{\bar{\alpha}_{\mathrm{I}_{2}}\left[\mathrm{I}_{2}\right]}
$$

The amount of light absorbed by uranyl ions in the photostationary state is:

$$
\mathrm{L}_{\mathrm{UO}_{2}^{++}}^{\text {abs }}=\mathrm{L}-\mathrm{L}_{\mathrm{I}_{2}}^{\mathrm{abs}}{ }^{*}=\frac{\mathrm{KL}_{\text {total }}^{\text {abs }}}{\left[\mathrm{I}_{2}\right]^{*}+\mathrm{K}}
$$

If the quantum yields of the forward and the backward reaction were the same (e.g., unity), the photostationary state would be simply the state in which one-half of the light is absorbed by $\mathrm{UO}_{2}^{++}$, and the other half by $\mathrm{I}_{2}$

$$
\left[\mathrm{I}_{2}\right]^{*}=\mathrm{K}
$$

independently of light intensity.

The quantum yield of the forward reaction may be 1 , since $\mathrm{I}^{-}$is present in concentrations of the order of $10^{-2} \mathrm{M}$ which should be enough for all excited $\mathrm{UO}_{2}^{++}$ions to encounter $\mathrm{I}^{-}$ions within the period of excitation. The quantum yield of the back reaction, on the other hand, may be $<1$ [because of the lower concentration of $U(I V)$, or because of primary recombination of some of the iodine atom pairs formed by the photochemical process, $\left.\mathrm{I}_{2} \stackrel{\mathrm{h \nu}}{\rightleftharpoons} \mathrm{I}+\mathrm{I}\right]$. This will make $\left[\mathrm{I}_{2}\right] *>\mathrm{K}$, but leave it independent of light intensity. On the other hand, since the absorption spectra of the two colored species, $\mathrm{UO}_{2}^{++}$and $\mathrm{I}_{2}$, are different, the constant $\mathrm{K}$, and with it the photostationary concentration of iodine, would depend on the spectral composition of the light used.

To sum up, if (1) were a purely photochemical reaction in both directions, the intensity of illumination, while affecting the rate of approach to the photostationary state, would not affect the composition of the solution once this state has been reached; the latter would, however, depend on the spectrum of the illuminating light.

Experimentally, $\left[\mathrm{I}_{2}\right] *$ is practically independent of light intensity only in strong light; it declines to zero as light becomes weaker. Assuming that this decline is real (and not due merely to a very slow approach to the 
equilibrium), it can be explained by assuming that the photochemical back reaction is superimposed on a slow thermal back reaction. The limiting value of $\left[\mathrm{I}_{2}\right]^{*}$, reached in strong light, can be derived from the data in Table 4.1; it is of the order of $5 \times 10^{-4} \mathrm{M}$. Inserted in (12) and (10) this gives a value of about 200 for the ratio $\bar{\alpha}_{\mathrm{I}_{2}} / \bar{\alpha} \mathrm{UO}_{2}^{++}$. The absorption coefficients of $\mathrm{UO}_{2}^{++}$in aqueous solution for visible light are of the order of 1-10; those of iodine are of the order of 100-1000, so that their ratio is, in fact, of the order of $10^{2}$. More exact verification is not possible on the basis of Ouellet's results, since they were obtained in white light of unknown spectral composition. (Also, the quantum yield of the two reactions needs to be determined experimentally.)

An equation can be derived for the stationary concentration, $\left[\mathrm{I}_{2}\right]^{*}$, as a function of light intensity, containing, as parameters, the rate constant of the thermal back reaction,

$$
\mathrm{U}(\mathrm{IV})+\mathrm{I}_{2} \stackrel{\mathrm{k}_{1}^{\prime}}{\longrightarrow} \mathrm{U}(\mathrm{VI})+2 \mathrm{I}^{-},
$$

and the quantum yields of the forward and the reverse photochemical reaction, $\gamma$ and $\gamma^{\prime}$. This equation is of the third order, even under the simplest assumptions; the primitive measurements of Ouellet do not justify an effort to analyze them by means of such an elaborate equation. It can be seen without mathematical analysis that $\left[\mathrm{I}_{2}\right]^{*}$ will increase with $\sqrt{\mathrm{L}}$ at low intensities (where the back reaction is practically entirely thermal) and approach saturation in strong light, where the back reaction is practically completely photochemical. This is in general agreement with the experiment.

If this interpretation is correct, the reaction of uranyl ions with iodide offers an interesting subject for more precise study, as a rather unusual example of an inorganic oxidation-reduction system in which visible light accelerates the reaction in both directions.

Carter and Weiss (1940) noted that the oxidation of uranous salts to uranyl salts by iodine is retarded by acids. (A similar observation was made in 1909 by $\mathrm{McCoy}$ and Bunzel in the case of oxidation of uranous salts by oxygen.) They therefore expected to find the stationary amount of iodine, produced by illumination of $\mathrm{UO}_{2}^{++}+\mathrm{I}^{-}$mixtures, to increase with acidity. This expectation was confirmed by the experimental results listed in Table 4.2.

The complete absence of iodine in illuminated solutions containing no added acid contradicts the above-described earlier results of Hatt and Ouellet (cf. Table 4.1). However, exact comparison would require the consideration of intensity and spectral composition of the light used in the two investigations. It will also be noted that Ouellet used a 10:1 excess of uranyl sulfate over iodide, while Carter and Weiss operated with a reverse ratio of the two components. This may change the character and the concentration of the complexes present in solution. 
10

Table 4.2

IODINE LIBERATION FROM IODIDE BY URANYL IONS IN LIGHT (after Carter and Weiss, 1940)

$0.0166 \mathrm{M} \mathrm{UO}_{2} \mathrm{SO}_{4} ; 0.15 \mathrm{M} \mathrm{KI} ;\left[\mathrm{I}_{2}\right]$ present after one hour illumination

\begin{tabular}{|c|c|c|}
\hline Acid added & {$\left[\mathrm{I}_{2}\right]$, moles/liter } & {$[\mathrm{U}(\mathrm{IV})]$, moles/liter } \\
\hline None & 0 & 0 \\
$1.0 \mathrm{M}$ & $0.125 \times 10^{-3}$ & $0.15 \pm 0.05 \times 10^{-3}$ \\
$2.0 \mathrm{M}$ & $0.25 \times 10^{-3}$ & $0.30 \pm 0.05 \times 10^{-3}$ \\
\hline
\end{tabular}

The photochemical reaction of uranyl ions with iodide ions in the presence of oxygen was studied quantitatively by Schneider (1935). In his paper, sensitization was attributed to "collisions of the second kind," i.e., to energy transfer from $\mathrm{UO}_{2}^{++*}$ to $\mathrm{I}^{-}$. However, the $\mathrm{I}^{-}$ions have no excited electronic states low enough to permit the acceptance of the excitation energy of $\mathrm{UO}_{2}^{++*}$; neither is the latter sufficient to bring about the dissociation:

$$
\mathrm{UO}_{2}^{++*}+\mathrm{I}^{-} \cdot \mathrm{H}_{2} \mathrm{O} \longrightarrow \mathrm{UO}_{2}^{++}+\mathrm{I}+\mathrm{H}+\mathrm{OH}^{-}
$$

(a type of elementary photochemical processes suggested by Franck and Haber). Schneider suggested that energy transfer is made possible in this case by an (at least partial) utilization of the recombination energy of the atoms $\mathrm{H}$ and $\mathrm{I}$ :

$$
\mathrm{UO}_{2}^{++*}+\mathrm{I}^{-} \cdot \mathrm{H}_{2} \mathrm{O} \longrightarrow \mathrm{UO}_{2}^{++}+\mathrm{HI}+\mathrm{OH}^{-}\left(\longrightarrow \mathrm{UO}_{2}^{++}+\mathrm{H}^{+}+\mathrm{I}^{-}+\mathrm{OH}^{-}\right)
$$

The net chemical change in (15) is zero, and Schneider suggested that iodine liberation only occurs when the HI molecules meet an oxidant, such as molecular oxygen, before dissociating into $\mathrm{H}^{+}+\mathrm{I}^{-}$. He concluded from this theory that no iodine at all should be liberated in the absence of oxygen and gave Fig. 4.1 as experimental confirmation of this prediction. However, this conclusion contradicts the results of the above-described experiments of Hatt, Ouellet, and Carter and Weiss who have observed and measured the iodine production in oxygen-free atmosphere.

On theoretical grounds, the hypothesis of interim HI formation is implausible. Pringsheim (1937) pointed out that the assumption of collisions of the second kind as mechanism of quenching of $\mathrm{UO}_{2}^{++}$fluorescence by iodide ions encounters grave difficulties (cf. Chap. 3), and Weiss (1938) suggested 


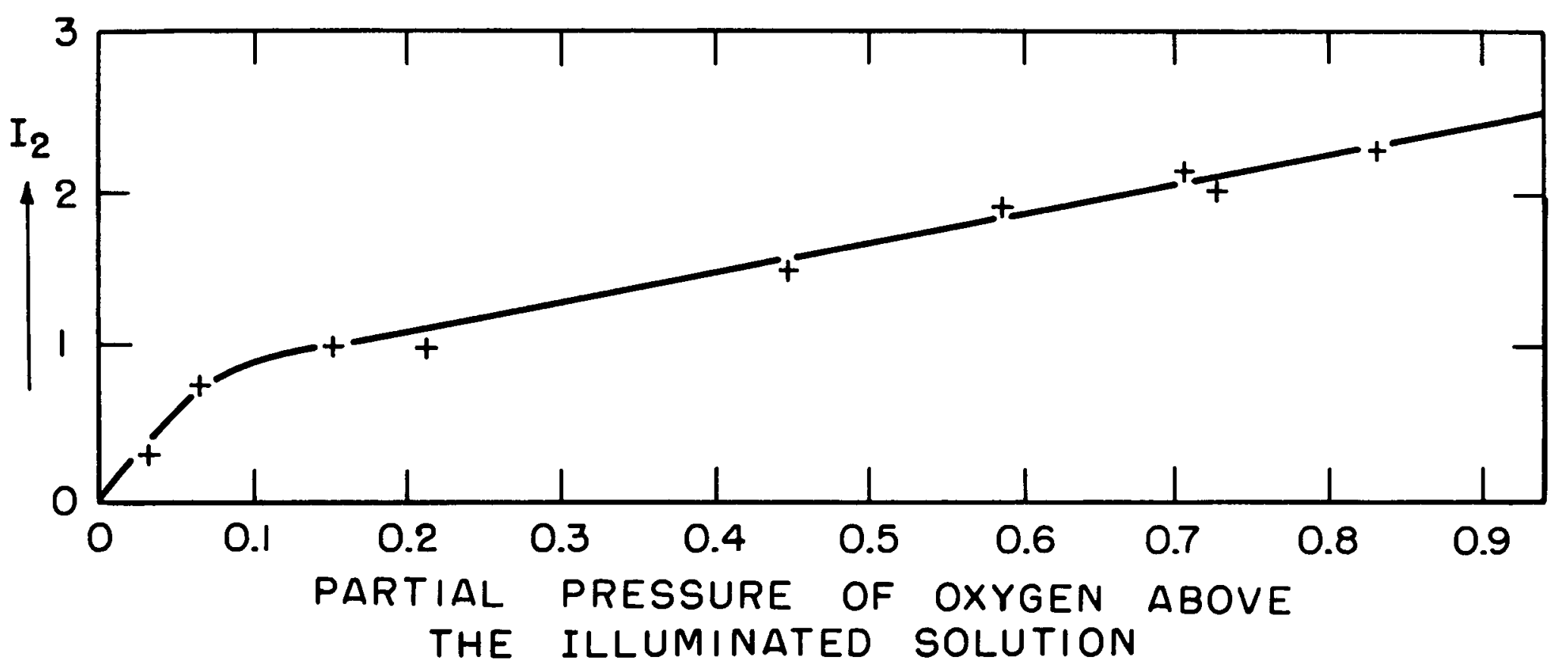

Fig. 4.I. Dependence of iodine formation (in relative units) on oxygen concentration. Solution: $0.025 \mathrm{~N} \mathrm{KI}, 0.05 \mathrm{M} \mathrm{UO}_{2} \mathrm{SO}_{4}$ (after Schneider, 1935). 


\section{2}

that Schneider's results could be much better interpreted by assuming a transfer of electrons (rather than a transfer of energy) from the excited molecule to the quencher. If (13) is the primary process of quenching, the increased yield of iodine in the presence of oxygen can be explained by competition between the reoxidation of $\mathrm{UO}_{2}^{+}$by $\mathrm{I}$ and by $\mathrm{O}_{2}$.

$$
\begin{aligned}
& \mathrm{UO}_{2}^{++}+\mathrm{I}^{-} \stackrel{\mathrm{h} \nu}{\longrightarrow} \mathrm{UO}_{2}^{+}+\mathrm{I} \\
& \mathrm{UO}_{2}^{+}\left\{\begin{array}{l}
+\mathrm{I} \longrightarrow \mathrm{UO}_{2}^{++}+\mathrm{I}^{-} \\
+1 / 4 \mathrm{O}_{2}+\mathrm{H}^{+} \longrightarrow \mathrm{UO}_{2}^{++}+1 / 2 \mathrm{H}_{2} \mathrm{O}
\end{array}\right\} \begin{array}{l}
\text { competitive } \\
\text { re-oxidation } \\
\text { of } \mathrm{U}(\mathrm{V})
\end{array} \\
& \mathrm{I}+\mathrm{I} \longrightarrow \mathrm{I}_{2}
\end{aligned}
$$

Fig. 4.2 shows the yield of iodine (in relative units) as a function of iodide concentration in $0.025 \mathrm{M} \mathrm{UO}_{2} \mathrm{SO}_{4}$ solution according to Schneider. The two curves are for solutions with and without added acid. The effect of acid concentration is shown in Fig. 4.3, in which the yield is plotted against acidity.

The gradual approach to [I-] saturation could be understood on the basis of either the electron transfer or the energy transfer theory. In the absence of acid, the rate is "half-saturated" at about $5 \times 10^{-4} \mathrm{M}$ iodide; if it is assumed that the reaction of $\mathrm{UO}_{2}^{++*}$ with $\mathrm{I}^{-}$competes with fluorescence, half-saturation must be achieved when $\left.k_{\phi}=k^{-}\right]$, (where $k_{\phi}$ is the rate constant of fluorescence, or $\sim 10^{4} \mathrm{sec}^{-1}$ for $\mathrm{UO}_{2}^{++}$; cf. Chap. 3). This gives $k \approx 2 \times 10^{7}$. (A value of the same order of magnitude, $k=5 \times 10^{7}$, was found by Carter and Weiss for the rate constant of quenching of uranyl nitrate fluorescence by iodide.) In the presence of $0.008 \mathrm{~N} \mathrm{H}_{2} \mathrm{SO}_{4}$ the curve rises much more steeply and, after reaching saturation, shows a slow decline with increasing $\left[\mathrm{I}^{-}\right]$. Dis regarding this decrease, we estimate that the rate is half-saturated at about $2 \times 10^{-4} \mathrm{M}$, corresponding to $\mathrm{k}=5 \times 10^{7}$. The order of magnitude of these $k$ values $\left(2-5 \times 10^{7}\right)$ appears at first to be incompatible with the assumption of a reaction by the first encounter between $\mathrm{UO}_{2}^{++*}$ and $\mathrm{I}^{-}$ions: gas-kinetical methods for the calculation of collision frequencies give about $10^{-8} \mathrm{sec}$ as the average interval between two collisions of heavy particles, such as $\mathrm{UO}_{2}^{++}$and $\mathrm{I}^{-}$, at one atmosphere partial pressure (i.e., at a concentration of about $5 \times 10^{-2} \mathrm{M}$ of each component), and thus $\tau_{0}=5 \times 10^{-10} \mathrm{sec}$ for the average collision interval at $1 \mathrm{M}$. This would mean $k=1 / \tau_{0} \simeq 2 \times 10^{9} \mathrm{sec}^{-1}$ for the rate constant of a reaction occurring by the first collision or a hundred times the experimental rate constant of both the fluorescence quenching and the iodine liberation. However, encounters in a solution, particularly between ions, probably are spaced wider than collisions in a gas of equal concentration. (This wider spacing between encounters compensates for the so-called "cage effect" - the longer average period which particles spend together once they find themselves inside a common hydration sphere.) This effect could perhaps reduce the order of magnitude of $\mathrm{k}$ for a first-encounter reaction between uranyl and iodide ions from $10^{9}$ to $10^{7}$. 


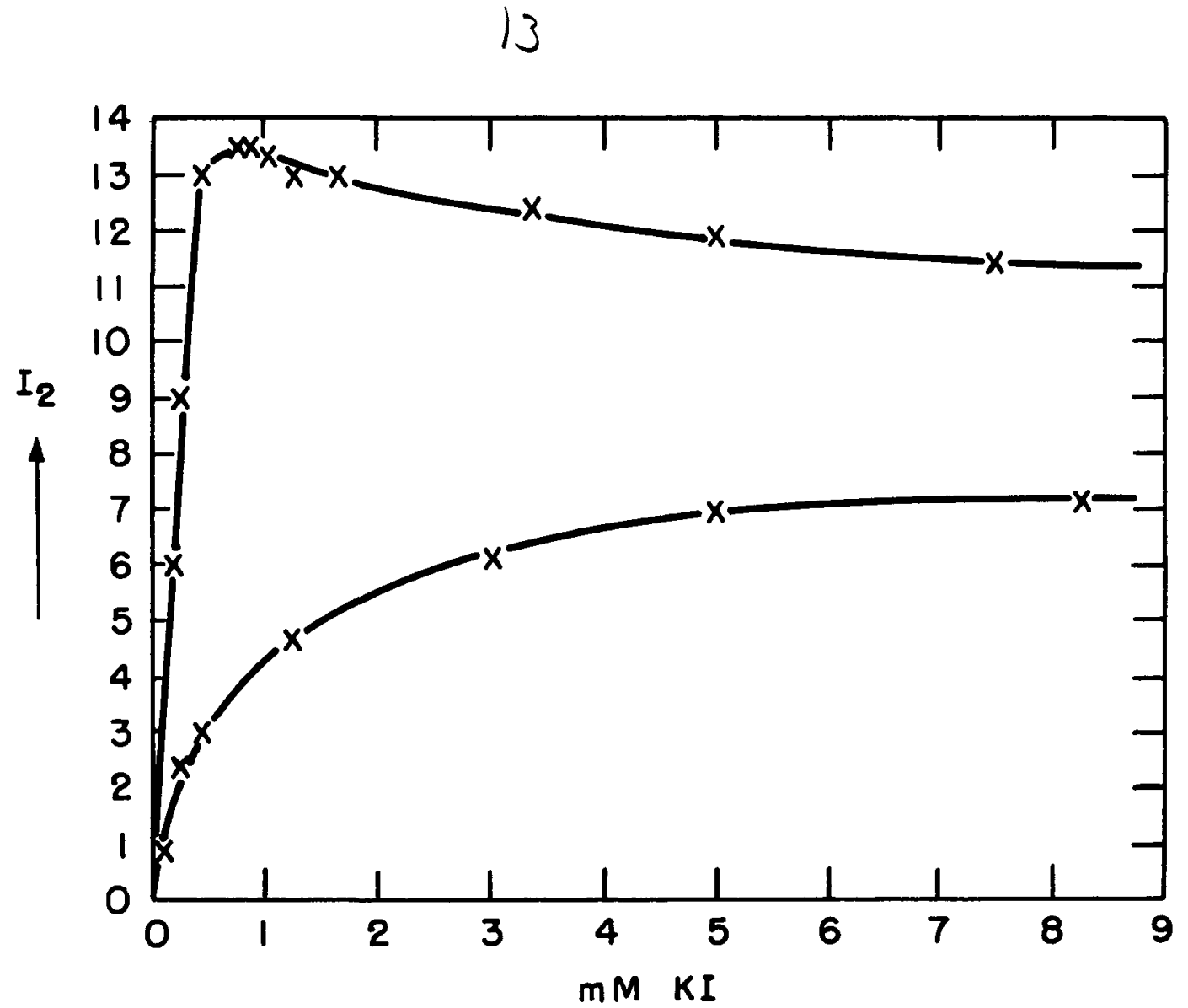

Fig. 4.2. Iodine formation (in relative units) in light in $\mathrm{KI}+\mathrm{UO}_{2} \mathrm{SO}_{4}$ solution os function of iodide concentration. Upper curve, with $0.008 \mathrm{~N} \mathrm{H}_{2} \mathrm{SO}_{4}$. Lower curve, without added ocid (after Schneider, 1935). 


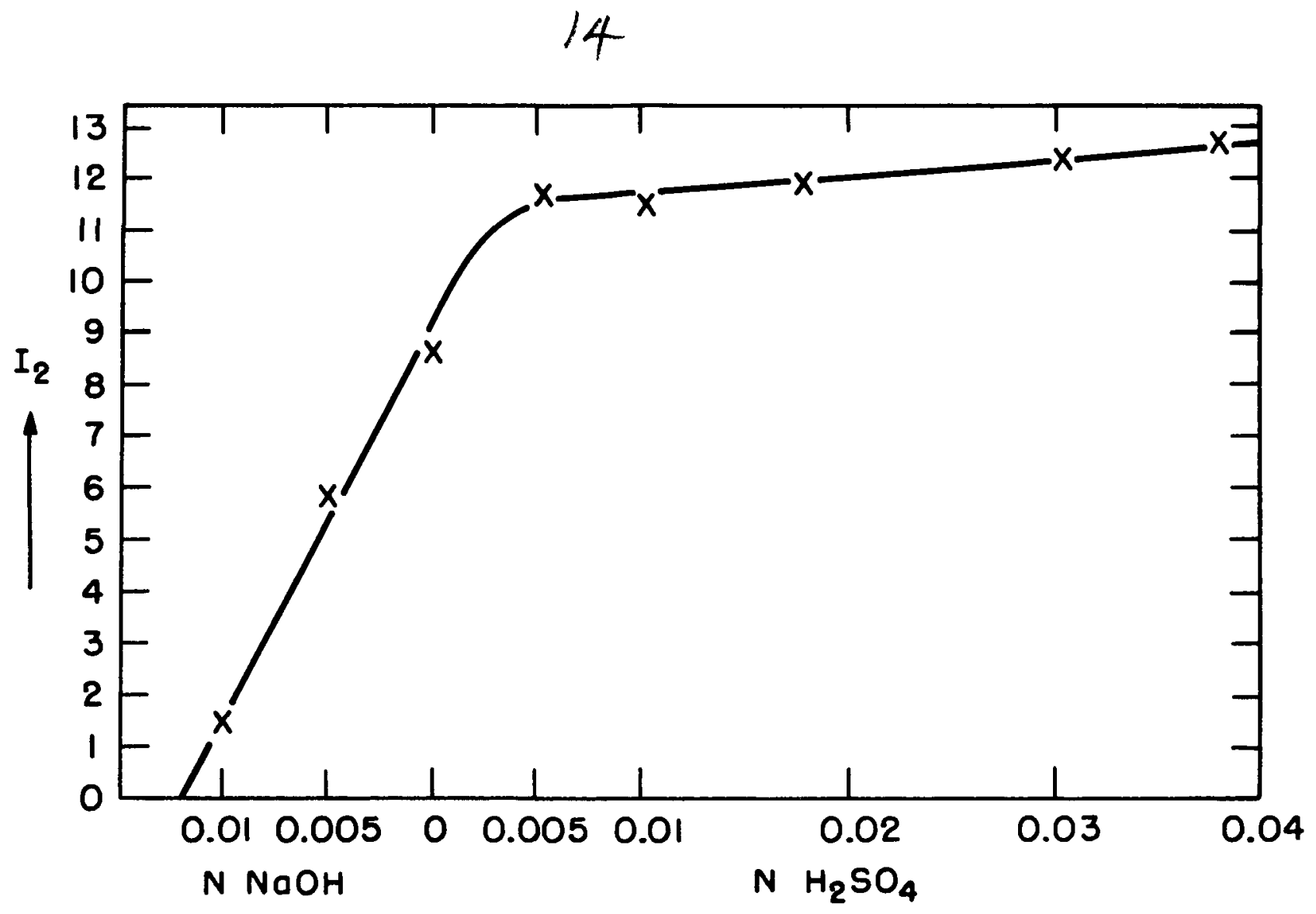

Fig. 4.3. Iodine formation (in relative units) in illuminated solution $\left(0.02 \mathrm{M}\right.$ in $\mathrm{I}_{2}, 0.025 \mathrm{M}$ in $\left.\mathrm{UO}_{2} \mathrm{SO}_{4}\right)$ as function of acidity (ofter Schneider, 1935). 


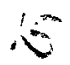

The decrease in the rate of reaction with increasing $\mathrm{pH}$ may be due to an association of $\mathrm{UO}_{2}^{++}$ions with $\mathrm{OH}^{-}$or $\mathrm{O}^{--}$ions (cf. Chap. 2). In this interpretation we have to assume that complex uranyl ions have less inclination than free $\mathrm{UO}_{2}^{++}$ions to react with $\mathrm{I}^{-}$after excitation, perhaps in consequence of more rapid energy dissipation in the complex. For example, one could imagine that, in the complex, the primary photochemical reaction causes an electron to be transferred to the anion: $\mathrm{UO}_{2}^{++} \mathrm{OH}^{-} \stackrel{\mathrm{h} \nu}{\longrightarrow} \mathrm{UO}_{2}^{+} \mathrm{OH}$. The electron immediately returns back to the cation, and the excitation energy is dissipated by the coupling of this electron transfer with molecular vibrations. If this mechanism really occurs, it should be recognizable by a quenching effect of $\mathrm{OH}^{-}$ions on the fluorescence of $\mathrm{UO}_{2}^{++}$. Unfortunately, no reliable measurements of the yield of fluorescence of uranyl ions are available at present for any $\mathrm{pH}$ value - not to speak of a systematic study of this yield as a function of $\mathrm{pH}_{\text {o }}$

A similar suggestion could also be used to interpret the decline which the iodine formation shows (in acid solution) when [ $\mathrm{I}^{-}$] becomes $>2 \times 10^{-3} \mathrm{M}$ (and, incidentally, to explain the difference between the results of Carter and Weiss and of Ouellet, noted above). The required assumption is, however, that in this case the reaction between $\mathrm{UO}_{2}^{++*}$ and $\mathrm{I}^{-}$is less likely to occur when these two ions are associated in a complex, such as $\mathrm{UO}_{2}^{++} \mathrm{I}^{-}$, than when they meet in solution. This sounds paradoxical, but may be true - for example, because the primary back reaction (electron transfer from I to $\mathrm{UO}_{2}^{+}$) may have a higher probability in the complex than in a colliding and immediately separating ion pair.

At very high $\mathrm{KI}$ concentrations, the iodine liberation increases again (Fig. 4.4), perhaps because of formation of a new kind of complex.

Qualitatively similar results were obtained by Schneider with uranyl nitrate in the presence of KI or LiI.

The initial quantum yield of iodine liberation, $\gamma_{0}$ (in $0.025 \mathrm{M} \mathrm{UO}_{2} \mathrm{SO}_{4}+0.02 \mathrm{~N} \mathrm{KI}$ ), was found by Schneider to be somewhat smaller than 1 :

\begin{tabular}{|l|l|}
\hline$\lambda(\mathrm{m} \mu)$ & $\gamma_{0}$ \\
\hline 435.8 & 0.57 \\
406 & 0.32 \\
366 & 0.70 \\
\hline
\end{tabular}

That $\gamma_{0}$ is smaller than 1 may be due to the above-mentioned "primary back reaction" of $\mathrm{UO}_{2}^{+}$and $\mathrm{I}$, occurring before the separation of the two reaction products by diffusion ("cage effect"). This recombination may occur not only when the ions are associated in a complex (as suggested above for $\mathrm{UO}_{2}^{+} \mathrm{OH}^{-}$and $\mathrm{UO}_{2}^{++} \mathrm{I}^{-}$) but also - albeit with a lesser probability - when they 


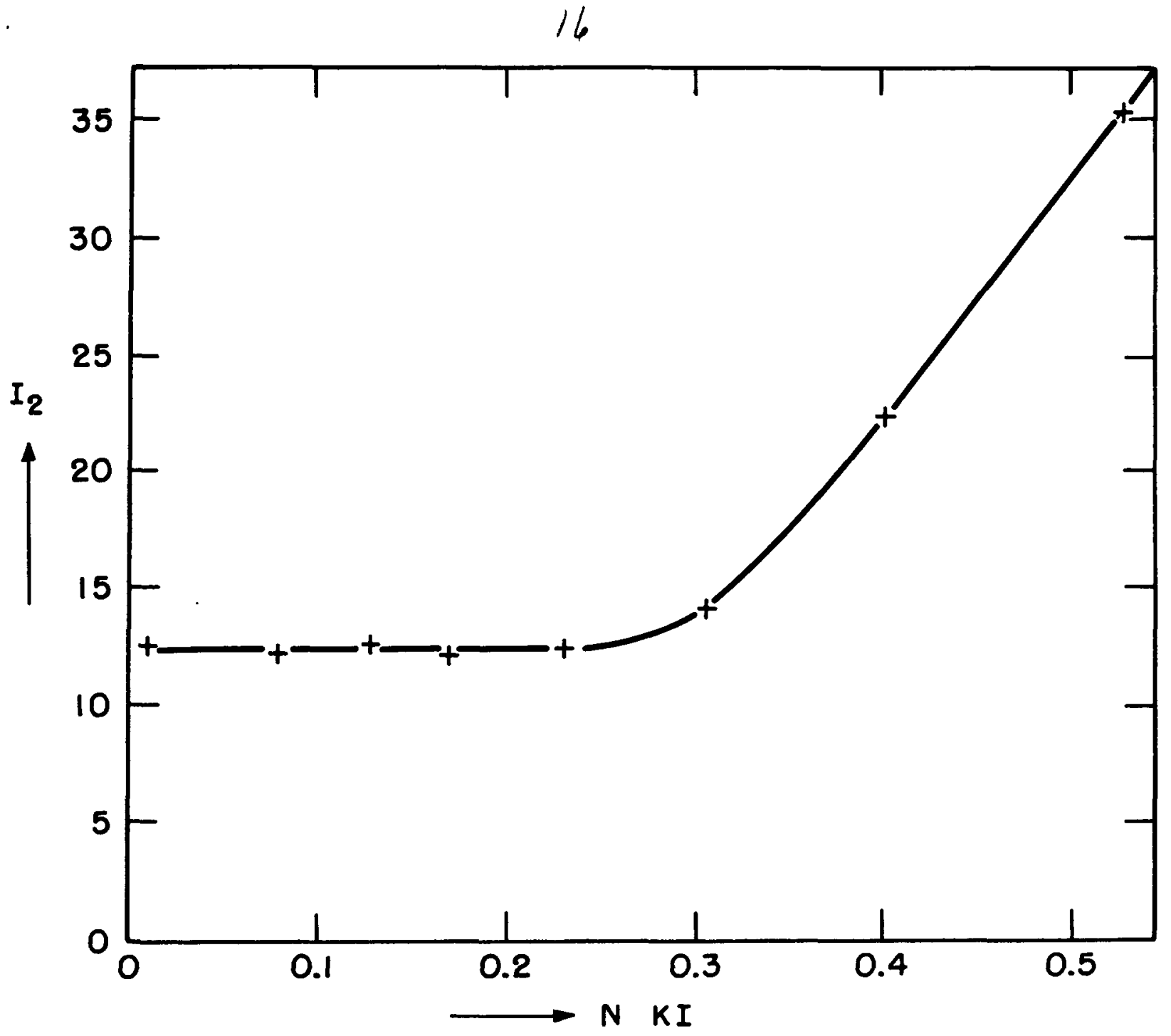

Fig. 4.4. Increase of photochemical iodine formotion in uranyl + iodide solutions of high iodide concentrations (after Schneider, 1935). 
react during a kinetic encounter. The increase of $\gamma_{0}$ with decreasing wave length (between 406 and $366 \mathrm{~m} \mu$ ) can then be attributed to increased probability of escape from recombination when the products are formed with a higher kinetic energy, (the energy of a $366 \mathrm{~m} \mu$ quantum being larger than that of the $406 \mathrm{~m} \mu$ quantum). The renewed increase of $\gamma$ at $436 \mathrm{~m} \mu$ requires, however, a different interpretation.

The reaction of $\mathrm{UO}_{2}^{++}$with $\mathrm{I}^{-}$in the presence of air was also studied by Montignie (1938), but in a rather crude way. He found that the decomposition in an open vessel is considerably more rapid than in a sealed bulb $\left(4 \% \mathrm{I}_{2}\right.$ liberated in four days in a sealed bulb, $7 \%$ in an open vessel). Montignie interpreted the reaction as oxidation of uranyl iodide by oxygen:

$$
\mathrm{UO}_{2} \mathrm{I}_{2}+\mathrm{H}_{2} \mathrm{O}+1 / 2 \mathrm{O}_{2} \longrightarrow \mathrm{UO}_{2}(\mathrm{OH})_{2}+\mathrm{I}_{2}
$$

In this scheme the uranyl salt is hydrolyzed while serving as catalyst for the oxidation of iodide by oxygen. Solid uranyl iodide is, in fact, an unstable compound, but its aqueous solutions have been described as stable (cf. Katz and Rabinowitch, 1951, pp 595-6). Of course, it is not impossible that such solutions might be hydrolyzed in light, but there seem to be no reas on why hydrolysis should be a necessary concomitant of uranyl-sensitized oxidation of iodide.

1.2 Oxidation of Other Inorganic Reductants - Another photochemical reaction of $\mathrm{UO}_{2}^{++}$with an inorganic reductant was studied by Diénert and Villemaine (1934); the reductant was hypophosphate. Rosenheim and Trewendt (1922) had previously found no interaction of $\mathrm{UO}_{2}^{++}$and hypophosphate in the dark in strongly acid solution (while a precipitate was produced in weakly acid or neutral solution). In light the formation of a green colloidal precipitate was observed by Dienert and Villemaine even in the presence of strong sulfuric acid. It was formed in $150 \mathrm{sec}$ in diffuse light and in $50 \mathrm{sec}$ in direct sunlight. Precipitation ceased when the vessel was again transferred into darkness.

Lipkin and Weissman (1942) made qualitative observations of the photochemical behavior of solutions of uranyl salts in the presence of various reductants. The results obtained with inorganic reductants are summarized in Table 4.3. The report did not make it clear whether the experiments were carried out with the exclusion of air or in its presence.

The same authors attempted to produce internal photochemical oxidation-reductions in crystalline salts of uranyl cations containing oxidizable anions. They obtained indications of a positive effect in uranyl potassium ferrocyanide, $\mathrm{UO}_{2} \mathrm{~K}_{2} \mathrm{Fe}(\mathrm{CN})_{6}$, but no signs of reaction in solid uranyl sulfite, phosphite, metarsenite, hypophosphite, uranate, and thiosulfate (as well as in several salts containing organic anions). 


\section{8}

Table 4. 3

REDUCTION OF INORGANIC COMPOUNDS BY UO ${ }_{2}^{++}$IONS IN LIGHT

(after Lipkin and Weissman, 1942)

\begin{tabular}{|l|c|c|c|c|c|}
\hline \multicolumn{1}{|c|}{ UO $_{2}^{++}$compound } & Reductant & Solvent & Temp., ${ }^{\circ} \mathrm{K}$ & Fluorescence & Reduction \\
\hline Sulfite & $\mathrm{H}_{2} \mathrm{SO}_{3}$ & $\mathrm{H}_{2} \mathrm{SO}_{4}$ & 90 & strong & no \\
Sulfite & $\mathrm{H}_{2} \mathrm{SO}_{3}$ & $\mathrm{H}_{2} \mathrm{SO}_{4}$ & 193 & weak & yes \\
Sulfite & $\mathrm{H}_{2} \mathrm{SO}_{3}$ & $\mathrm{H}_{2} \mathrm{SO}_{4}$ & 293 & none & yes \\
Sulfate & $\mathrm{NH}_{2} \mathrm{NH}_{2}$ & $\mathrm{H}_{2} \mathrm{SO}_{4}$ & 293 & none & no \\
$\left(\mathrm{NH}_{4}\right)_{2} \mathrm{CO}_{3}$ complex & $\mathrm{NH}_{2} \mathrm{NH}_{2}$ & $\mathrm{H}_{2} \mathrm{O}$ & 293 & none & yes \\
Bromide & $\mathrm{SOCl}_{2}$ & $\mathrm{SOCl}_{2}$ & 293 & none & no \\
Acetate & $\mathrm{SOCl}_{2}$ & $\mathrm{SOCl}_{2}$ & 293 & none & no \\
\hline
\end{tabular}

Schwab and Issidoridis (1942) found evidence of photochemical $\mathrm{UO}_{2}^{++}$ reduction in adsorbed layers on inorganic adsorbers, such as $\mathrm{Al}_{2} \mathrm{O}_{3}$, or $\mathrm{ZnO}$; the yellow color of uranyl ions changed in light to greenish-brown. This occurred only in acid media. No change was observed with glass powder, $\mathrm{MgO}, \mathrm{SnO}_{2}, \mathrm{SiO}_{2}, \mathrm{CdCO}_{3}$, or uranyl aluminate as adsorber. The effect disappeared when weak oxidants were added to the solution.

1.3 Uranyl-sensitized Oxidation of Water by Bromate - Uranyl ions do not oxidize water in light; i.e., illuminated aqueous uranyl salt solutions liberate no oxygen. Since excited $\mathrm{UO}_{2}^{++}$ions have an electron affinity sufficient to discharge $\mathrm{OH}^{-}$ions, the absence of oxygen liberation must be attributed to effective back reaction (as suggested above on p. 10). Baur (1918) observed that oxygen is liberated from illuminated uranyl sulfate solution if bromate is added $\left(0.025 \mathrm{M} \mathrm{UO}_{2} \mathrm{SO}_{4}, 0.025 \mathrm{M} \mathrm{KBrO}, 0.5 \mathrm{~N} \mathrm{H}_{2} \mathrm{SO}_{4}\right)$. Sixty cc oxygen were evolved from such a solution exposed to sunlight for two weeks [together with about an equal amount of nitrogen, attributed by Baur to the decomposition of $\left(\mathrm{NH}_{4}\right)_{2} \mathrm{SO}_{4}$ present as impurity in $\mathrm{UO}_{2} \mathrm{SO}_{4}$ ]. If oxygen in this experiment actually was the product of oxidation of water, a possible mechanism is

$$
\begin{aligned}
& \mathrm{U}(\mathrm{VI})+\mathrm{OH}^{-} \stackrel{\text { light }}{=} \mathrm{U}(\mathrm{V})[\text { or } 1 / 2 \mathrm{U}(\mathrm{IV})+1 / 2 \mathrm{U}(\mathrm{VI})]+\mathrm{OH} \\
& \mathrm{U}(\mathrm{V})[\text { or } 1 / 2 \mathrm{U}(\mathrm{IV})+1 / 2 \mathrm{U}(\mathrm{VI})]+1 / 6 \mathrm{BrO}_{3}^{-}+\mathrm{H}^{+} \longrightarrow \mathrm{U}(\mathrm{VI}) \\
& +1 / 6 \mathrm{Br}^{-}+1 / 2 \mathrm{H}_{2} \mathrm{O}
\end{aligned}
$$

$4 \mathrm{OH} \longrightarrow 2 \mathrm{H}_{2} \mathrm{O}+\mathrm{O}_{2}$ 
In other words, the re-oxidation of $U(V)$ [or $U(I V)]$ by bromate (reaction $18 \mathrm{~b}$ ) may so successfully compete with its re-oxidation by hydroxyl radicals (back reaction in 18 a) that some hydroxyl radicals will be left free for conversion to oxygen.

However, the experimental results of Baur are in need of confirmation, particularly because some gas was also obtained in his experiments by irradiation of the bromate solution without the presence of uranyl salt. 


\section{$2 \sigma$ \\ 2. PHOTOCHEMICAL REACTIONS OF URANYL IONS WITH ORGANIC COMPOUNDS}

A characteristic feature of the reactions of $\mathrm{UO}_{2}^{++}$ions with organic compounds in light is the combination of direct photochemical oxidation of the organic material by the uranyl ion land the concomitant reduction of $\mathrm{U}(\mathrm{VI})$ to $\mathrm{U}(\mathrm{IV})$ ] with sensitized decomposition (usually de-carboxylation) of the acid, which leaves U(VI) unchanged. Decarboxylation can be interpreted as dismutation (internal oxidation-reduction), in which one part of the acid is reduced, while the other part is oxidized to carbon dioxide. It can be suggested that in reactions of this type light-excited uranyl ions oxidize one part of the organic molecule and are then oxidized back to the U(VI) level by the other part, thus serving as light-activated dismutation catalysts. Reactions of both types can occur in the absence of oxygen; in the presence of the latter, a third reaction becomes possible - sensitized autoxidation of the organic reductant.

\subsection{Monobasic Aliphatic Acids}

(a) Formic Acid - Fay (1896), in describing the photodecomposition of oxalic and other organic acids by uranyl ions in sunlight, mentioned that he could obtain no evidence of a reaction with formic acid. The reason may be the comparatively weak absorption of light by uranyl-formic acid complexes in the visible and near ultraviolet (comparethe $\epsilon$ values at $300 \mathrm{~m} \mu$ in Tables 2.2 and 2.8; the difference is probably even more pronounced at $\lambda>300 \mathrm{~m} \mu)$. The first positive observation was made by Schiller, (1912) in Baur's laboratory, on the occasion of a study of photogalvanic potentials (Becquerel effect). He noted that in a uranyl salt solution containing $0.025 \mathrm{M}$ sodium formate, the electrode potential gradually grew more positive upon exposure to light, and attributed this change to the reaction

$$
\mathrm{UO}_{2}^{++}+3 \mathrm{H}^{+}+\mathrm{HCOO}^{-} \stackrel{\text { light }}{\longrightarrow} \mathrm{U}^{+4}+\mathrm{CO}_{2}+2 \mathrm{H}_{2} \mathrm{O}
$$

This slow, irreversible reaction formed the background for a more rapid, reversible change, which caused a shift of the electrode potential in the opposite direction for the duration of illumination. (Under the most favorable conditions, this shift was as wide as 0.6 volt, e.g., from -0.33 to +0.26 volt; cf. below, the section on photogalvanic effect.)

The irreversible reaction (19), which was very slow in the light of a Nernst burner, became much more rapid in the light of a mercury lamp. The reaction product was pure carbon dioxide; no formation of carbon monoxide was observed. 


\section{1}

Courtois (1913) prepared solid uranyl formate (yellow crystals, which he identified as $\mathrm{UO}_{2}(\mathrm{COOH})_{2} \cdot \mathrm{H}_{2} \mathrm{O}$ and dehydrated at $150^{\circ} \mathrm{C}$ ) and found dilute solutions of this compound to be unstable, particularly in light. In the pres ence of air, a $2 \%$ solution exposed to light rapidly formed a violet $\mathrm{U}_{3} \mathrm{O}_{8}$ hydrate; an abundant precipitatè of basic uranyl formate was formed simultaneously.

In the absence of air, the precipitate was initially white, and the solution became green. Later, gas bubbles appeared. After two weeks' exposure, the precipitate was green and the solution colorless, but the gas evolution continued slowly. The gas contained both carbon dioxide and carbon monoxide, with an excess of the former.

Müller (1915) described the photochemical sensitivity of solid uranyl formate: The intensely yellowish-green crystals acquired dark green or even black color upon illumination by a mercury arc. In aqueous or alcoholic solution of the same salt, $\mathrm{U}_{3} \mathrm{O}_{8}$ hydrate was precipitated upon illumination.

Hofmann and Schumpelt (1916) confirmed that uranyl formate is very sensitive to light. Yellow aqueous solutions of this salt became dark green in sunlight, and a black powder was precipitated. Distillation of the mixture after exposure indicated the presence of some formaldehyde (identified by violet coloring with morphine), an observation which caused Hofmann to speculate on the possible similarity of this reaction to photosynthesis.

A more systematic investigation of the uranyl - formic acid reaction in light was carried out, in Baur's laboratory, first by Hatt, and later by Ouellet.

Hatt (1918) confirmed Schiller's finding that the reaction of $\mathrm{UO}_{2}^{++}$ions and $\mathrm{HCOOH}$ in light gives pure carbon dioxide and no carbon monoxide (contrary to the findings of Courtois). He illuminated uranyl sulfate solution in dilute sulfuric acid in the presence of formic acid with the light of a mercury arc. Air was excluded by sealing off the reaction tubes under carbon dioxide. The progress of reaction was determined by U(IV) titration with permanganate. The following are some of the results obtained by Hatt:

Effect of $\mathrm{UO}_{2}^{++}$Concentration - The formation of U(IV) was found to begin with almost the same velocity at two different $\mathrm{UO}_{2}^{++}$concentrations, one twice as high as the other. This indicates that the rate of light absorption was approximately the same in both cases (probably, absorption was practically complete even in the more dilute solution). However, the reaction approached completion more rapidly in the more concentrated solution. The suggestion that this may be due to a competition for light quanta between $\mathrm{UO}_{2}^{++}$and the newly-formed $\mathrm{U}^{+4}$ (which, at a given value of $\mathrm{U}^{+4}$, will be the less effective the higher the concentration of $\mathrm{UO}_{2}^{++}$) was rejected by Hatt because of his inability to explain, on this basis, the shape of the curves of reaction velocity as function of time. Hatt suggested that the cause of the 


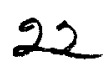

slowing-down of the reaction with time is an anti-catalytic action of the reaction products, specifically, U(IV) - an effect which, for some reason, is the more effective the lower the U(VI) concentration.

Effect of Light Intensity - The initial velocity of the reaction proved to be proportional to light intensity.

Effect of Additions - The following additions were found to retard the reaction strongly:

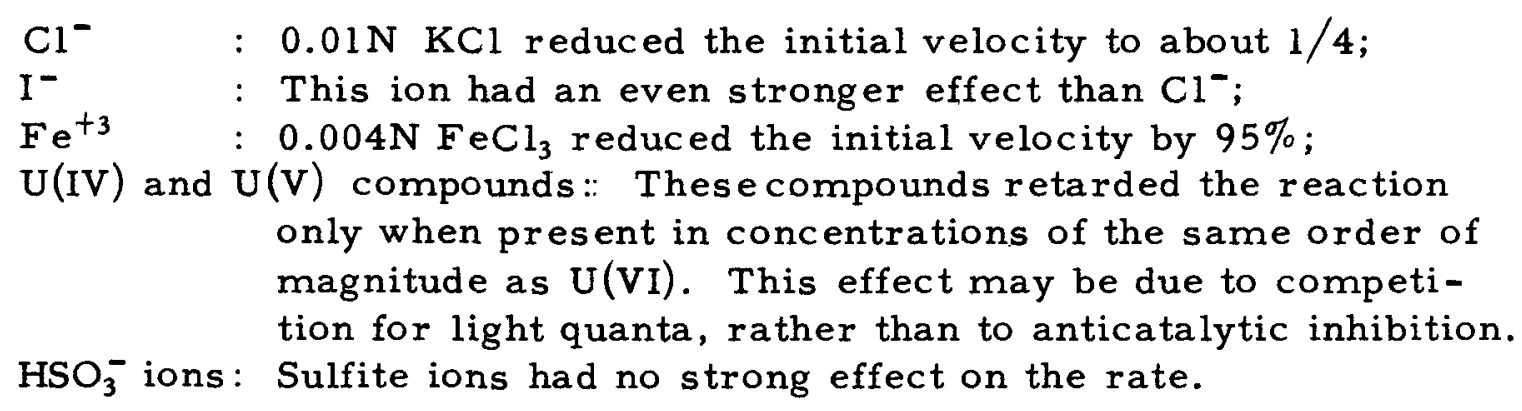

Quantum Yield - Hatt, using published data for the intensity of the mercury arc, and assuming complete absorption, calculated a quantum yield of 0.4 for the initial velocity of formate oxidation by uranyl ions. In a subsequent publication from Baur's laboratory, Büchi (1924) mentioned 0.7 as the quantum yield of the same reaction, but it was not explained why this higher value was substituted for Hatt's value of 0.4. (Still later, cf. below, Ouellet estimated that, under most favorable conditions, the quantum yield should be near 1.0.)

The influence of various salts on the rate of photochemical reaction between $\mathrm{UO}_{2}^{++}$and $\mathrm{HCOOH}$ also was investigated by Berger (1925), whose point of view was quite different from that of Baur and his co-workers. Berger considered this effect as related to the effect of salts on the rate of ordinary chemical reactions between ions (Brönsted's theory). With this concept in mind, he studied the salt effect in more dilute solutions than those used by Hatt (e.g., $0.0674 \mathrm{~N} \mathrm{COOH}^{-}, 0.00795 \mathrm{~N} \mathrm{UO}_{2}^{++}, 0.0599 \mathrm{Nfree} \mathrm{HCOOH}$ ). He illuminated the solutions at $10^{\circ} \mathrm{C}$ with a mercury lamp in the presence of varying amounts of $\mathrm{KCl}, \mathrm{NaCl}, \mathrm{KBr}, \mathrm{MgCl}_{2}, \mathrm{MgSO}_{4}, \mathrm{Na}_{2} \mathrm{SO}_{4}$, and $\mathrm{K}_{2} \mathrm{SO}_{4} . \mathrm{Fig} .4 .5$ shows the effect of six of these salts on the initial rate of $\mathrm{CO}_{2}$ liberation.

Berger stated that the observed salt effects can be interpreted if the "reaction complex" is assigned the composition $\left\{\mathrm{UO}_{2}^{++}+\mathrm{H}^{+}+3 \mathrm{HCOO}^{-}\right\}$, and if the influence of ionic strength on the equilibrium concentration of this complex is calculated by means of Brönsted's equation. The proportionality between the calculated concentrations of the reaction complex, [C], and the observed relative rate of reaction, $\mathrm{v}_{\mathrm{rel}}$, was best in the case of $\mathrm{KCl}$ ( $\mathrm{Table} 4.4$ ). 


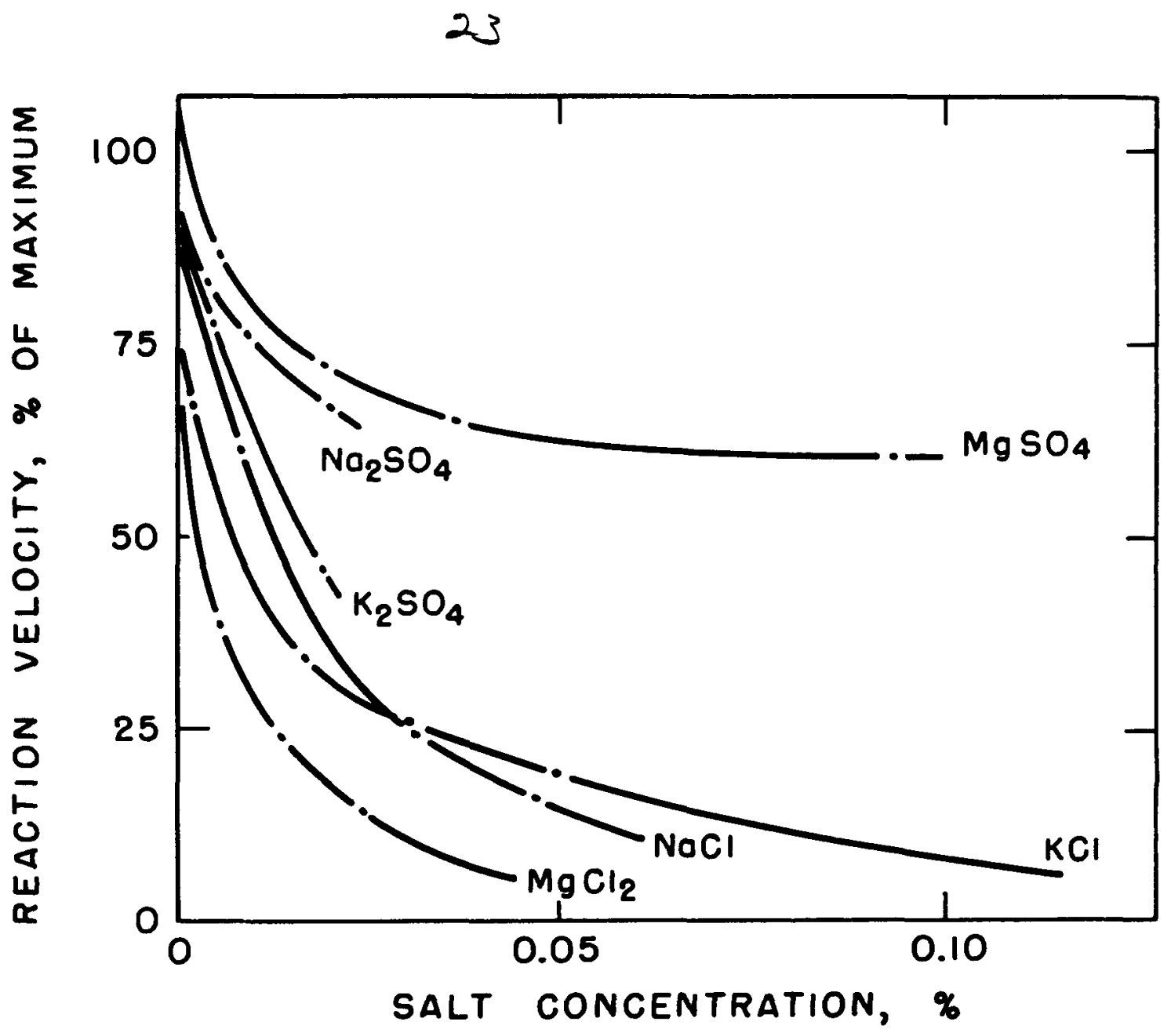

Fig. 4.5. Effect of solts on the uranyl--formic ocid reaction (after Berger, 1925). 
Table $4.4^{24}$

EFFECT OF POT ASSIUM CHLORIDE ON PHOTOXIDATION OF FORMIC ACID (AFTER BERGER, 1925)

\begin{tabular}{|l|l|l|l|l|}
\hline$[\mathrm{KCl}]$, moles/liter & 0.01 & 0.02 & 0.05 & 0.10 \\
\hline \hline $\mathrm{v}_{\mathrm{rel}}$ (interpolated) & 0.44 & 0.33 & 0.18 & 0.09 \\
{$[\mathrm{C}]$ (calculated) } & 0.43 & 0.31 & 0.19 & 0.10 \\
\hline
\end{tabular}

However, Berger did not inquire whether the equilibrium concentration of the postulated penta-molecular complex can be high enough to account for the high observed absolute yield of decomposition. Since the latter has a quantum yield of the order of 1, Berger's hypothesis is improbable. Subsequent investigations indicated that a much simpler, binary complex probably accounts for much of the reaction.

Baur $(1929,1932)$ saw in the inhibition of the uranyl formate reaction by salts (including the effects observed by Berger) a confirmation of his "depolarization" theory. He thought that to prove this it was sufficient to show that the inhibition can be represented by an equation of the type

$$
\mathrm{v}=a v_{0} /(1+b[c])
$$

where [c] is the concentration of the inhibitor, and a and b are constants. This equation ("Stern-Volmer equation"), however, is valid for all cases of competition between a monomolecular and a bimolecular reaction (cf. discussion below), and can therefore not be used to support a specific mechanism.

In applying Eq. (20), Baur mainly used the elaboration of Hatt's results in a more detailed investigation by Ouellet. Ouellet (1931) used white light, with ultraviolet and infrared filtered out; a reaction vessel without inhibitor served as an actinometer for the determination of relative light intensity. The $\mathrm{UO}_{2} \mathrm{SO}_{4}$ solution was excluded in the same way as by Hatt, (cf. above), and the $\mathrm{KMnO}_{4}$ titration method again was used for the determination of U(IV).

The effect of the following additions on the time curves of the photochemical reduction of $U(V I)$ to $U(I V)$ was measured:

Strong Inhibitors: Hydroquinone, $\mathrm{Cr}_{2} \mathrm{O}_{7}^{--}, \mathrm{NO}_{2}^{-}, \mathrm{Fe}^{++}$(according to Hatt, $\mathrm{Cl}^{-}, \mathrm{I}^{-}, \mathrm{Fe}^{+3}$ belong to the same class).*

*Ouellet mentions only $\mathrm{Fe}^{++}$, but Hatt's experiments explicity referred to $\mathrm{FeCl}_{3}$. It is possible that the effects first attributed to $\mathrm{Fe}^{+3}$ were later decided to have been due to $\mathrm{Fe}^{+2}$ contamination. 


\section{5}

Medium Strong Inhibitors: $\mathrm{Ag}^{+}, \mathrm{CN}^{-}, \mathrm{Hg}^{++}$(according to Hatt, also $\mathrm{V}_{2} \mathrm{O}_{5}$ and $\left.\mathrm{VO}\right)$.

Weak Inhibitors: $\mathrm{NO}_{3}^{-}, \mathrm{Co}^{++}, \mathrm{Cr}^{+3}, \mathrm{Cu}^{++}, \mathrm{Mn}^{++}, \mathrm{F}^{-},\left(\right.$also $\mathrm{HSO}_{3}^{-}, \mathrm{ac}-$ cording to Hatt).

No Effect: $\mathrm{Na}_{3} \mathrm{PO}_{4}, \mathrm{MgSO}_{4}, \mathrm{NH}_{4} \mathrm{COOCH}_{3}$.

Of those inhibitors, $\mathrm{Ag}^{+}$and $\mathrm{Hg}^{++}$are themselves reduced (to metallic silver and $\mathrm{Hg}_{2}^{++}$respectively). $\mathrm{Cr}_{2} \mathrm{O}_{7}^{--}$changes color, but others, such as the halide ions, ferrous sulfate and hydroquinone, appear to act as true anti-catalysts. With chromate and the vanadium compounds, induction periods were observed, during which the added compound probably served as oxidant, instead of the $\mathrm{U}(\mathrm{VI})$.

Effect of [HCOOH] - The rate of photoreduction was found by Ouellet to increase with increasing concentration of formic acid until a "saturation" was reached somewhere above $10 \%$; practically no difference in rate was observed between $12.5 \%$ and $50 \%$ acid. Ten per cent $\mathrm{HCOOH}$ corresponds to about $2 \mathrm{M}$; this is a very high concentration to be required for the "saturation" of a photochemical process if this process were to occur by the first kinetic encounter between light-excited ions and the acid molecules (cf. dis cussion below, p. 26. The effect of inhibitors ( $\mathrm{FeSO}_{4}$ was used as an example) was found to decrease with increasing concentration of formic acid.

Effect of $\left[\mathrm{UO}_{2}^{++}\right]$- The rate of formation of U(IV) increased with increasing concentration of $\mathrm{UO}_{2}^{++}$, reached a maximum in the neighborhood of $0.16 \mathrm{M}$, and then declined again.

Quantum Yield - Ouellet pointed out that Hatt's quantum yield estimate was made at a suboptimal concentration of formic acid (0.1N). Multiplication of his value $(\gamma=0.4)$ by the ratio found by Ouellet between the rate in $0.1 \mathrm{~N}$ acid, and the maximum rate, gave for the maximum quantum yield

$$
\gamma=0.97 \simeq 1
$$

Analytical Expression - Ouellet found that (in agreement with Baur's expectation) the inhibiting effect of various "de-sensitizers" can be expressed by Eq. (20), in which [c] is the concentration of the inhibitor. The values of the constants $a$ and $b$ are given in Table 4.5. These analytical formulations apply to initial velocities. As U(IV) is formed, it acts as an additional "autoinhibitor"; its effect, too, can be represented by an equation of the type (20). 
26

Table 4.5

\begin{abstract}
EFFECT OF INHIBITORS ON PHOTOXIDATION OF FORMIC ACID BY URANYL IONS (BAUR)
\end{abstract}

\begin{tabular}{|l|l|r|}
\hline \multirow{2}{*}{ Inhibitor } & \multicolumn{2}{|c|}{ Constants in Eq. (20) } \\
\cline { 2 - 3 } & $\mathrm{a}$ & $\mathrm{b}$ \\
\hline \hline $\mathrm{Cl}^{-}$ & 1.27 & 430 \\
$\mathrm{Fe}^{++}$ & 0.89 & 5000 \\
$\mathrm{Hydroquinone}$ & 1.1 & 4520 \\
$\mathrm{Co}^{++}$ & 0.66 & 66 \\
$\mathrm{Mn}^{++}$ & 1.07 & 21 \\
\hline
\end{tabular}

Discussion - The mechanism of the uranyl-formate reaction has not been fully clarified by the investigations of Ouellet, which had the typical quantitative and theoretical shortcomings of the (qualitatively often valuable) work from Baur's laboratory.

The spectroscopic studies described in Chap. 2 (Sec. 22) make it probable that the reaction occurs not - or not mainly - by kinetic encounters between free excited uranyl ions and free formate ions (or formic acid molecules) in solution, but either partially or exclusively by the excitation of preformed complexes of both reactants. The high concentration of formic acid (about $2 \mathrm{~N}$ ) required to obtain the maximum quantum yield supports the assumption that light absorbed by free $\mathrm{UO}_{2}^{+{ }^{+}}$ions does not contribute significantly to the reaction. The natural lifetime of excited $\mathrm{UO}_{2}^{++}$ions, calculated from the integrated intensity of the absorption band, is of the order of $10^{-3} \mathrm{sec}$; the good fluorescence yield indicates that this lifetime is abridged by less than a factor of 10 in consequence of radiationless energy dissipation. Even a lifetime of $10^{-4} \mathrm{sec}$. should be sufficient for every free $\mathrm{UO}_{2}^{++*}$ ion to encounter, during the excitation period, a $\mathrm{HCOOH}$ molecule (or a $\mathrm{COOH}^{-}$ion), at formate concentrations of the order of, say, $10^{-3} \mathrm{M}$ (cf. p. $\underline{8}$ for similar calculation for $\mathrm{UO}_{2}^{++}$and $\mathrm{I}^{-}$encounters) while the maximum quantum yield is obtained only at concentration of the acid a thousand times higher. One could suggest that reaction between $\mathrm{UO}_{2}^{++*}$ and formate requires thermal activation energy in addition to the excitation energy of the uranyl icn, but this is not very plausible. It seems much more likely that "saturation" of the uranyl-formic acid reaction with formic acid occurs when all uranyl ions are complexed with formate. Determining what kind of complexes are responsible would require a special spectroscopic and kinetic investigation. Offhand, one would attribute the reaction mainly or 


\section{1}

exclusively to the simplest binary complex, $\left\{\mathrm{UO}_{2}^{++} \mathrm{HCOO}^{-}\right\}$. According to its estimated equilibrium constant (cf. Table 2.7), this complexing should approach completeness in about $1 \mathrm{M}$ formic acid, the same concentration region in which the reaction with uranyl reaches its full rate. However, the relative importance of higher complexes cannot be estimated until

(a) their existence and equilibrium constants are known, and (b) their absorption curves have been determined. The higher complexes, studied by Ahrland (cf. Chap. 2), with other anions (e.g., acetate) have, in general, increasingly intense absorption, particularly at the longer waves. Therefore, a comparatively small number of these complexes may absorb a disproportionately high fraction of incident light, particularly in certain wave length regions, and thus account for a disproportionately large fraction of photochemical change.

The large photogalvanic effect observed in the system $\mathrm{UO}_{2}^{++}+\mathrm{HCOO}^{-}$ (cf. p. 20) indicates that the primary effect of light is the reversible formation of high energy products - probably free radicals - e.g.,

$$
\left\{\mathrm{UO}_{2}^{++} \cdot \mathrm{HCOO}^{-}\right\} \underset{\text { dark }}{\frac{\text { light }}{\text { dark }}}\left\{\mathrm{UO}_{2}^{+} \cdot \mathrm{HCOO}\right\} \rightleftharpoons \mathrm{UO}_{2}^{+}+\mathrm{HCOO}
$$

where braces refer to a complex. Liberation of carbon dioxide may require the interaction of two $\mathrm{HCOO}$ radicals:

$$
\mathrm{HCOO}+\mathrm{HCOO} \longrightarrow \mathrm{HCOOH}+\mathrm{CO}_{2}
$$

in competition with the back reaction in (21).

In this picture, the inhibiting effect of the "de-sensitizers," studied by Hatt, Berger, and Ouellet, can be due either to their influence on the equilibrium concentration of the complex, or to their effect on the kinetics of photoxidation. Since the complex contains at least one, and probably two, ions, an electrostatic "salt effect" on its equilibrium concentration is inevitable, and exact determinations of the equilibrium constant should take it into account. It is, however, unlikely that this effect can be strong enough to explain the inhibition. Foreign anions could affect the equilibrium concentration of the complex more effectively and in a more specific way namely, by displacing the formate anion from the complex. However, the fact that the strongest "de-sensitizers" are either oxidants or reductants suggests that kinetic phenomena may be more important than equilibrium effects. Kinetic inhibition can have two reasons: the added ions may either retard the forward reactions, or accelerate the back reaction.

When $\mathrm{UO}_{2}^{++*}$ and $\mathrm{COOH}^{-}$react by kinetic encounters, the effect of oxidizable inhibitors could consist in their direct competition with formic acid as oxidation substrate in the photochemical process, e.g., 


$$
\mathrm{UO}_{2}^{++*}+\left\{\begin{array}{c}
28 \\
\mathrm{HCOO}^{-} \longrightarrow \mathrm{UO}_{2}^{+}+\mathrm{HCOO} \text { (main reaction) } \\
+\mathrm{I}^{-} \longrightarrow \mathrm{UO}_{2}^{+}+\frac{1}{2} \mathrm{I}_{2} \text { (competing reaction with } \\
\text { inhibitor) }
\end{array}\right.
$$

With constant [ $\left.\mathrm{HCOO}^{-}\right]$, the effect of increased iodide concentration would then obey an equation of the type (20).

If, however, $\mathrm{HCOO}^{-}$and $\mathrm{UO}_{2}^{++}$react when they are combined in a complex, the interference of an inhibitor with the photochemical forward reaction appears unlikely; in this case, "kinetic" inhibition may be due to a catalytic effect of the inhibitor on the back reaction. For example, the back reaction in $(21)$ :

$$
\mathrm{UO}_{2}^{+}+\mathrm{HCOO}-\mathrm{UO}_{2}^{++}+\mathrm{HCOO}^{-}
$$

could be catalytically accelerated by iodide (or other oxidizable compounds) in the following way:

$$
\begin{aligned}
& \mathrm{HCOO}+\mathrm{I}^{-} \longrightarrow \mathrm{HCOO}^{-}+\mathrm{I}\left(\text { or } \frac{1}{2} \mathrm{I}_{2}\right) \\
& \mathrm{I}\left(\text { or } \frac{1}{2} \mathrm{I}_{2}\right)+\mathrm{UO}_{2}^{+} \longrightarrow \mathrm{UO}_{2}^{++}+\mathrm{I}^{-}
\end{aligned}
$$

An easily reducible inhibitor - suchas $\mathrm{Hg}^{++}$- also may act catalytically on the back reaction, by reacting in the reverse order, first with the reductant, and then with the oxidant:

$$
\begin{aligned}
& \mathrm{UO}_{2}^{+}+\mathrm{Hg}^{++} \longrightarrow \mathrm{UO}_{2}^{++}+\mathrm{Hg}^{+} \\
& \mathrm{Hg}^{+}+\mathrm{HCOO} \longrightarrow \mathrm{Hg}^{++}+\mathrm{HCOO}^{-}
\end{aligned}
$$

Curves showing the over-all rate as function of $\left[\mathrm{I}^{-}\right]$or $\left[\mathrm{Hg}^{++}\right]$, derived from mechanisms $(21),(22),(25)$ or (21), (22), (26), are more complicated than those based on Eq. (20) (because the catalytic back reactions compete with reaction (21), which is of second order in respect to [ $\left.\mathrm{HCOO}^{-}\right]$), but have the same general characteristics - initial linearity and ultimate "saturation." A choice between these relationships and Eq. (20) could be made only on the basis of much more precise measurements than those of Baur and co-workers.

The dependence of the yield on the concentration $\left[\mathrm{UO}_{2}^{++}\right]$, with its peculiar maximum at about $0.16 \mathrm{M}$, offers another interesting problem. The initial increase of the yield undoubtedly is due to increased light absorption, which gradually becomes complete. (An additional cause of increase may be the gradual concentration of the light absorption in a thin layer near the entrance wall of the vessel, which leads to a higher density of primary photoproducts - such as free radicals - and thus increases the probability of bimolecular reactions of these radicals relative to the probability of their practically monomolecular "de-activation." If this factor is important, it 


\section{9}

should be possible to produce similar effects by an increase in light intensity; in other words, the quantum yield should be higher in stronger light.) The decline of the yield at the higher values of [ $\left.\mathrm{UO}_{2}^{++}\right]$is more difficult to explain.

Ouellet interpreted this decline as evidence of "self-de-sensitization" of uranyl ions. The mechanism of de-sensitization proposed by him is unsatisfying, but the effect itself is probably real and is paralleled by many similar observations on different sensitizers. An increase in the concentration of the light-absorbing species beyond a certain limit very often leads to a decline in the yield of the photochemical reaction. One explanation of this effect is dimerization (or more generally, polymerization) of the absorbing molecules and a more efficient dissipation of excitation energy in the dimer or polymer (as revealed by the disappearance of fluorescence). Sometimes, however, the decline in the photochemical yield (and the "self-quenching" of fluorescence) are observed at concentrations where the absorption spectrum does not reveal any changes one might expect to find in case of polymerization. Förster (and others) suggested that, in such cases, a very small (and therefore spectroscopically unidentifiable) proportion of dimeric or polymeric molecules suffices to accelerate substantially the dissipation of excitation energy, because energy exchange between resonating molecules occurs with high efficiency, even across several molecular layers of the solvent. The excitation energy consequently performs a kind of "Brownian movement" through the solution. If, in this migration, the excitation visits a dimeric or polymeric molecule, it is promptly dissipated, and quenching and deactivation result. Other interpretations of self-quenching and decline in photochemical yield at high concentrations of the absorbing species, also based on the energy transfer concept, have been suggested by Vavilov and by Franck. Vavilov simply postulated a certain probability of energy dis sipation in each transfer; Franck suggested that dissipation occurs when the excitation energy visits a "hot" molecule, i.e., a molecule in which many vibrations are excited.

It will be noted that only one photochemical reaction - the photoxidation of formate to carbon dioxide, with reduction of U(VI) to U(IV) (Eq. 19) was postulated in the system uranyl + formate. No observations exist which would suggest the simultaneous occurrence of sensitized decomposition (dis mutation) of $\mathrm{HCOOH}$, which would lead to $\mathrm{H}_{2}$ and $\mathrm{CO}_{2}$ (while analogous reactions are common with the higher aliphatic acids).

The reasons can be sought in the difference between the reactions

and

$$
\mathrm{HCOOH} \longrightarrow \mathrm{H}_{2}+\mathrm{CO}_{2}
$$

$$
\mathrm{RCOOH} \longrightarrow \mathrm{RH}+\mathrm{CO}_{2}
$$


30

In the first case, an $\mathrm{H}-\mathrm{C}$ bond must be broken and an $\mathrm{H}-\mathrm{H}$ bond formed; in the second, a $\mathrm{C}-\mathrm{C}$ bond is broken (which is about $20 \mathrm{kcal}$ weaker than the $\mathrm{H}-\mathrm{C}$ bond), and a $\mathrm{C}-\mathrm{H}$ bond is formed (which is only $\sim 5 \mathrm{kcal}$ weaker than the $\mathrm{H}-\mathrm{H}$ bond). Consequently, the second reaction requires $15 \mathrm{kcal}$ less energy than the first one. As suggested, the two steps in the sensitized dismutation may be (a) photochemical oxidation of the carboxyl group by excited uranyl ions and (b) reduction of the alkyl group by the reduction product of uranyl ions, e.g., in the form of $\mathrm{UO}_{2}^{+}$:

$$
\begin{aligned}
& \mathrm{RCOOH}\left(\text { or } \mathrm{RCOO}^{-}+\mathrm{H}^{+}\right)+\mathrm{UO}_{2}^{++} \stackrel{\text { light }}{=} \mathrm{RCOH}^{+} \\
& \left(\text {or } \mathrm{RCOO}+\mathrm{H}^{+}\right)+\mathrm{UO}_{2}^{+} \\
& \mathrm{UO}_{2}^{+}+\mathrm{RCOOH}^{+}\left(\text {or } \mathrm{RCOO}+\mathrm{H}^{+}\right)-\mathrm{UO}_{2}^{++}+\mathrm{RH}+\mathrm{CO}_{2}
\end{aligned}
$$

Because of the above-mentioned higher energy requirement, the $\mathrm{UO}_{2}^{+}$ion may be incapable of reacting in a similar manner with $\mathrm{HCOOH}$ :

$$
\begin{aligned}
& \mathrm{UO}_{2}^{++}+\mathrm{HCOOH}\left(\text { or } \mathrm{HCOO}^{-}+\mathrm{H}^{+}\right) \stackrel{\text { light }}{=} \mathrm{UO}_{2}^{+}+\mathrm{HCOOH}^{+} \\
& \left(\text {or } \mathrm{HCOO}+\mathrm{H}^{+}\right) \\
& \mathrm{UO}_{2}^{+}+\mathrm{HCOOH}^{+}\left(\text {or } \mathrm{HCOO}+\mathrm{H}^{+}\right) \longrightarrow \mathrm{UO}_{2}^{++}+\mathrm{H}_{2}+\mathrm{CO}_{2}
\end{aligned}
$$

Consequently, the only reaction actually occurring is that resulting in the reduction of $U(V I)$ and oxidation of formic acid.

It could further be suggested that photoxidations generally result from reactions within an (uranyl + acid) complex, while sensitized decompositions occur by kinetic encounters; the absence of sensitized decomposition in the case of formic acid could then be correlated with the apparent exclusive role of complexes as reactants in this case. With other organic acids, in which photoxidation and sensitized dismutation both occur, photochemical reactions appear to be brought about both by light absorption in uranyl-acid complexes, and by encounters of excited uranyl ions with acid molecules (or their anions). In the reaction with acetate, the correlation between complex formation and photoxidation seems to be that suggested above for formic acid (cf. p. 35), but in the reaction with oxalate, it seems to be reversed (at least according to the data of Pitzer, Gordon and Wilcox, p. 59), with sensitized decomposition occurring by internal oxidationreduction in the complex, and uranyl reduction to uranous salt by reactors involving free excited uranyl ions. However, the interpretation is very uncertain in both cases, and the very assumption of a correlation between the type of reaction and the absorbing species is at present only a working hypothesis.

(b) Acetic Acid - In uranyl salt-acetic acid solutions, both photoxidation and photocatalytic decarboxylation are known to occur. The conditions governing the relative rates of these two reactions are not yet well understood, as the following chronological review of the experimental investigations will show. 


\section{3}

The earliest observations were concerned with the formation of a precipitate in illuminated uranyl acetate solutions. Bach $(1893,1894,1898)$ believed that he had proved that this precipitate - which consisted of the hydroxide of an oxidation stage lower than $\mathrm{U}(\mathrm{VI})$ (probably $\mathrm{U}_{3} \mathrm{O}_{8} \cdot 2 \mathrm{H}_{2} \mathrm{O}$ ) - was formed only in vessels through which a stream of carbon dioxide was conducted, and concluded that he had succeeded in achieving a photochemical reduction of carbon dioxide, thus imitating the photosynthes is by green plants. He then made experiments in which dimethyl aniline was added to the uranyl acetate solution prior to exposure to light and found that only when the solution was traversed by a stream of carbon dioxide did a blue coloration appear. He saw in this a proof of the formation of formaldehyde by photochemical reduction of carbonic acid. Euler (1904) showed, however, that the acceleration of $\mathrm{U}_{3} \mathrm{O}_{8}$ hydrate precipitation in light by carbon dioxide was due simply to the removal of air [which re-oxidizes U(IV) to U(VI)] and that the same effect could also be obtained by bubbling nitrogen through the vessel. He was unable to confirm Bach's observations with dimethyl aniline. Bach later (1904, 1906) acknowledged the correctness of Euler's criticisms and retracted his original claims.

Fay (1896) was the first to pay attention to gas liberation which occurs during the photochemical decomposition of uranyl acetate. He found it to be very slow, acetic acid occupying an intermediate position between propionic acid, which he found to be rapidly decomposed by $\mathrm{UO}_{2}^{++}$in light, and formic acid, which he was unable to decompose in this way at all. (How ever, we have seen above that $\mathrm{HCOOH}$ can be decomposed, under favorable conditions, with a quantum yield close to 1 ; we noted there that Fay's observations can be explained by the fact that the absorption bands of the uranyl-formate complex lie at shorter wave lengths than those of the uranylpropionate complex. A similar explanation can be suggested for the intermediate behavior of acetic acid; cf. Table 2.8. Fay could obtain measurable quantities of gas only from a mixture of $15 \mathrm{cc}$ glacial acetic acid and $5 \mathrm{cc}$ of a "concentrated" uranyl acetate solution; after six weeks of exposure to the sun, $13.4 \mathrm{cc}$ gas were collected, consisting of equal volumes of $\mathrm{CO}_{2}$ and $\mathrm{CH}_{4}$. This composition indicated sensitized decarboxylation (dismutation) without simultaneous oxidation-reduction [which could be expected to produce primarily $\mathrm{CH}_{3} \mathrm{COO}$ radicals and $\mathrm{UO}_{2}^{+}$ions, and, ultimately, oxidation products of acetic acid, such as $\mathrm{C}_{2} \mathrm{H}_{6}+\mathrm{CO}_{2}$, and reduction products of $\mathrm{U}(\mathrm{VI})$, such as $\mathrm{U}(\mathrm{IV})$ or $\left.\mathrm{U}_{3} \mathrm{O}_{8}\right]$.

Aloy $(1900,1901)$ noted that the precipitation [which indicates partial reduction of $\mathrm{U}(\mathrm{VI})$ ] is made much more rapid by the addition, to aqueous uranyl acetate solution of ether (or aldehyde, or glucose) or by the use of $90 \%$ alcohol as solvent. A voluminous precipitate was obtained within a few minutes under these conditions; after several washings with boiling water, it was free of acetate and consisted of pure $\mathrm{U}_{3} \mathrm{O}_{8}$ hydrate. A reaction that is completed so rapidly must be a thermal chain reaction of $\mathrm{UO}_{2}^{+}{ }^{+}$with the organic compound, in which only the initial step is photochemical. 
32

Zehenter (1900) noted that solutions of the double acetates, $\mathrm{KUO}_{2}\left(\mathrm{COOCH}_{3}\right)_{3}$ and $\mathrm{NaUO}_{2}\left(\mathrm{COOCH}_{3}\right)_{2}$, are practically photostable, in contrast to that of simple uranyl acetate, $\mathrm{UO}_{2}\left(\mathrm{COOCH}_{3}\right)_{2}$.

C. Neuberg (1908) found glyoxalic acid among the products of acetate photolysis sensitized by uranyl salts.

Baur (1908) predicted that photodecomposition of acetate by uranyl ions should give $\mathrm{H}_{2}$ and $\mathrm{CO}_{2}$ as the main products. In a subsequent experimental investigation (1918) he could not confirm this prediction; neither could he repeat Fay's observation of the predominant formation of $\mathrm{CH}_{4}$ and $\mathrm{CO}_{2}$. Instead, he found $\mathrm{CO}_{2}+\mathrm{C}_{2} \mathrm{H}_{6}$ as the main products, together with "a little hydrogen." (One hundred cc of a $0.08 \mathrm{M}$ solution of uranyl acetate, containing 2 moles/liter of free acetic acid, gave, in two days, $84 \mathrm{cc}$ of gas of which $54.3 \mathrm{cc}$ proved to be $\mathrm{CO}_{2}, 24 \mathrm{cc} \mathrm{C}_{2} \mathrm{H}_{6}, 2.4 \mathrm{cc}$ was thought to be $\mathrm{H}_{2}$, and $1.1 \mathrm{cc} \mathrm{O}_{2} ;$ )

Baur formulated the reaction, in his peculiar electrochemical notation:

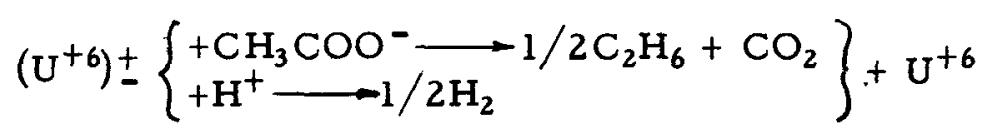

Translated into the language of photochemistry, the reaction sequence (29) implies that the photoxidation of acetic acid, e.g.,

$$
\mathrm{UO}_{2}^{++*}+\mathrm{CH}_{3} \mathrm{COO}^{-} \longrightarrow \mathrm{UO}_{2}^{+}+\mathrm{CH}_{3} \mathrm{COO} \longrightarrow \mathrm{UO}_{2}^{+}+1 / 2 \mathrm{C}_{2} \mathrm{H}_{6}+\mathrm{CO}_{2}
$$

is followed by re-oxidation of $U(V)$ by water:

$$
\mathrm{UO}_{2}^{+}+\mathrm{H}^{+} \longrightarrow \mathrm{UO}_{2}^{++}+1 / 2 \mathrm{H}_{2}
$$

Reaction ( $29 \mathrm{~b}$ ) could explain the liberation of hydrogen - if it actually does take place, which is doubtful. The main reaction, leading to ethane and carbon dioxide, certainly is not sensitized decomposition of acetic acid into $1 / 2 \mathrm{H}_{2}+1 / 2 \mathrm{C}_{2} \mathrm{H}_{6}+\mathrm{CO}_{2}$ (as Baur assumed), but its photochemical oxidation to $\mathrm{C}_{2} \mathrm{H}_{6}$ and $\mathrm{CO}_{2}$ without the formation of hydrogen but with the reduction of an equivalent quantity of $U(V I)$ to $U(I V)$, as expressed in Eq. (30):

$$
\mathrm{UO}_{2}^{++}+2 \mathrm{H}^{+}+2 \mathrm{CH}_{3} \mathrm{COOH} \stackrel{\text { light }}{\longrightarrow} \mathrm{C}_{2} \mathrm{H}_{6}+2 \mathrm{CO}_{2}+2 \mathrm{H}_{2} \mathrm{O}+\mathrm{U}^{+4}
$$

Baur and Rebmann (1922) later found that Fay had observed correctly, and that methane in fact can be produced by the photodecomposition of acetic acid. In other words, in addition to the oxidation-reduction (30), sensitized decarboxylation: 
$\mathrm{CH}_{3} \mathrm{COOH} \frac{\mathrm{UO}_{2}^{++}}{\text {light }} \mathrm{CH}_{4}+\mathrm{CO}_{2}$

also occurs in varying proportion.

The reaction products obtained in this investigation were mixtures of $\mathrm{CO}_{2}, \mathrm{CH}_{4}$ and $\mathrm{C}_{2} \mathrm{H}_{6}$; the proportion of ethane increased with an increase in the concentration of acetate relative to that of $\mathrm{UO}_{2}^{++}$(brought about by the addition of free acetic acid, or of sodium acetate, to uranyl acetate solution).

Hydrogen was not regularly present, although "traces" were sometimes observed, and its previous identification as reaction product by Baur was now attributed to confusion with carbon monoxide.

Typical compositions of reaction gases are given in Table 4.6.

Table 4.6

PRODUCTS OF URANYL-SENSITIZED PHOTOCHEMICAL

DECOMPOSITION OF ACETIC ACID

(AFTER BAUR AND REBMANN, 1922)

A

\begin{tabular}{|c|c|c|c|c|c|}
\hline \multirow{2}{*}{$\mathrm{U}(\mathrm{VI})$ acetate, $\%$} & \multirow{2}{*}{$\begin{array}{c}\text { Free } \\
\text { Acetic } \\
\text { Acid, \% }\end{array}$} & \multicolumn{4}{|c|}{ Products, $\%$} \\
\hline & & $\mathrm{CO}_{2}$ & $\mathrm{O}_{2}$ & $\mathrm{CH}_{4}$ & $\mathrm{~N}_{2}$ \\
\hline 6.8 & 12 & 18.6 & 0.9 & 43.8 & 12.0 \\
\hline 4.6 & 40 & 56.3 & 0 & 43.9 & $0^{(a)}$ \\
\hline 2.3 & 54 & 42.0 & 0.5 & 43.4 & $4.6^{(b)}$ \\
\hline
\end{tabular}

(a) After 13 days

(b) After 20 days

B

\begin{tabular}{|c|c|c|c|c|c|c|c|c|}
\hline \multirow{2}{*}{$\begin{array}{c}\text { U(VI) acetate, } \\
\%\end{array}$} & \multirow{2}{*}{$\begin{array}{c}\text { Na acetate, } \\
\%\end{array}$} & $\begin{array}{c}\text { Acetic } \\
\text { Acid } \\
\%\end{array}$ & \multicolumn{6}{|c|}{ Products, \% } \\
\cline { 5 - 9 } & $\%$ & $\mathrm{CO}_{2}$ & $\mathrm{O}_{2}$ & $\Delta \mathrm{CH}_{4}$ & $\mathrm{~N}_{2}$ & $\mathrm{CO}$ & $\mathrm{C}_{2} \mathrm{H}_{6}$ \\
\hline 1.6 & 1.4 & 0 & 40.1 & 0.4 & 43.5 & 14.0 & 0 & 1.9 \\
1.6 & 2 & 10 & 45.4 & 1.8 & 10.9 & 2.7 & 3.6 & $\begin{array}{r}17.4(\mathrm{a}) \\
7.4\end{array}$ \\
1.6 & 37.7 & 27.0 & 1.6 & 47.0 & 11.4 & 0 & 5.0 \\
\hline
\end{tabular}

(a) After 2 days

(b) After 6 days 


\section{4}

Addition of $\mathrm{Cl}^{-}$or $\mathrm{Hg}^{++}$was found by Baur and Rebmann to inhibit the reaction; addition of $\mathrm{FeSO}_{4}$ or $\mathrm{HCOOH}$ was found to prevent it completely (in the second case, without decomposition of formic acid!). This "negative catalysis" can occur by any of the four "static" or "kinetic" mechanisms suggested on p. 28 for a similar inhibition in the system uranyl salt + formic acid, such as displacement of acetate from the complex with uranyl, deflection of the oxidative action of activated $\mathrm{UO}_{2}^{++}$ions to the inhibitor (the photoxidation of which is later reversed in the dark), e.g.,

$$
\mathrm{UO}_{2}^{++}+\mathrm{Fe}^{++} \frac{\text { light }}{\text { dark }} \mathrm{UO}_{2}^{+}+\mathrm{Fe}^{+3}
$$

or catalytic acceleration of back reactions, which prevents the stabilization of the primary oxidation products of acetic acid:

$$
\begin{aligned}
& \mathrm{UO}_{2}^{++*}+\mathrm{CH}_{3} \mathrm{COOH} \longrightarrow \mathrm{UO}_{2}^{+}+\mathrm{CH}_{3} \mathrm{COOH}^{+} \text {(Primary forward } \\
& \text { reaction) } \\
& \text { C }+\mathrm{CH}_{3} \mathrm{COOH} \longrightarrow \mathrm{C}_{2} \mathrm{H}_{6}+2 \mathrm{CO}_{2}+2 \mathrm{H}^{+} \text {(Secondary forward }
\end{aligned}
$$

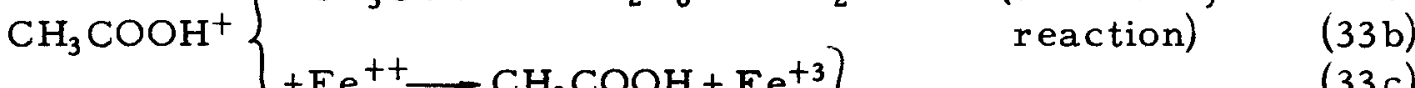

$$
\begin{aligned}
& \left\{+\mathrm{Fe}^{++} \longrightarrow \mathrm{CH}_{3} \mathrm{COOH}+\mathrm{Fe}^{+3}\right\}(33 \mathrm{c}) \\
& \mathrm{Fe}^{+3}+\mathrm{UO}_{2}^{+}-\mathrm{Fe}^{++}+\mathrm{UO}_{2}^{++} \quad \quad\left\{\begin{array}{l}
\text { (Cataly } \\
\text { action })
\end{array}\right.
\end{aligned}
$$

Substitution of (33b) for (33a), followed by (33c), leads to complete restoration of the original composition.

In some experiments, Baur and Rebmann also found small amounts of carbon monoxide, which they attributed to intermediate formation of glyoxalic acid, suggested earlier by Neuberg and Bacon:

$$
\mathrm{CH}_{3} \mathrm{COOH} \frac{+\mathrm{O}}{-2 \mathrm{H}}-\mathrm{OCH} \cdot \mathrm{COOH} \stackrel{-2 \mathrm{H}}{-} \mathrm{CO}+\mathrm{CO}_{2}
$$

Aloy and Rodier (1922) again studied the photoxidation of acetate in the presence of ether. The precipitated product was found to be $\mathrm{U}_{3} \mathrm{O}_{8}$ (aq.). It dissolved in acetic acid, giving a mixture of U(VI) and U(IV) acetates.

Aloy and Valdiguié $(1923,1925)$ extended the study of the reaction as it occurs in the presence of organic additions, by the observation of solutions in which glucose and methylene blue were added to uranyl acetate. They noted that uranyl acetate had no effect on glucose or methylene blue in the dark, even at elevated temperatures, but that it rapidly catalyzed, in light and in the absence of air, the oxidation of glucose by methylene blue. 


\section{5}

Phenols, although easily oxidizable, did not react with uranyl acetate and methylene blue in light; admixture of phenol also prevented the oxidation of glucose. Hydroquinone, too, acted as a "protector."

As in the case of inorganic ions, protecting substances can be conceived either as substituting for acetate in the role of oxidation substrates, or as acting as catalysts in the back reaction between the primary oxidation and reduction products.

Later, Aloy and Valdiguid (1925) found that decoloration of methylene blue by light in the presence of uranyl acetate also occurs if aldehydes and unsaturated hydrocarbons (ethylene, amylene, acetylene and certain cyclic compounds) are provided as reductants instead of glucose.

Most of these experiments can be repeated with uranyl sulfate (instead of acetate); we will therefore return to them in Sec. 4. It is not clear from the description whether in these experiments the possibility of a direct photochemical action on methylene blue was eliminated. (This could have been done by showing that no decoloration occurs in the absence of uranyl salts.)

Courtois (1923) described some new observations on the decomposition of stoichiometric uranyl acetate solutions in light. A yellow precipitate was formed after several days' exposure to diffuse illumination; the precipitate was identified as basic $U(V I)$ acetate. In direct sunlight, on the other hand, a violet precipitate of $U(V I, I V)$ hydroxide was obtained in the presence of ether and air. Without air, the decomposition is slowed down; the solution becomes opaque, but no precipitate appears. Without ether, but in the presence of air, the violet precipitate is formed rather rapidly if the solution is concentrated. The sluggish gas evolution produces carbon dioxide and methane.

The question of whether the uranyl acetate reaction occurs by light absorption in a complex or by encounter of excited uranyl with acetate molecules or ions was first raised by the spectroscopic observations of Henri and Landau (1914). Their results - indicating the existence of a complex were given in Table 2.6; Table 2.8 showed those of a somewhat more extensive study of Ghosh and Mitter (1928), while Figs. 2.8D and 2.8E illustrated the more recent and precise spectroscopic determinations of the complexing constants by Ahrland (1951). The latter lead to a value of 240 (moles/liter) $^{-1}$ for the first association constant of $\mathrm{UO}_{2}^{+}$and $\mathrm{CH}_{3} \mathrm{COO}-, 2.3 \times 10^{4}$ (moles/liter) ${ }^{-2}$ for the second one, and $2.2 \times 10^{6}$ (moles/liter $)^{-3}$ for the third one $\left(20^{\circ} \mathrm{C}\right.$, ionic strength 1.0).

Since photosensitized decarboxylation, according to Baur and Rebmann, increases with decreasing ratio [acetate]/[uranyl], a possible working hypothesis is that photoxidation [e.g., reaction (30)] occurs when light is absorbed 
by uranyl acetate complexes, and sensitized decarboxylation [reaction (31)] when light is absorbed by free uranyl ions (which then react by encounters with acetic acid molecules). This agrees with the conclusion (cf. preceding section) that in the reaction with formic acid, where only complexes seem to react, oxidation-reduction is the only observed reaction (cf., however, the apparently different relationship in the case of oxalate, p. 37). A quantitative test of the hypothesis that photoxidation results from light absorption by complexes has been made possible by Ahrland's determinations of the complexing constants, but has not yet been attempted. The relative role of the binary and the higher complexes also could be evaluated from Ahrland's data; the photochemical importance of the higher complexes may be out of proportion with their relative concentration, if the light used is absorbed by them much more strongly than by the free ions or simpler complexes.

(c) Higher Monobasic Acids - Only incidental observations are available on the reaction of $\mathrm{UO}_{2}^{++}$in light with propionic, butyric, and valeric acid.

Prince L. L. Bonaparte $(1842,1843)$ noted that a solution of uranyl valerate, exposed to sunlight in a closed bottle, decomposes into violet uranium oxide or U(IV) valerate, and gaseous oxidation products of valeric acid.

Wisbar (1891) exposed to sunlight a solution of butyric acid, $\mathrm{C}_{3} \mathrm{H}_{7} \mathrm{COOH}$, to which $\mathrm{UO}_{2}\left(\mathrm{NO}_{3}\right)_{2}$ had been added, and observed a decomposition accompanied by liberation of gas. Analysis of the latter showed $32 \% \mathrm{CO}_{2}$. The remainder, made oxygen-free by phosphorus, contained $5 \% \mathrm{~N}_{2}$ (obviously, air was not effectively excluded). The other $93 \%$ was a combustible gas; its combustion gave a three-fold volume of $\mathrm{CO}_{2}$, indicating that it was propane. The decomposition thus probably occurred according to the equation:

$$
\mathrm{C}_{3} \mathrm{H}_{7} \cdot \mathrm{COOH} \frac{\mathrm{UO}_{2}}{\text { light }}-\mathrm{C}_{3} \mathrm{H}_{8}+\mathrm{CO}_{2}
$$

The fact that some $\mathrm{CO}_{2}$ was "missing" (32\% instead of $50 \%$ ) was attributed by Wisbar to losses of this gas by dissolution in water.

Fay (1896) investigated butyric as well as isobutyric acid and found both to decompose readily in sunlight in the presence of uranyl nitrate. Gas analysis confirmed the observations made by $\mathrm{W}$ isbar with $\mathrm{n}$-butyric acid. The liberated gas contained $50 \% \mathrm{CO}_{2}$ and $50 \%$ of a hydrocarbon, the combustion of which gave the volume change expected for $\mathrm{C}_{3} \mathrm{H}_{8}$. A viscous, green liquid or a light-green precipitate was formed.

Similar experiments with propionic acid gave about $50 \% \mathrm{CO}_{2}$ and approximately $50 \%$ of a hydrocarbon (for confirmation see Bacon, 1907). The combustion of the latter gave a volume change corresponding to $\mathrm{n}=2.38$ in $\mathrm{C}_{\mathrm{n}} \mathrm{H}_{2 \mathrm{n}+2}$ - possibly $\mathrm{C}_{2} \mathrm{H}_{6}$. 
Butyric, propionic and iso butyric acid decomposed at approximately the same rate. (As mentioned before, the cause of differences in the rate of photochemical decomposition of mixtures of $\mathrm{UO}_{2}^{++}$with different aliphatic acids, noted by earlier observers, probably lies in the different intensity of light absorption in the visible and near ultraviolet by the complexes formed by these acids with uranyl ions.)

Courtois $(1914,1923)$ found dilute uranyl propionate and butyrate solutions to be "very stable" in darkness and in diffuse light. In sunlight, both solutions decomposed in the same way, in the presence as well as in the absence of air. A violet $\mathrm{U}_{3} \mathrm{O}_{8}$ hydrate was precipitated during the first day, without appreciable gas evolution; on the second day, gas evolution began. The gas proved to be $\mathrm{CO}_{2}+\mathrm{C}_{n} \mathrm{H}_{2 n}$, with combustion experiments giving $\mathrm{n}=1.84$ for propionate $\left(\mathrm{C}_{2} \mathrm{H}_{6}\right.$ ?). In the case of butyrate, Courtois found a "mixture of hydrocarbons."

In saturated propionate solution, the reduction of uranyl to $\mathrm{U}_{3} \mathrm{O}_{8}$ is complete after a month of exposure to sunlight; it is accelerated by the presence of ether, even in dilute uranyl salt solution. In methanol solution, the precipitation is rapid, giving violet $\mathrm{U}_{3} \mathrm{O}_{8} \cdot 2 \mathrm{H}_{2} \mathrm{O}$.

Isobutyrate, valerate and isovalerate behave similarly; the decomposition becomes more rapid with increasing molecular weight of the acid.

2.2 Dibasic Aliphatic Acids - The acids studied were oxalic acid and its higher homologues - malonic acid, succinic acid and pyrotartaric acid. By far the most extensive work was carried out with oxalic acid.

(a) Oxalic Acid - Ebelmen (1842) noted that a hydrated uranium oxide can be prepared by decomposition of a uranyl oxalate solution in light. The clear solution became turbid when exposed to light; a brownish-violet precipitate, which Ebelmen identified as a $\mathrm{U}_{3} \mathrm{O}_{8}$ hydrate (cf. Katz and Rabinowitch, 1951, Chap. 11), was formed, while a mixture of carbon monoxide and carbon dioxide escaped into the atmosphere. Nièpce de Saint Victor and Corvisart (1860) reported that a solution containing $1 \%$ uranyl nitrate and $4 \%$ oxalic acid could be boiled for $40 \mathrm{hr}$ in the dark without visible reaction, but evolved a combustible gas immediately upon exposure to light, even at $0^{\circ} \mathrm{C}$. Similar results were obtained when U(VI) oxide was used instead of nitrate. Seekamp (1862), too, found that a solution containing $5 \%$ oxalic acid and $1 \%$ uranyl nitrate evolved gas bubbles in light; the solution became green and then discharged a green precipitate of uranous oxalate, $\mathrm{U}\left(\mathrm{C}_{2} \mathrm{O}_{4}\right)_{2}$. The total gas produced consisted of $43 \%$ carbon monoxide and $57 \%$ carbon dioxide, but the ratio of the two components changed with the progress of the reaction. The residual solution was colorless, acid, and contained no oxalate ions; the products of its distillation with sulfuric acid indicated the presence of formic acid. (At first, in 1862, Seekamp thought that formic acid was a secondary product, due to a photochemical reaction 
between carbon monoxide and water; later, in 1865, he suggested direct formation of formic acid by de-carboxylation of oxalic acid, $\mathrm{HOOC} \cdot \mathrm{COOH} \longrightarrow \mathrm{CO}_{2}+\mathrm{HCOOH}$, which is much more plausible.)

Bolton (1866) observed that uranyl-potassium fluoride solutions react with oxalic acid in light, giving a mixture of a brownish-red with a green precipitate (the first one probably was identical with Ebelmen's uranium hydroxide, the second one with Seekamp's uranous oxalate).

Fay (1896) first described the work done by H. C. Jones, confirming the formation of carbon dioxide, carbon monoxide and formic acid by photochemical decomposition of uranyl oxalate. Jones varied the concentrations of uranyl oxalate and of free oxalic acid and found that one molecule of carbon dioxide was always formed when one molecule of oxalic acid was decomposed $\left(\triangle \mathrm{CO}_{2}=-\Delta \mathrm{C}_{2} \mathrm{H}_{2} \mathrm{O}_{4}\right)$, but that the relative quantities of carbon monoxide and formic acid, $\triangle \mathrm{CO}$ and $\triangle \mathrm{HCOOH}$, depended on the specific conditions of the experiment, and that the sum $(\triangle \mathrm{CO}+\triangle \mathrm{COOH})$ usually was slightly smaller than $\Delta \mathrm{CO}_{2}$. These observations are consistent with the assumption that the main reaction was the sensitized decomposition of oxalic acid, either by the reaction:

$$
\mathrm{COOH} \cdot \mathrm{COOH} \frac{\text { light }}{\mathrm{UO}_{2}^{++}} \mathrm{CO}_{2}+\mathrm{CO}+\mathrm{H}_{2} \mathrm{O}
$$

or by the reaction

$$
\mathrm{COOH} \cdot \mathrm{COOH} \frac{\text { light }}{\mathrm{UO}_{2}^{++}} \mathrm{CO}_{2}+\mathrm{HCOOH}
$$

[Reaction (37) could be the first step of reaction (36).] The observed slight excess of $\mathrm{CO}_{2}$ conceivably could be due to a third sensitized reaction:

$$
\mathrm{COOH} \cdot \mathrm{COOH} \frac{\text { light }}{\mathrm{UO}_{2}^{++}} 2 \mathrm{CO}_{2}+\mathrm{H}_{2}
$$

but the above-mentioned formation of uranous oxalate and of $\mathrm{U}_{3} \mathrm{O}_{8}$ hydrate (which was also noted by Jones) makes it much more likely that the excess carbon dioxide originated in photochemical oxidation of oxalic acid by uranyl ions:

$$
\mathrm{COOH} \cdot \mathrm{COOH}+\mathrm{UO}_{2}^{++}+2 \mathrm{H}^{+} \stackrel{\text { light }}{\longrightarrow} 2 \mathrm{CO}_{2}+\mathrm{U}^{+4}+2 \mathrm{H}_{2} \mathrm{O}
$$

By gradually depleting the photocatalyst, reaction (39) limits the amount of oxalic acid that can be decomposed photocatalytically by a given amount of uranyl ions. 
The composition of the precipitate was found by Jones to depend on the ratio $x=$ [oxalic acid]/[uranyl]. When this ratio was high, the precipitate consisted of a mixture of green crystals with an amorphous green mass; when it was lower, the precipitate consisted mainly of the green mass, which gradually became purplish-brown. The latter product was obtained also by photodecomposition of a uranyl oxalate solution without added oxalic acid.

Continuing Jones' work, Fay tried to separate the two components of the precipitate. First he isolated the greenish crystalline precipitate and found it to be uranous oxalate hexahydrate, $\mathrm{U}\left(\mathrm{C}_{2} \mathrm{O}_{4}\right)_{2} \cdot 6 \mathrm{H}_{2} \mathrm{O}$ (thus confirming Seekamp's observations). Then he prepared the purplish-brown, amorphous product by photochemical decomposition of uranyl oxalate without added oxalic acid. No gas evolution was observed in this experiment. (Perhaps carbon dioxide was tied up, under these conditions, by the formation of U(IV) carbonate, which can effectively compete with the formation of oxalate when no excess oxalate ions are present.) Upon drying, the product became yellow; in this state, it contained from 1 to $1.5 \%$ carbon. Fay therefore considered the purplish-brown precipitate as the salt of an organic acid, rather than as a hydroxide (as suggested by Ebelmen). Ebelmen's analysis was, however, confirmed by Aloy and Rodier (1920) and Courtois (1923). The latter found that the purplish-brown $\mathrm{U}_{3} \mathrm{O}_{8}$ hydrate, precipitated by light from uranyl oxalate solution, is transformed, by washing with cold water, into yellow $\mathrm{UO}_{3} \cdot 2 \mathrm{H}_{2} \mathrm{O}$. This oxidation can already occur during the photochemical reaction before the sedimentation of the precipitate.

Obviously, when U(IV) ions are formed by reduction of $\mathrm{UO}_{2}^{++}$ions in a solution that contains hydroxyl and oxalate anions, and in which carbon dioxide and formic acid are produced at the same time, a competition must ensue between hydrolysis [i.e., as sociation of U(IV) cations with hydroxyl ions, and subsequent precipitation of a hydroxide] and the complexing of the same cations with oxalate, carbonate or formate anions, and ensuing precipitation of basic or neutral U(IV) salts by reactions (40a) and (40b).

$$
\left.\begin{array}{l}
\begin{array}{l}
\mathrm{U}(\mathrm{IV})+\mathrm{HOOC} \cdot \mathrm{COOH} \longrightarrow \mathrm{U}(\mathrm{IV}) \text { oxalate } \\
\mathrm{U}(\mathrm{IV})+\mathrm{CO}_{2}+\mathrm{H}_{2} \mathrm{O} \longrightarrow \mathrm{U}(\mathrm{IV}) \text { carbonate }
\end{array}
\end{array}\right\} \text { (green precipitate) }
$$

The composition of the precipitate actually formed must therefore depend on the $\mathrm{pH}$ of the solution and on the relative concentrations of oxalate, carbonate and formate ions at the time of precipitation.

An additional complication arises from the possibility of precipitation of $U(V I)$ together with $U(I V)$, e.g., in the form of a $\mathrm{U}_{3} \mathrm{O}_{8}$ hydrate. For mally, this precipitation can be interpreted as resulting from the capacity of $\mathrm{U}(\mathrm{VI})$ derived anions, such as $\left[\mathrm{UO}_{2}^{++}\left(\mathrm{OH}^{-}\right)_{4}\right]$ - to enter into competition with other anions for the U(IV) cations, e.g.,

$$
\mathrm{U}^{+4}+2 \mathrm{H}_{4} \mathrm{UO}_{6}^{--} \longrightarrow \mathrm{U}\left(\mathrm{H}_{4} \mathrm{UO}_{6}\right)_{2}\left(=\mathrm{U}_{3} \mathrm{O}_{8} \cdot 4 \mathrm{H}_{2} \mathrm{O}\right) \text { (brown-violet precipitate) }
$$




\section{0}

Another possible mechanism of $\mathrm{U}_{3} \mathrm{O}_{8}$ precipitation is via the $\mathrm{UO}_{2}^{++}$ions that had been hydrolyzed according to the Eq. (42a):

$$
\begin{aligned}
& 2 \mathrm{UO}_{2}^{++}+\mathrm{H}_{2} \mathrm{O} \rightleftharpoons\left(\mathrm{UO}_{2}-\mathrm{O}-\mathrm{UO}_{2}\right)^{++}+2 \mathrm{H}^{+}\left(=\mathrm{U}_{2} \mathrm{O}_{5}^{++}+2 \mathrm{H}^{+}\right) \\
& \mathrm{U}_{2} \mathrm{O}_{5}^{++}+\mathrm{U}^{+4}+6 \mathrm{OH}^{-} \longrightarrow \mathrm{U}_{3} \mathrm{O}_{8} \cdot 3 \mathrm{H}_{2} \mathrm{O}
\end{aligned}
$$

Fay checked whether formic acid can be formed from water and carbon monoxide in light in the presence of $\mathrm{UO}_{2}^{++}$ions and obtained negative results, confirming Seekamp's second interpretation (cf. above, p. 37). The formic acid produced by photochemical reaction of uranyl and oxalate must thus be a direct decomposition product of oxalic acid.

Bacon $(1907,1910)$ also measured the rate of decomposition of oxalic acid (in sunlight) in relation to the concentrations $\left[\mathrm{UO}_{2}^{++}\right]$and $\left[\mathrm{H}_{2} \mathrm{C}_{2} \mathrm{O}_{4}\right]$. He found a "saturation" in respect to $\left[\mathrm{UO}_{2}^{++}\right]$(probably due to complete absorption of the light used) at $0.2 \mathrm{~g}$ uranyl acetate in $100 \mathrm{cc}$, in the presence of $0.5 \mathrm{~g}$ oxalic acid. Saturation with respect to $\mathrm{H}_{2} \mathrm{C}_{2} \mathrm{O}_{4}$ occurred between $0.3 \mathrm{~g}$ and $1.0 \mathrm{~g}$ oxalic acid in $100 \mathrm{cc}$, in the presence of $0.1 \mathrm{~g} \mathrm{UO}_{2}^{++}$(i.e., $>1.0 \mathrm{~mole}$ oxalate per mole uranyl; see below). Addition of acid or alkali had no effect on the rate as long as the solution remained acid. Uranyl nitrate gave the same results as uranyl acetate, and ammonium oxalate the same as free oxalic acid. Phenol, aniline, malachite green, methyl violet and fluorescein were found to act as inhibitors. Temperature changes $\left(30-100^{\circ} \mathrm{C}\right)$ had no influence. Only very little formic acid was found by Bacon among the products of decomposition.

These early experiments have clearly established the complex character of the photochemical reaction of uranyl ions with oxalate. This reaction obviously includes:

(1) Photochemical oxidation of oxalic acid by uranyl [reaction (35)], followed by various association and precipitation reactions of U(IV), such as $(40 \mathrm{a}),(40 \mathrm{~b})$ or $(41)$;

(2) Uranyl-sensitized decomposition of oxalic acid (dismutation, decarboxylation), described by Eqs. (36) and (37), and probably also:

(3) Sensitized autoxidation, in cons equence of re-oxidation of U(IV) in air:

$$
\begin{aligned}
\mathrm{U}(\mathrm{VI}) & +\mathrm{HOOC} \cdot \mathrm{COOH} \stackrel{\text { light }}{\longrightarrow} \mathrm{U}(\mathrm{IV})+2 \mathrm{CO}_{2}+2 \mathrm{H}^{+} \stackrel{+1 / 2 \mathrm{O}_{2}}{\longrightarrow} \mathrm{U}(\mathrm{VI}) \\
& +2 \mathrm{CO}_{2}+\mathrm{H}_{2} \mathrm{O}
\end{aligned}
$$

Subsequent investigators have attempted to establish the mechanism of the various reactions and the conditions under which the one or the other predominates, but the picture is still far from complete. 
Bruner and Kozak (1911) were interested in photocatalytic reactions. They took it for granted that photocatalytic autoxidations caused by uranyl salts are due to reaction sequences of type (43); but found it more difficult to explain photocatalytic decompositions (decarboxylations) of type (36) and (37), which appear to involve no intermediate reduction of uranyl to uranous ions. In the hope of clarifying the mechanism of the reactions, they studied the kinetics of the formation of formic acid in uranyl-sensitized photodecomposition of oxalic acid, i.e., reaction (37).

Bruner and Kozak found that in a solution containing $0.5 \mathrm{~g}$ oxalic acid and $0.1 \mathrm{~g}$ uranyl nitrate in $20 \mathrm{cc}$, as much as $26-29 \%$ of decomposed oxalate was converted to formic acid. When the concentration of uranyl nitrate was raised from 0.03 to $0.4 \mathrm{~g}$, the proportion of formic acid increased. Increase of oxalate concentration, up to $\left[\mathrm{H}_{2} \mathrm{C}_{2} \mathrm{O}_{4}\right]=0.2 \mathrm{~g}$ in $20 \mathrm{cc}$, caused an increase in the total rate of decomposition; from there on (in agreement with the earlier findings of Bacon) the reaction appeared "saturated" with oxalic acid (cf. below). A "saturation curve" was also obtained with varying [ $\mathrm{UO}_{2}^{++}$] (again confirming Bacon's findings); the rate reached its limiting level at about $0.5 \mathrm{~g}$ uranyl nitrate in $20 \mathrm{cc}$, corresponding to about $0.07 \mathrm{M}$, much higher than was found by Bacon. However, if saturation is due to total light absorption, the level at which it occurs will depend on the thickness of the absorbing layer and the spectral composition of the light used. As in Bacon's experiments, temperature changes $\left(4-80^{\circ} \mathrm{C}\right)$ had no noticeable effect on the decomposition rate.

Bruner and Kozak's experiments on the effect of wavelength and light intensity were too primitive for valid conclusions.

In contrast to Bruner and Kozak, Boll (1913) could find no formic acid at all in the products of uranyl-sensitized photodecomposition of oxalic acid $\left[10^{-3} \mathrm{M} \mathrm{UO}_{2}\left(\mathrm{NO}_{3}\right)_{2}+10^{-3} \mathrm{M} \mathrm{H}_{2} \mathrm{C}_{2} \mathrm{O}_{4}\right]$; the conductivity of the solution after the reaction was negligible. He made the first attempt to determine the quantum yield of the uranyl-sensitized oxalate decomposition and found very high values, $>500$. He concluded that this reaction does not obey Einstein's law of photochemical equivalency, but is a "catalytic" reaction in which light acts as a catalyst. These results were not confirmed by subsequent investigators.

Mathews and Dewey (1913) gave time curves of the photodecomposition of oxalic acid in the presence of varying amounts of uranyl nitrate. They noted that substitution of sulfate or acetate for nitrate left the results unchanged.

Henri and Landau (1914) compared the absorption spectra of uranyl nitrate, sulfate, chloride, and oxalate solutions, with and without the addition of oxalic acid. The results (cf. Table 2.6) indicated the formation of uranyloxalate complexes with enhanced absorption. Complexing appeared to be strong, but not quite complete, in stoichiometric uranyl oxalate solution. 


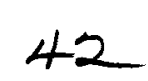

After this conclusion had been reached, much of the study of the mechanism of the uranyl-oxalate reaction was directed toward the understanding of the roles played in this reaction by various complex and non-complex molecular and ionic species. Unfortunately, no study of the uranyl oxalate system by spectrographic or potentiometric methods has yet been carried out that would take into consideration incomplete acid dissociation, uranyl ion hydrolysis, ionic strength effects, and the possibility of formation of higher complexes in the same way as this was done by Ahrland for the uranyl acetate, thiocyanate, formate and sulfate systems (Chap. 2). As a result, interpretation of the kinetics of the most important photochemical reaction of the uranyl ion still has to be based on inadequate spectroscopic studies of Henri and Landau, (1914) and of Ghosh and Mitter (1928) (cf Chap. 2).

Baur (1919) began his studies of the uranyl oxalate reaction by dis cussing it from the point of view of his concept of "photolys is as molecular electrolysis" (cf. p. 7). By analogy with macroscopic electrolysis of oxalic acid, which produces glyoxylic acid $(\mathrm{CHO} \cdot \mathrm{COOH})$, and also glycolic acid at the cathode, he proposed the reaction scheme:

$$
[\mathrm{U}(\mathrm{VI})]_{--}^{++}\left\{\begin{array}{l}
+\mathrm{CHO} \cdot \mathrm{COOH} \longrightarrow \mathrm{CO}+\mathrm{CO}_{2}+2 \mathrm{H}^{+} \\
+\mathrm{COOH} \cdot \mathrm{COOH} \longrightarrow \mathrm{CHO} \cdot \mathrm{COOH}+\mathrm{H}_{2} \mathrm{O}+2 \mathrm{H}^{+}
\end{array}\right\}+\begin{aligned}
& (44 \mathrm{a}) \\
& \mathrm{U}(\mathrm{VI}) \\
& (44 \mathrm{~b})
\end{aligned}
$$

in which glyoxylic acid appears as an intermediate product (produced by "cathodic depolarization" and consumed by "anodic depolarization").

Baur and Rebmann (1922) then undertook an experimental study. They asked whether the glyoxylic acid - which, according to scheme $(44 \mathrm{a}, \mathrm{b})$, should occur as intermediate - could be made to accumulate by replacing it in the upper half of the process by another reductant ("anodic depolarizer"), such as $\mathrm{KI}, \mathrm{FeSO}_{4}, \mathrm{HCOOH}$, or hydroquinone; however, efforts to prove the ac cumulation of glyoxylic acid in the presence of these reductants had no success. In this study, the effect of certain additions on the rate and character of decomposition was noted. For example, addition of $10 \mathrm{cc}$ saturated $\mathrm{HgCl}_{2}$ solution (to a mixture of $25 \mathrm{cc} 0.5 \mathrm{~N}$ oxalic acid $+5.5 \mathrm{cc}$ saturated $\mathrm{UO}_{2} \mathrm{SO}_{4}$ solution $+10 \mathrm{cc} 0.5 \mathrm{~N} \mathrm{H}_{2} \mathrm{SO}_{4}+150 \mathrm{cc} \mathrm{H}_{2} \mathrm{O}$ ) increased the proportion of carbon dioxide in the gaseous products from 35-40 to 50-55\%, decreasing correspondingly the proportion of carbon monoxide. Calomel was formed. This observation was explained by the reaction scheme:

$$
[\mathrm{U}(\mathrm{VI})]_{--}^{++}\left\{\begin{array}{l}
+\mathrm{C}_{2} \mathrm{O}_{4}^{--} \longrightarrow 2 \mathrm{CO}_{2} \\
+2 \mathrm{HgCl}_{2} \longrightarrow \mathrm{Hg}_{2} \mathrm{Cl}_{2}+2 \mathrm{Cl}^{-}
\end{array}\right\}+\mathrm{U}(\mathrm{VI})
$$

with $\mathrm{HgCl}_{2}$ acting as "cathodic depolarizer." As usual, Baur's "polarization" and "depolarization" reactions can be replaced by reduction and reoxidation of the sensitizer, e.g., 


$$
\begin{gathered}
43 \\
\mathrm{U}(\mathrm{VI})+\mathrm{C}_{2} \mathrm{O}_{4}^{--} \stackrel{\text { light }}{\longrightarrow} 2 \mathrm{CO}_{2}+\mathrm{U}(\mathrm{IV}) \\
\mathrm{U}(\mathrm{IV})+2 \mathrm{HgCl}_{2} \longrightarrow \mathrm{U}(\mathrm{VI})+\mathrm{Hg}_{2} \mathrm{Cl}_{2}+2 \mathrm{Cl}^{-}
\end{gathered}
$$

The effect of potassium iodide was found to be similar to that of calomel, but somewhat weaker (the proportion of $\mathrm{CO}_{2}$ was increased only slightly, from 40 to $46 \%$ ); some iodine was formed. Since iodide is a reductant, it was postulated that it acts as "anodic depolarizer" in competition with oxalate:

$$
\begin{aligned}
& {[\mathrm{U}(\mathrm{VI})]_{- \pm}^{++}\left\{\begin{array}{l}
+2 \mathrm{I}^{-} \longrightarrow \mathrm{I}_{2} \\
+\mathrm{U}(\mathrm{VI}) \longrightarrow \mathrm{U}(\mathrm{IV})
\end{array}\right\}+\mathrm{U}(\mathrm{VI})} \\
& {[\mathrm{U}(\mathrm{VI})]_{--}^{++}\left\{\begin{array}{l}
+\mathrm{C}_{2} \mathrm{O}_{4}^{--} \longrightarrow 2 \mathrm{CO}_{2} \\
+\mathrm{I}_{2} \longrightarrow 2 \mathrm{I}^{-}
\end{array}\right\}+\mathrm{U}(\mathrm{VI})}
\end{aligned}
$$

This combination of "polarizing" and "depolarizing" reactions is equivalent to a primary photoxidation of $\mathrm{I}^{-}$to $\mathrm{I}_{2}$ by excited uranyl ions, followed by a uranyl-sensitized oxidation of $\mathrm{C}_{2} \mathrm{O}_{4}^{--}$to $\mathrm{CO}_{2}$ by iodine.

Addition of ferrous sulfate $\left(2.5 \mathrm{~g} \mathrm{FeSO}_{4}\right.$ in $40 \mathrm{cc}$, containing some $\left.\mathrm{Fe}^{+3}\right)$ strongly increased the formation of carbon dioxide in light (from 51 to $72 \%$ ); the solution became green in consequence of U(IV) formation. The total yield of decomposition increased. These effects could be explained in the same way as those of iodide, with $\mathrm{Fe}^{+2}$ and $\mathrm{Fe}^{+3}$ substituting for $\mathrm{I}^{-}$and $\mathrm{I}_{2}$, respectively, in Eqs. (48) and (49) (or in equivalent equations not using Baur's "electrochemical" notation). Sodium sulfite, despite its reducing properties, had no effect.

Addition of formic acid led to simultaneous decomposition of both $\mathrm{H}_{2} \mathrm{C}_{2} \mathrm{O}_{4}$ and $\mathrm{HCOOH}$.

Organic reductants, such as pyrogallol $(7.3 \mathrm{~g})$ or hydroquinone (19 g in $50 \mathrm{cc}$ water), added to $100 \mathrm{cc}$ solution containing $5 \mathrm{~g}$ sodium uranate and $5 \mathrm{~g}$ oxalate, produced effects similar to those of iodide or ferrous sulfate.

In a neutral solution of sodium diuranate $\left(\mathrm{Na}_{2} \mathrm{U}_{2} \mathrm{O}_{7}\right)$ and uranyl oxalate, light also caused the production of carbon dioxide; the latter was formed in excess of the amount corresponding to catalytic decomposition into $\mathrm{HCOOH}$ and $\mathrm{CO}_{2}$, indicating some photoxidation.

In another paper, Baur (1922) described the results of experiments made in his laboratory by Haggenmacher, in which the yield of formic acid was determined by distillation instead of by oxidation with $\mathrm{HgCl}_{2}$ in the reaction mixture (the method used by Bruner and Kozak), because in the latter procedure U(IV) also can be oxidized, making the results unreliable whenever photoxidation accompanies catalytic decomposition. 


\section{4}

The formation of formic acid was qualitatively confirmed, but only small quantities of this acid were found. The amount of $\mathrm{CO}_{2}$ formed was somewhat higher than that of $\mathrm{CO}$; the excess decreased with the decreasing ratio $x=\left[\mathrm{H}_{2} \mathrm{C}_{2} \mathrm{O}_{4}\right] /\left[\mathrm{UO}_{2} \mathrm{SO}_{4}\right]($ Table 4.7). This could be due either to formic acid formation (Eq. 37) or oxidation-reduction (Eq. 39); for an argument in favor of the first explanation see below.

Table 4.7

$\triangle \mathrm{CO}_{2} / \triangle \mathrm{CO}$ RATIO IN THE DECOMPOSITION PRODUCTS OF OXALIC ACID (BAUR, 1922)

\begin{tabular}{|c|c|c|}
\hline $\begin{array}{c}0.5 \mathrm{M} \\
\mathrm{H}_{2} \mathrm{C}_{2} \mathrm{O}_{4}, \\
\mathrm{cC}\end{array}$ & $\begin{array}{c}0.77 \mathrm{M} \\
\mathrm{UO}_{2} \mathrm{SO}_{4}, \\
\mathrm{cc}\end{array}$ & $\Delta \mathrm{CO}_{2} / \Delta \mathrm{CO}$ \\
\hline 8.5 & 2 & 1.20 \\
8.5 & 4.2 & 1.23 \\
8.5 & 11.0 & 1.05 \\
8.5 & 18.0 & 1.03 \\
\hline
\end{tabular}

A new investigation of the uranyl-oxalate reaction in light was carried out in Baur's laboratory by Büchi (1924). His aim was to decide whether the decomposition takes place by encounters between free, excited $\mathrm{UO}_{2}^{++}$ions and $(\mathrm{COOH})_{2}$ molecules (or oxalate ions), or by internal rearrangement in a complex of the two reactants. In favor of complex formation, Büchi quoted the cryoscopic observations of Dittrich, who found that $\mathrm{UO}_{2} \mathrm{SO}_{4}$ is less strongly dissociated into ions than $\mathrm{UO}_{2} \mathrm{Cl}_{2}$ or $\mathrm{UO}_{2}\left(\mathrm{NO}_{3}\right)_{2}$, the fact that the conductivity of uranyl oxalate solutions is much lower than that of uranyl sulfate solutions, and Henri and Landau's spectroscopic observations.

He considered the latter as proving the existence of a $1: 1$ complex, $\mathrm{UO}_{2} \mathrm{C}_{2} \mathrm{O}_{4}$, in solution. The enhanced solubility of $\mathrm{UO}_{2} \mathrm{C}_{2} \mathrm{O}_{4}$ in the presence of oxalic acid can be considered as indicating the formation of complexes with more than one oxalate ion (or oxalic acid molecule) per uranyl ion.

In Büchi's experiments, mixtures containing $0.06 \mathrm{M} \mathrm{UO}_{2}^{++}$salt and from 0.0004 to $0.13 \mathrm{M} \mathrm{H}_{2} \mathrm{C}_{2} \mathrm{O}_{4}$ were illuminated in a $2.7 \mathrm{~cm}$ deep vessel by a $1500 \mathrm{w}$ incandescent lamp. With $0.03 \mathrm{M} \mathrm{H}_{2} \mathrm{C}_{2} \mathrm{O}_{4}$, the rate of decomposition remained constant until $35 \%$ of the oxalate was used up. Exclusion of air had no influence. Doubling of all concentrations increased the rate by only $15 \%$.

Change in oxalate concentration (at constant $\left[\mathrm{UO}_{2}^{++}\right]$) had a strong effect on the over-all rate (cf. Table 4.8 ). 
45

Table 4.8

EFFECT OF OXALATE CONCENTRATION ON RATE OF URANYL OXALATE DECOMPOSITION IN LIGHT

(AFTER BÜCHI, 1924)

$[$ Uranyl $]=0.06 \mathrm{M}$

\begin{tabular}{|c|c|}
\hline $\mathbf{x}=[$ Oxalate $] /[$ Uranyl $]$ & $\Delta[$ Oxalate $] / \Delta \mathrm{t}, \mathrm{m} / \mathrm{hr}$ \\
\hline 8 & 0.086 \\
0.25 & 0.022 \\
\hline
\end{tabular}

The "saturation" of the reaction with oxalic acid occurred under these conditions in the neighborhood of $x=$ [oxalate] $/[$ uranyl] $=1$ (Table 4.9). This is a result which Büchi considered as indicating the formation of a stable complex of one uranyl ion and one oxalate ion.

Table 4.9

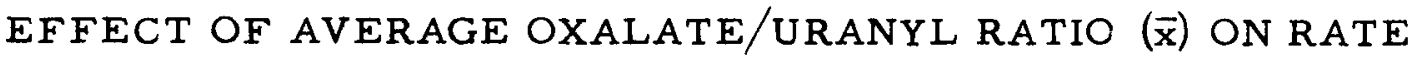
OF URANYL SENSITIZED OXALATE DECOMPOSITION (AFTER BÜCHI, 1924)

\begin{tabular}{|c|c|c|c|c|c|c|}
\hline$\overline{\mathbf{x}}$ & 7.2 & 2.0 & 1.43 & 0.84 & 0.43 & 0.27 \\
\hline $\begin{array}{c}\text { relative } \\
\text { yield }\end{array}$ & 1.05 & 1.00 & 0.97 & 0.83 & 0.48 & 0.27 \\
\hline
\end{tabular}

The yield of U(IV) was $<1 \%$ of that of decomposed oxalic acid, ex-n cept in the presence of much excess acid $\left(\mathrm{H}_{2} \mathrm{C}_{2} \mathrm{O}_{4}\right.$ or $\left.\mathrm{H}_{2} \mathrm{SO}_{4}\right)$, where it reached $2-3 \%$. Addition of formic acid did not increase the U(IV) formation, indicating that U(IV) does not arise through secondary oxidation of formate.

Effect of additions: $0.6 \mathrm{M} \mathrm{H}_{2} \mathrm{SO}_{4}\left(6 \mathrm{H}_{2} \mathrm{SO}_{4}\right.$ to $\left.1 \mathrm{H}_{2} \mathrm{C}_{2} \mathrm{O}_{4}\right)$ decreased the decomposition rate by $34 \%$, a result which was attributed by Büchi to the displacement of oxalate from its complex with the uranyl ion by the sulfate.

The effect of hydrochloric acid (0.06 M) was similar, yielding a $12 \%$ decrease in rate. An equivalent quantity of formic acid had no effect on the rate of decomposition of oxalic acid. In contrast to Baur and Rebmann, Büchi found formic acid to be protected from photochemical decomposition by the presence of oxalate. He suggested that this may explain why considerable 


$$
46
$$

quantities of this acid can be found among the decomposition products of oxalic acid. (The relative yields of the decomposition of the two acids may depend not only on their relative concentrations, but also on wavelength, since the absorption spectra of the two complexes are different.) Büchi confirmed Brinerand Kozak's findings that the proportion of formic acid in the product increases with decreasing ratio [oxalate]/[uranyl], as well as with increased acidity (cf. Table 4.10); this explains the findings of Baur and of Bacon, who worked in $0.5 \mathrm{M} \mathrm{H}_{2} \mathrm{SO}_{4}$ and in $5 \%$ oxalic acid, respectively. The formation of $U$ (IV), on the other hand, increases with acidity, but not enough to compensate for the decrease in formic acid production.

Table 4.10

FORMIC ACID PRODUCTION BY SENSITIZED OXALATE DECOMPOSITION AS FUNCTION OF OXALATE/URANYL RATIO, $x$, AND OF ACIDITY (AFTER BÜCHI, 1924)

\begin{tabular}{|c|c|c|c|c|c|}
\hline & \multicolumn{2}{|c|}{ [Oxalate]/[Uranyl] } & \multicolumn{2}{c|}{ [Oxalate]/[Uranyl] = 2 } \\
\cline { 2 - 6 } & 1 & 2 & 8 & with $0.06 \mathrm{M} \mathrm{HCl}$ & with $0.6 \mathrm{M} \mathrm{H}_{2} \mathrm{SO}_{4}$ \\
\hline $\begin{array}{c}\% \text { formic } \\
\text { acid }\end{array}$ & 40 & 36 & 26 & 7 & 6 \\
\hline
\end{tabular}

The decomposition of uranyl oxalate solution without added oxalic acid proceeds in an apparently different way. Formic acid is formed in this case as well, but much more reduction to U(IV) takes place.

In discussing these results, Büchi used the generally accepted ideas of photochemistry, rather than Baur's "electro-photochemical" concepts. The fact that he found oxalate saturation near $x=1$, led him to assume that the reaction occurs in a stable $1: 1$ complex ( $\mathrm{UO}_{2}^{++}+$oxalate). If one assumes that this complex is practically undissociable, its concentration must increase linearly between $x=0$ and $x=1$, and then become constant.

If the light absorption by free uranyl ions is entirely ineffective, the curve showing reaction rate (quantum yield $\gamma$ ) as function of $x$ also should show, at $\mathbf{x}=1$, a break between a linearly ascending and a horizontal branch.

This, of course, cannot be strictly true. The association constant cannot be infinitely large; complete association, therefore, must be approached asymptotically. For $1: 1$ association, the proportion of $\mathrm{UO}_{2}^{++}$bound in a complex with oxalate is determined by the equations: 


$$
\begin{aligned}
& \left.\mathrm{K}\left[\mathrm{UO}_{2}^{++}\right] \times \text {[oxalate }\right]=[\text { complex }] \\
& {\left[\mathrm{UO}_{2}^{++}\right]+[\text {complex }]=\left[\mathrm{UO}_{2}^{++}\right]_{0}} \\
& \text { [oxalate }]+[\text { complex }]=[\text { oxalate }]_{0}
\end{aligned}
$$

where [UO $\left.{ }^{+}\right]_{0}$ and [oxalate] $]_{0}$ are the total amounts of the two reaction components. (In this formulation, the distribution of free oxalate between neutral molecules, monovalent ions, and divalent ions is neglected; cf. below.) Eqs. (50a) -(50c) lead to a quadratic equation for [complex] as function of $\left.\mathbf{x}(\mathbf{x}=\text { [oxalate }]_{0} /\left[\mathrm{UO}_{2}^{++}\right]_{0}\right)$, which can be formulated so as to contain either the total uranyl concentration, $\left[\mathrm{UO}_{2}^{++}\right]_{0}$, or the total oxalate concentration, [oxalate $]_{0}$, as parameter.

$$
[\text { complex }]=\frac{\mathrm{K}\left[\mathrm{UO}_{2}^{++}\right]_{0}(1+\mathrm{x})+1}{2 \mathrm{~K}}-\sqrt{\frac{\mathrm{K}\left[\mathrm{UO}_{2}^{++}\right]_{0}(1+\mathrm{x})+1}{2 \mathrm{~K}}-\mathrm{x}\left[\mathrm{UO}_{2}^{++}\right]_{0}}
$$

(or a similar equation with $\left[\mathrm{UO}_{2}^{++}\right]_{0}$ replaced by [oxalate $]_{0}$, and $\mathrm{x}$ replaced by $1 / x)$.

If $\mathrm{K}\left[\mathrm{UO}_{2}^{++}\right]_{0} \gg 1$, Eq. (51) simplifies, as expected, to [complex] $=$ $\mathbf{x}\left[\mathrm{UO}_{2}^{++}\right]_{0}=[\text { oxalate }]_{0}$; if $\mathrm{K}$ [oxalate $]_{0}>>1$, the corresponding equation with [oxalate $]_{0}$ as parameter simplifies to $[$ complex $]=(1 / x)$ (oxalate $)_{0}=\left[\mathrm{UO}_{2}^{++}\right]_{0}$.

If we assume that the rate of decomposition is equal to the number of quanta of light absorbed in unit time by the complex (and if oxalate itself does not absorb in the spectral region used), we obtain for the quantum yield:

$$
\gamma=\frac{\alpha_{c}[\text { complex }]}{\alpha_{c}[\text { complex }]+\alpha_{f}\left[\mathrm{UO}_{2}^{++}\right]}=\frac{\alpha_{c}[\text { complex }]}{\left(\alpha_{c}-\alpha_{f}\right)[\text { complex }]+\alpha_{f}\left[\mathrm{UO}_{2}^{++}\right]_{0}}
$$

where $\alpha_{c}$ and $\alpha_{f}$ are the absorption coefficients of complexed and free uranyl ions, respectively. If either [complex] $\gg\left[\mathrm{UO}_{2}^{++}\right]$(meaning practically com-

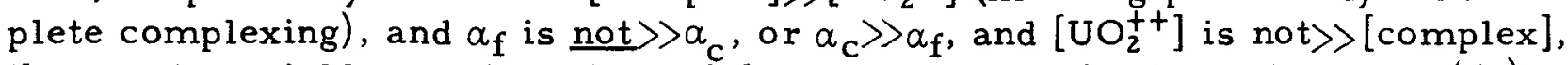
the quantum yield must be unity. If the two terms in the denominator of (52) are of the same order of magnitude, an expression for $\gamma$ as function of $\mathrm{x}$ can be obtained by insertion of (51) into (52). However, the resulting equation will contain [ $\left.\mathrm{UO}_{2}^{++}\right]_{0}$ or [oxalate $]_{0}$ as separate parameters, and not merely their ratio, $\mathbf{x} ; \gamma$ will be a function of $\mathbf{x}$ alone only if the complex is stable, namely: 


$$
\begin{aligned}
\gamma & =\frac{\alpha_{c} x}{\alpha_{c} x-\alpha_{f}(x-1)}=\frac{48}{\left(\alpha_{c}-\alpha_{f}\right)-\left(\alpha_{f} / x\right)} \\
& \simeq \frac{1}{1-\alpha_{f} x / \alpha_{c}}\left(\text { if } \alpha_{c} \gg \alpha_{f}\right) \text { for } x<1 \\
\gamma & =1 \text { for } x>1
\end{aligned}
$$

The alternative collision mechanism of reaction gives, for the probability of an encounter between an excited $\mathrm{UO}_{2}^{++}$ion and an oxalate molecule or ion, the "Stern-Volmer type" equation: Eq. (55). If each encounter results in reaction, the same equation applies also to the quantum yield of the decomposition of oxalate:

$$
\gamma=\frac{v_{2}[\text { oxalate }]_{0}}{v_{1}+v_{2}[\text { oxalate }]_{0}}=\frac{[\text { oxalate }]_{0}}{v_{1} / v_{2}+[\text { oxalate }]_{0}}
$$

where $v_{2}$ is the bimolecular rate constant of the reaction of excited uranyl ions with oxalate, and $v_{1}$ the monomolecular rate constant of the de-activation of excited uranyl ions by fluorescence and energy dissipation.

According to Eq. (55), $\gamma$ must approach unity asymtotically with increasing [oxalate]. An important difference between the two mechanisms is that in the first one, for a given value of [oxalate],$\gamma$ depends on $x$, i.e., on $\left[\mathrm{UO}_{2}^{++}\right]_{0}$, while in the second case, $\gamma$ does not depend on [ $\left.\mathrm{UO}_{2}^{++}\right]$, but only on the oxalate concentration.

Büchi gave Fig. 4.6 as proof of the actual occurrence of a break in the yield vs. $x$ curve at $x=1$. He pointed out that if the experimental results in the range below $x=1$ are used to determine the parameters in Eq. (55), a quantum yield of $\gamma=0.23$ is calculated for $x=1$ while the experimental value is close to 1.0 . This was derived by Büchi from four $\gamma$ determinations with white light filtered through crystal violet and rhodamin; assuming $\bar{\lambda}=420 \mathrm{~m} \mu$, he obtained $\gamma=1.03-1.15$ (see, however, below for recent redeterminations of the quantum yield, which gave $\gamma$ values $<1$ ).

The initial slope of the curve in Fig. 4.6 is determined by the ratio of the absorption coefficients of the free (or sulfate-complexed) uranyl and the oxalate-complexed uranyl; Büchi calculated for this ratio a value of $1: 1.3$ (comp. Table 4.8).

Baur (1924) supplemented Büchi's result by an “interpretation” in the electrochemical language. His original mechanism with glyoxalic acid as intermediate (Eq. 44a, b) required two quanta, or $\gamma=0.5$; to explain Büchi's value of $\gamma=1$, Baur now wrote 


\section{9}

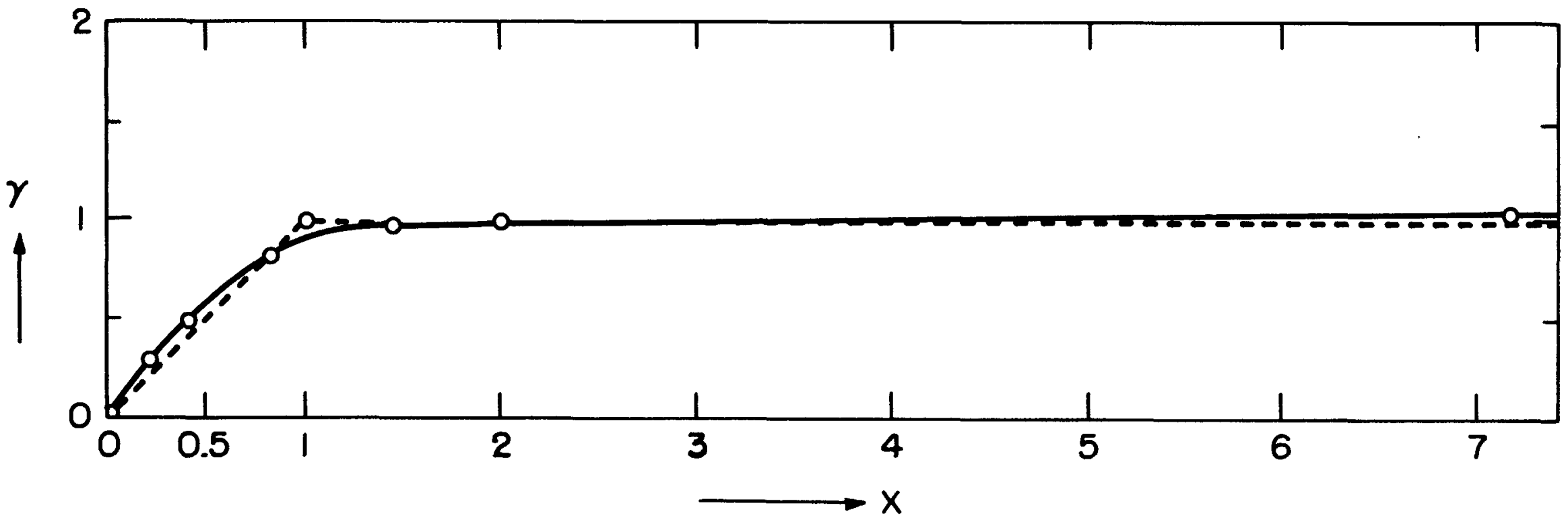

Fig. 4.6. Quantum yield of uranyl-sensitized oxalate decomposition as function of the ratio $x=[$ oxalate]/[uranyl] (after Buchi, 1924). 


$$
\mathrm{U}(\mathrm{VI})_{-}^{+}\left\{\begin{array}{c}
\frac{50}{+-}+-\mathrm{OOC}-\mathrm{CO}_{2} \\
\left.+-\mathrm{OOC}+2 \mathrm{H}^{+} \stackrel{\mathrm{H}}{-\mathrm{O}}\right\}
\end{array}\right\}+\mathrm{U}(\mathrm{VI})
$$

for the reaction in presence of much $\mathrm{H}^{+}$, and

$$
\mathrm{U}(\mathrm{VI}) \pm\left\{\begin{array}{l}
+-\mathrm{OOC}-\mathrm{CO}_{2} \\
+-\mathrm{CO}^{-}-\mathrm{OOC}+\mathrm{H}^{+} \stackrel{\mathrm{HCOO}}{-}
\end{array}\right\}+\mathrm{U}(\mathrm{VI})
$$

for reaction in less acid solution, using the same molecule of oxalate both as "anodic" and as "cathodic" depolarizer!

Equivalent interpretations in ordinary photochemistry are:

$$
\begin{aligned}
& \mathrm{U}(\mathrm{VI}) *+-00 \mathrm{CCOO}-\mathrm{U}(\mathrm{IV})+0 \mathrm{OOCCOO} \stackrel{+2 \mathrm{H}^{+}}{-} \mathrm{U}(\mathrm{VI})+\underset{(58 \mathrm{a})}{\mathrm{H}_{2} \mathrm{O}+\underset{\mathrm{CO}}{\mathrm{CO}}} \\
& \mathrm{U}(\mathrm{VI}) *+-\mathrm{OOCCOO}-\longrightarrow \mathrm{U}(\mathrm{IV})+00 \mathrm{OCOO} \stackrel{+\mathrm{H}^{+}}{\longrightarrow} \mathrm{U}(\mathrm{VI})+\mathrm{HCOO}^{-}+\mathrm{CO}_{2}
\end{aligned}
$$

Anderson and Robinson (1925) discussed the use of the oxalic acid uranyl system in an actinometer for ultraviolet light. Using mercury light of very high intensity (up to $10^{18}$ quanta absorbed per second), they obtained, in solutions containing from $2 \times 10^{-5}$ to $2 \times 10^{-2} \mathrm{M}$ uranyl nitrate, and $0.1 \mathrm{~N}$ in oxalic acid, quantum yields between $1 / 24$ and $1 / 557$. In a single experiment with monochromatic light ( $365 \mathrm{~m} \mu, 5 \times 10^{16}$ quanta/sec.), a value of $\gamma=1 / 37$ was found. The interpretation of the results was even less plausible than the numerical values. (For example, it was suggested that radioactivity of uranium may be responsible for its sensitizing properties; light absorption by $\mathrm{UO}_{2}^{++}$ions was treated as incidental, or even as inhibiting the decomposition of oxalic acid, etc.)

Bowen and Watts (1926) used the Anderson-Robinson "radiometer" but re-determined the quantum yield. In $0.01 \mathrm{M} \mathrm{UO}_{2} \mathrm{SO}_{4}+0.1 \mathrm{~N}$ oxalic acid, in the total light of a quartz lamp and assuming $\bar{\lambda}=313 \mathrm{~m} \mu$, they obtained, in three experiments, $\gamma \simeq 1.0$.

West, Muller and Jette (1928) discussed the relation between inhibition of a photochemical reaction and quenching of fluorescence of the lightabsorbing species, using as examples the effect of anions such as $\mathrm{C1}^{-}, \mathrm{Br}^{-}$, $\mathrm{CNS}^{-}, \mathrm{I}^{-}$on the decomposition of oxalate and on the fluorescence of uranyl salt solutions. 
51

Both effects increase in the above series, from $\mathrm{Cl}^{-}$to $\mathrm{I}^{-}$. This order was compared by West et al. with the order of ionic deformabilities; comparison with the order of electron affinities would be more pertinent, if one assumes quenching to be due to electron transfer (rather than energy transfer) from the excited uranyl ion to the quencher.

Numerical data on the quenching of $\mathrm{UO}_{2}^{++}$fluorescence and inhibition of sensitized oxalate decomposition were given in an accompanying paper by Muller (1928). Fig. 4.7 shows the anti-parallelism of decomposition rate and fluorescence. It will be noted that, in contrast to Buichi's findings, $\mathrm{H}_{2} \mathrm{C}_{2} \mathrm{O}_{4}$ saturation is reached here asymptotically, at about $\left[\mathrm{H}_{2} \mathrm{C}_{2} \mathrm{O}_{4}\right] /\left[\mathrm{UO}_{2}\right]=1.5$, rather than sharply at $\mathrm{x}=1$. The fluorescence becomes too weak for measurement above $\mathrm{x}=1$.

The effect of ions on the rate of oxalate decomposition is shown in Fig. 4.8 for $\left[\mathrm{UO}_{2}^{++}\right]=0.01 \mathrm{M}$, and $\left[\mathrm{H}_{2} \mathrm{C}_{2} \mathrm{O}_{4}\right]=0.1 \mathrm{M}$.

Comparing the observations of different investigators, we obtain Table 4.11 for the values of $x$ and for the absolute concentrations, [oxalate], at which "oxalate saturation" was observed.

Table 4.11

"SATURATION" OF THE URANYL-OXALATE REACTION WITH OXALATE

$$
\mathbf{x}=[\text { oxalate }]_{0} /[\text { urany } 1]_{0}
$$

\begin{tabular}{|l|c|cr|}
\hline \multirow{2}{*}{ Observer } & \multicolumn{3}{|c|}{ Saturating Value: } \\
\cline { 2 - 4 } & $\mathbf{x}$ & \multicolumn{2}{|c|}{ [oxalate] } \\
\hline Bacon (1907, 1910) & $\sim 10$ & $0.3 \mathrm{~g}$ in 100 cc. & $(0.05 \mathrm{M})$ \\
Bruner and Kozak (1911) & - & $0.2 \mathrm{~g}$ in 20 cc. & $(0.14 \mathrm{M})$ \\
Büchi (1924) & 1 & -- & $(0.06 \mathrm{M})$ \\
Müller (1928) & $\sim 1.5$ & -- & $(>0.02 \mathrm{M})$ \\
Pringsheim (1937) & $>1$ & & \\
\hline
\end{tabular}

(a) Complex saturation from spectral data (cf. Table 2.10).

Pierce (1929) compared the kinetics of uranyl-sensitized decomposition of oxalic acid with that of the decomposition of malonic acid (cf. below, p. 69). He found the temperature coefficient to be substantially 1 for oxalic acid $\left(3-73^{\circ} \mathrm{C}\right.$ ) (confirming the results of Bruner and Kozak, and Bacon), as against $1.13 \pm 0.02$ for malonic acid. A quantum yield $\gamma=0.25$ was found by Pierce, Leviton and Noyes for malonic acid decompositon (in $0.05 \mathrm{M}$ solution), as compared to $\gamma \cong 1$, given by Büchi for oxalic acid (in $0.06 \mathrm{M}$ oxalic acid). (More recent measurements, to be described below, gave $\gamma \simeq 0.6$ for oxalic acid decomposition.) 


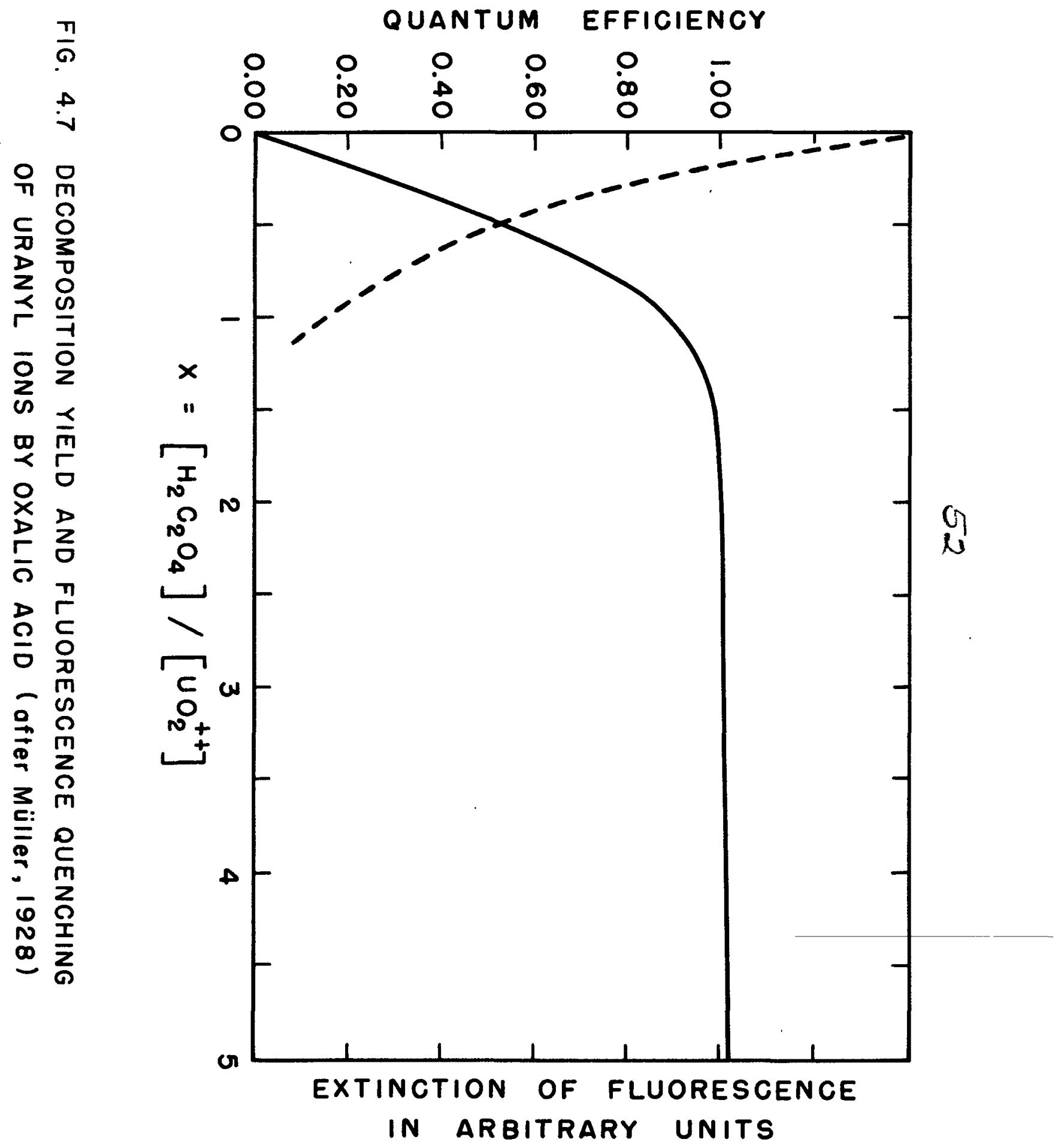


53

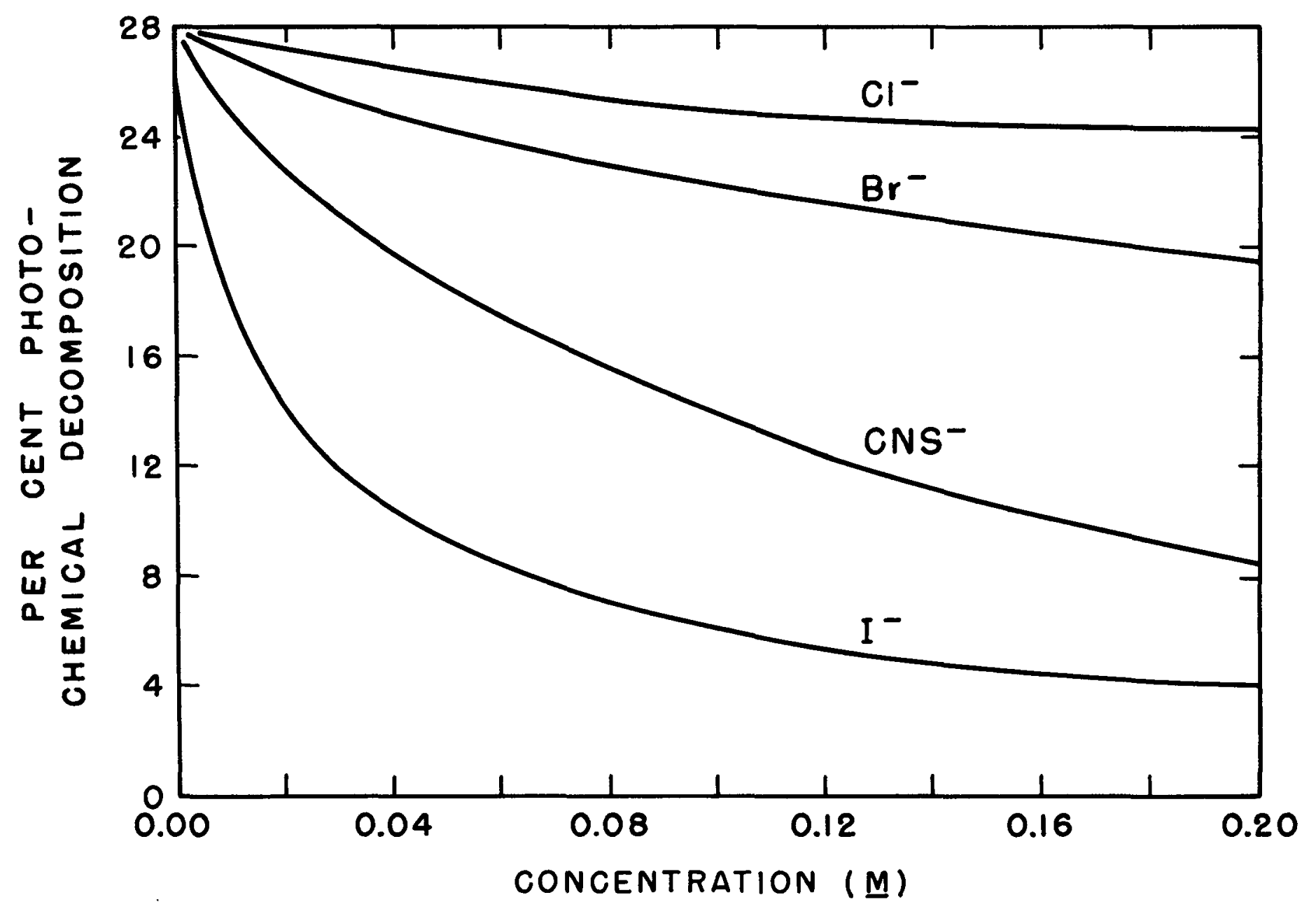

FIG. 4.8 EFFECT OF IONS ON DECOMPOSITION OF URANYL OXALATE IN LIGHT (after Miller, 1928) 


\section{4}

Discussing the relative merits of the "complex formation" theory (Büchi) and the "kinetic encounter" theory, Pierce favored the former, again quoting conductivity data (Dittrich) and spectroscopic evidence (Henri and Landau; Ghosh and Mitter). He submitted that the observed rate saturation in respect to oxalic acid concentration (Table 4.11) supports the complexing theory and contradicts the encounter theory "unless a very long life of [ $\left.\mathrm{UO}_{2}^{++}\right] *$ is assumed." [However, this lifetime in fact is long - of the order of $10^{-4} \mathrm{sec}$. Calculations show that for a lifetime of this duration the probability of an encounter with a reactant present in a concentration $>0.05 \mathrm{M}$ (Table 4.11) must be high.]

As a counter-argument supporting the encounter theory, Pierce quoted first the fact that the equilibrium constants calculated by Ghosh and Mitter, however high, are not high enough to assume complete complexing under the conditions of Büchi's experiments, which gave $\gamma=1$. More specifically, with the value given in Table $2.7(\mathrm{~K}=115)$ complexing should be about $2 / 3$ complete in a mixture of $0.06 \mathrm{M} \mathrm{UO}_{2}^{++}$and $0.06 \mathrm{M}$ oxalic acid; if complexes alone were assumed to react, a quantum yield of 1 could be expected under these conditions only if the absorption by the complex were very much stronger than that by the free ions; Pierce thought that experimental data do not confirm this suggestion. This is, however, not true for near ultraviolet and visible light; furthermore, according to more recent data, the quantum yield is closer to 0.5 than to 1.0 . The complex theory thus seems to be adequate to explain the results. However, Pierce pointed out that the complex theory is also less suitable than the encounter theory to explain the observed absence of a temperature coefficient, and the parallelism between the effects of ions on $\mathrm{UO}_{2}^{++}$fluorescence and on the sensitized decomposition of oxalate, illustrated in Fig. 4.8. The second argument, in particular, is not easily answered (cf. below). Pierce therefore suggested that perhaps free ions and complexes both take part in the reaction.

Leighton and Forbes (1930) studied the uranyl-sensitized oxalate reaction from the point of view of precision actinometry. They enumerated the advantages of the reaction: absence of dark reaction; a wide absorption band; "zero order" light reaction; temperature coefficient of practically unity; small effect of additions (?); ease of analysis (by means of permanganate titration of oxalate). Pointing out the wide discrepancies of previous quantum yield determinations (from $\gamma=0.04$ according to Anderson and Robinson, through $\gamma=1$ according to Bowen and Watts, and Büchi, to $\gamma \simeq 500$ according to Boll), Leighton and Forbes proceeded to systematic redetermination of $\gamma$ in monochromatic ultraviolet light. The yields were determined from 255 to $490 \mathrm{~m} \mu$, under the following conditions:
(a) $0.01 \mathrm{M} \mathrm{UO}_{2} \mathrm{SO}_{4} ; 0.05 \mathrm{M} \mathrm{H}_{2} \mathrm{C}_{2} \mathrm{O}_{4} ; 25^{\circ} \mathrm{C}$
(b) $0.01 \mathrm{M} \mathrm{UO}_{2} \mathrm{SO}_{4} ; 0.05 \mathrm{M} \mathrm{H}_{2} \mathrm{C}_{2} \mathrm{O}_{4} ; 9.8^{\circ} \mathrm{C}$
(c) 0.001 to $0.01 \mathrm{M} \mathrm{UO}_{2} \mathrm{SO}_{4} ; 0.01$ to $0.05 \mathrm{M} \mathrm{H}_{2} \mathrm{C}_{2} \mathrm{O}_{4} ; 25^{\circ} \mathrm{C}$ 
65

The results of experiment (a) and of one series in experiment (c) are shown in Fig. 4.9. It indicates that quantum yields are $\simeq 0.6$ at all wavelengths, but that an unmistakable minimum of $\gamma$ occurs at $366 \mathrm{~m} \mu$. Variations of [ $\mathrm{UO}_{2}^{++}$] have little effect on $\gamma$, as long as $x=\frac{\left[\mathrm{H}_{2} \mathrm{C}_{2} \mathrm{O}_{4}\right]}{\left[\mathrm{UO}_{2} \mathrm{SO}_{4}\right]}>5$.

Addition of sodium sulfate or sodium hydroxide was found to enhance light absorption; the latter was decreased by sulfuric acid. All three additions, particularly sulfuric acid.decreased the quantum yield. An attempt was made to correct the quantum yields by apportioning the light absorption between free $\mathrm{UO}_{2}^{++}$ions and uranyl oxalate complexes on the assumption that $\alpha_{\text {complex }}$ is the maximum absorption coefficient obtainable when [acid] $\gg[$ uranyl].

Related to total absorption, the quantum yields declined slightly from 0.59 at $x=\left[\mathrm{H}_{2} \mathrm{C}_{2} \mathrm{O}_{4}\right] /\left[\mathrm{UO}_{2}^{++}\right]=50$, to 0.52 at $\mathrm{x}=1$; they became prac tically constant $(\gamma=0.57$ to 0.59$)$ when related to the (calculated) absorption by a $1: 1$ complex alone. This somewhat improved constancy was considered as an argument for a $1: 1$ complex as the only carrier of the reaction.

The authors suggested that the parallelism of quenching and inhibition (Müller), which appears to favor the encounter theory (cf. above) could be explained by de-activating collisions of excited complexes with the in hibiting ions, or by displacement of oxalate ions from their complexes with uranyl by $\mathrm{CNS}^{-}, \mathrm{Br}^{-}$, or $\mathrm{I}^{-}$ions. The first hypothes is requires that the time between light absorption and reaction in a complex should not be small compared to the lifetime of excitation of a free atom or ion, while one would expect a reaction in a complex to follow excitation within a much shorter time - roughly the period of one or a few molecular vibrations $\left(10^{-12} \mathrm{sec}\right)$. The second hypothes is is feasible, but requires quantitative checking by spectroscopic or other measurements of the several complexing constants.

Checks on the temperature dependence of the reaction, made by Leighton and Forbes, indicated the need of determining the light absorption separately at each temperature; otherwise $Q_{10}$ values $>1$ may be obtained. For example, if the yield at $9.8^{\circ} \mathrm{C}$ is compared with that at $25^{\circ} \mathrm{C}$ without regard to changes in absorption, a temperature coefficient of 1.13 is calculated.

In concluding, the authors recommended a system containing $0.01 \mathrm{M}$ uranyl sulfate and $0.05 \mathrm{M}$ oxalic acid, at $25^{\circ} \mathrm{C}$, as best suitable for photometric purposes.

The uranyl-oxalate system was used by Heidt and Daniels (1932) as test system for a monochromater. They obtained the quantum yields listed in Table 4.12. The quantum yield appears to be independent of the anion. Addition of $1 \mathrm{M} \mathrm{H}_{2} \mathrm{SO}_{4}$ had no effect on the yield. The quantum yield found by Heidt and Daniels $(\gamma \simeq 0.5)$ is in satisfactory agreement with the results of Leighton and Forbes. 
56

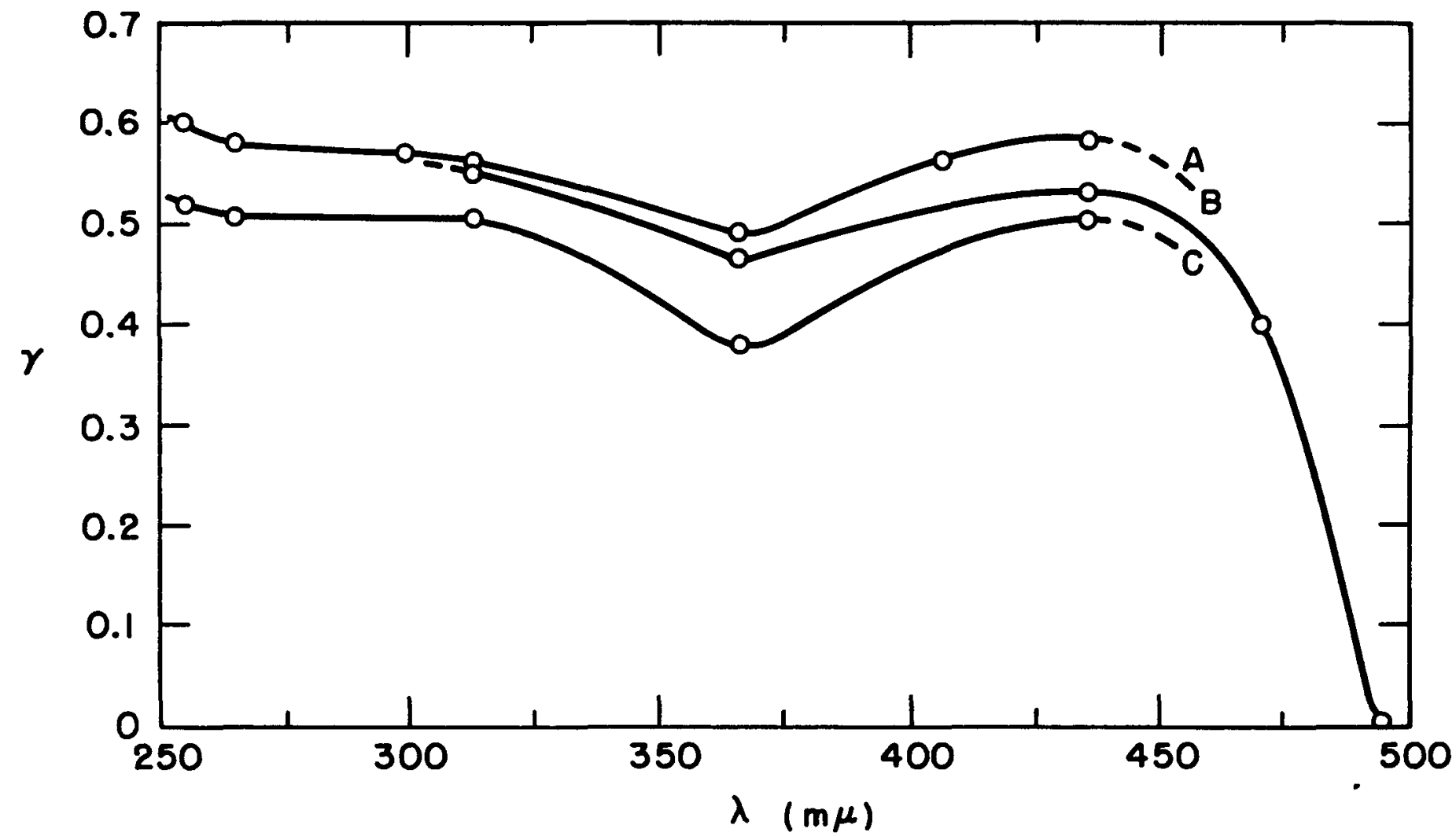

Fig. 4.9. Gross quantum yield of $25^{\circ}$ plotted against wavelength. Curve A summarizes experiment (a); Curve $B$, some solution unstirred; Curve $C$, a stirred solution $0.02 \mathrm{M}$ in $\mathrm{UO}_{2} \mathrm{SO}_{4}$ and $\mathrm{O} .04 \mathrm{M}$ in $\mathrm{H}_{2} \mathrm{C}_{2} \mathrm{O}_{4}$. 
5)

Table 4.12

QUANTUM YIELDS IN URANYL-OXALATE SYSTEM

(HEIDT AND DANIELS, 1932)

$313 \mathrm{~m} \mu$, at $25^{\circ} \mathrm{C}$

\begin{tabular}{|c|c|c|c|c|}
\hline \multicolumn{3}{|c|}{ Composition } & & \% absorption \\
\cline { 1 - 2 } salt & $\begin{array}{c}\text { conc., } \\
\mathrm{U}\end{array}$ & $\mathrm{H}_{2} \mathrm{C}_{2} \mathrm{O}_{4}, \mathrm{M}$ & $\begin{array}{c}\text { Average } \\
\text { quantum } \\
\text { yield }\end{array}$ \\
\hline $\mathrm{UO}_{2} \mathrm{C}_{2} \mathrm{O}_{4}$ & 0.0005 & 0.0045 & $72(2 \mathrm{~cm}$ cell $)$ & 0.64 \\
$\mathrm{UO}_{2} \mathrm{C}_{2} \mathrm{O}_{4}$ & 0.0017 & 0.0330 & $86(1 \mathrm{~cm} \mathrm{cell})$ & 0.46 \\
$\mathrm{UO}_{2} \mathrm{SO}_{4}$ & 0.0017 & 0.0330 & $86(1 \mathrm{~cm}$ cell $)$ & 0.59 \\
$\mathrm{UO}_{2}\left(\mathrm{NO}_{3}\right)_{2}$ & 0.0017 & 0.0330 & $86(1 \mathrm{~cm} \mathrm{cell})$ & 0.53 \\
\hline
\end{tabular}

Brackett and Forbes (1933) re-determined the quantum yield's at 278 and $253 \mathrm{~m} \mu$, and added a measurement at $208 \mathrm{~m} \mu$ (using a $\mathrm{Zn}$ spark as light source). Table 4.13 shows the results. The gross quantum yield at $208 \mathrm{~m} \mu$ was distinctly $(20 \%)$ smaller than at the longer waves (Fig. 4.10). It was natural to ascribe this to light absorption by oxalic acid. The following equation was used for correction:

$$
\gamma_{\text {corr }}=\frac{\gamma_{g r o s s}-\gamma\left(\mathrm{H}_{2} \mathrm{C}_{2} \mathrm{O}_{4}\right)\left(\alpha_{\mathrm{a}} \mathrm{c}_{\mathrm{a}} / \Sigma \alpha \mathrm{c}\right)}{\left(\Sigma \alpha \mathrm{c}-\alpha_{\mathrm{a}} \mathrm{C}_{\mathrm{a}}\right) / \Sigma \alpha \mathrm{c}}
$$

where $\gamma\left(\mathrm{H}_{2} \mathrm{C}_{2} \mathrm{O}_{4}\right)$ is the quantum yield of direct photochemical decomposition of oxalic acid; the $\alpha$ 's designate extinction coefficients, and the c's concentrations; the subscript a refers to free oxalic acid. The corrected curve (Fig. 4.10) shows a steady increase of $\gamma$ between 400 and $208 \mathrm{~m} \mu$, which could be attributed to decreasing "cage" effect (diminishing chance for the primary photochemical products to react back before their separation; the escape is faster when the products are formed by larger quanta and therefore with higher kinetic energies). The renewed increase of $\gamma$ at $\lambda>400 \mathrm{~m} \mu$ requires a different explanation.

It will be noted that in the figure corrections are made in two alternative ways - by assuming that the photochemical reaction occurs in complexes containing either one or two $\mathrm{C}_{2} \mathrm{O}_{4}$ groups (in other words, the concentration of free oxalic acid is calculated by deducting, from the total oxalate concentration, either one or two equivalents of the uranyl present). The experiments do not add new arguments for (or against) the assumption of complexes as reaction carriers. 


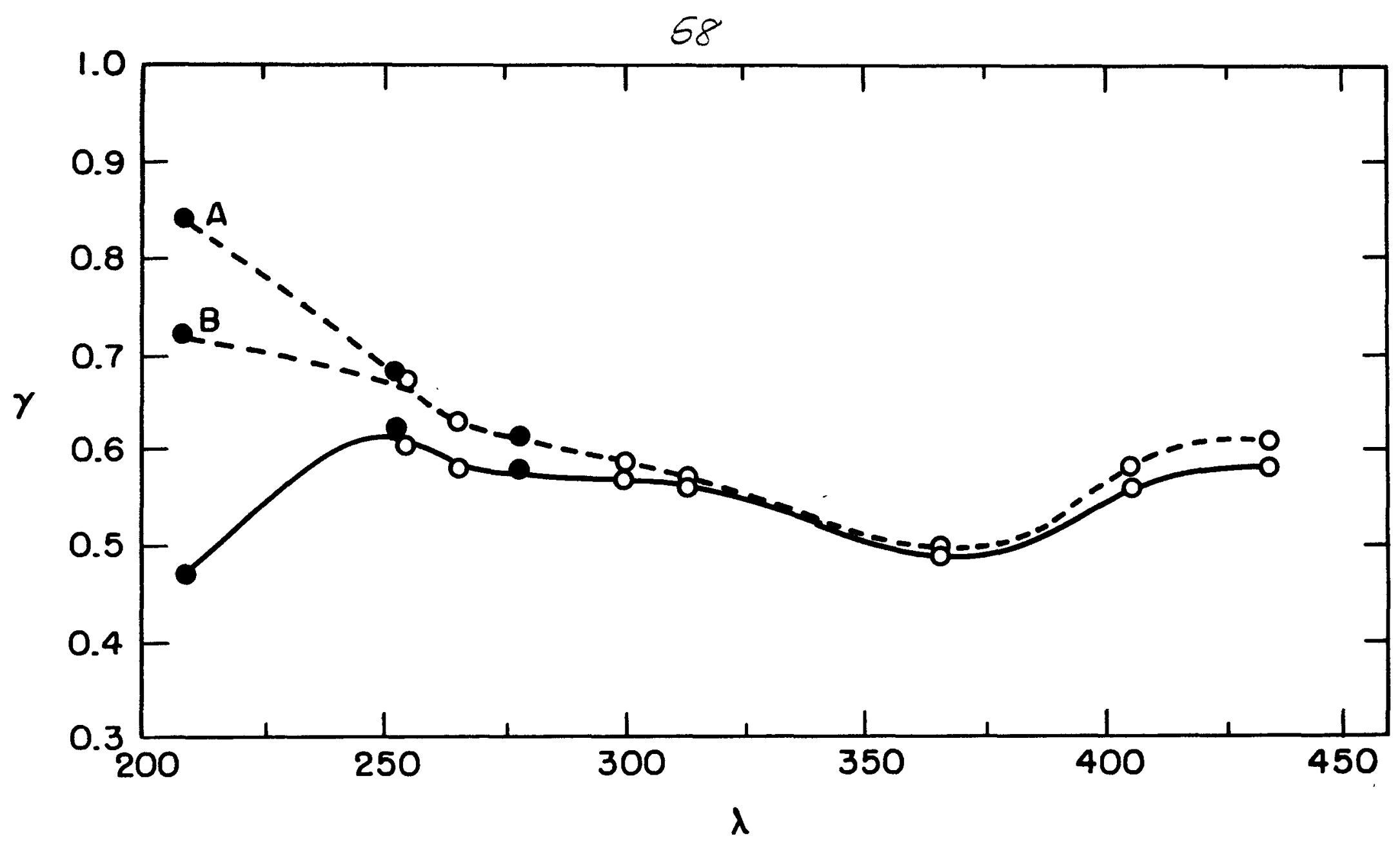

Fig. 4.10. Gross yield; - - corrected yield. $A$, if $\mathrm{UO}_{2} \mathrm{C}_{2} \mathrm{O}_{4}$ is the complex; $B$, if $\mathrm{UO}_{2}\left(\mathrm{C}_{2} \mathrm{O}_{4}\right)_{2}$ is the complex. For a solution $0.05 \mathrm{M}$ in $\mathrm{H}_{2} \mathrm{C}_{2} \mathrm{O}_{4}$ and $0.01 \mathrm{M}$ in $\mathrm{UO}_{2} \mathrm{SO}_{4}$. O, Leighton and Forbes; 0 , Forbes and Brockett; temp., $25^{\circ}$. A and B practically coincident at $255 \mathrm{~m} \mu$ and above. 
Table 4.13

QUANTUM YIELDS IN THE URANYL-OXALATE SYSTEM

(AFTER BRACKETT AND FORBES, 1933)

\begin{tabular}{|l|c|c|c|c|}
\hline$\lambda, \mathrm{m} \mu$ & $\begin{array}{c}{\left[\mathrm{UO}_{2}^{++}\right],} \\
\mathrm{M}\end{array}$ & $\begin{array}{c}{\left[\mathrm{H}_{2} \mathrm{C}_{2} \mathrm{O}_{4}\right],} \\
\mathrm{M}\end{array}$ & $\gamma$ & $\begin{array}{c}\text { probable } \\
\text { error }\end{array}$ \\
\hline 278 & 0.01 & 0.04853 & 0.59 & \pm 0.01 \\
253 & 0.01 & 0.04967 & 0.63 & \pm 0.03 \\
$208\left(28^{\circ}\right)$ & 0.01 & 0.04967 & 0.48 & \pm 0.01 \\
$208\left(28^{\circ}\right)$ & 0.03 & 0.04995 & 0.55 & \pm 0.01 \\
$208\left(28^{\circ}\right)$ & 0.02 & 0.01963 & 0.53 & \pm 0.01 \\
$208\left(28^{\circ}\right)$ & 0.00 & 0.05058 & 0.02 & \pm 0.01 \\
\hline
\end{tabular}

Forbes and Heidt (1934) made additional measurements at ten times lower concentrations than before $\left(0.001 \mathrm{M}\left[\mathrm{UO}_{2}\right]\right.$ and $\left.0.005 \mathrm{M}\left[\mathrm{H}_{2} \mathrm{C}_{2} \mathrm{O}_{4}\right]\right)$, in order to minimize the direct photochemical decomposition of oxalic acid (the absorption by oxalic acid decreased, in consequence of this change of concentration, much more strongly than the absorption by uranyl ions). The quantum yields remained the same as before, at $313,279,254$ and $220 \mathrm{~m} \mu$ (a slight drop, to $\gamma=0.50$, occurred at $208 \mathrm{~m} \mu$ ). Even at $0.005 \mathrm{M} \mathrm{UO}_{2} \mathrm{SO}_{4}+$ $0.0025 \mathrm{M}$ oxalic acid, the quantum yields were unchanged at 254,279 and $313 \mathrm{~m} \mu$. This result seems to be incompatible with the assumption of a $1: 1$ complex as the only reaction carrier, since the contribution of free $\mathrm{UO}_{2}^{++}$ions to the total absorption at $254-313 \mathrm{~m} \mu$ is unlikely to be quite negligible compared to that of an at least four times smaller amount of the complex.

Pitzer, Gordon and Wilson (1936) were interested in the factors affecting the ratio of photocatalytic and direct photochemical reaction. They measured the yield of U(IV) formation as function of the composition of the reaction mixture.

Figure 4.11 shows the proportion of direct oxidation reduction for an initial composition $\left[\mathrm{UO}_{2}^{++}\right]=\left[\mathrm{C}_{2} \mathrm{O}_{4}^{--}\right]($i.e., $\mathrm{x}=1)$.

The curve indicates that a rapid reduction of $U(V I)$ begins when the oxalic acid concentration had become smaller than that of uranyl $(x<1)$. [The increase in $\Delta \mathrm{CO}_{2} / \triangle \mathrm{CO}$ ratio with increasing $\mathrm{x}$ observed by $\mathrm{Baur}$ ( $\mathrm{cf}$. Table 4.7) must therefore be attributed to enhanced formation of formic acid, and not oxidation-reduction.] 


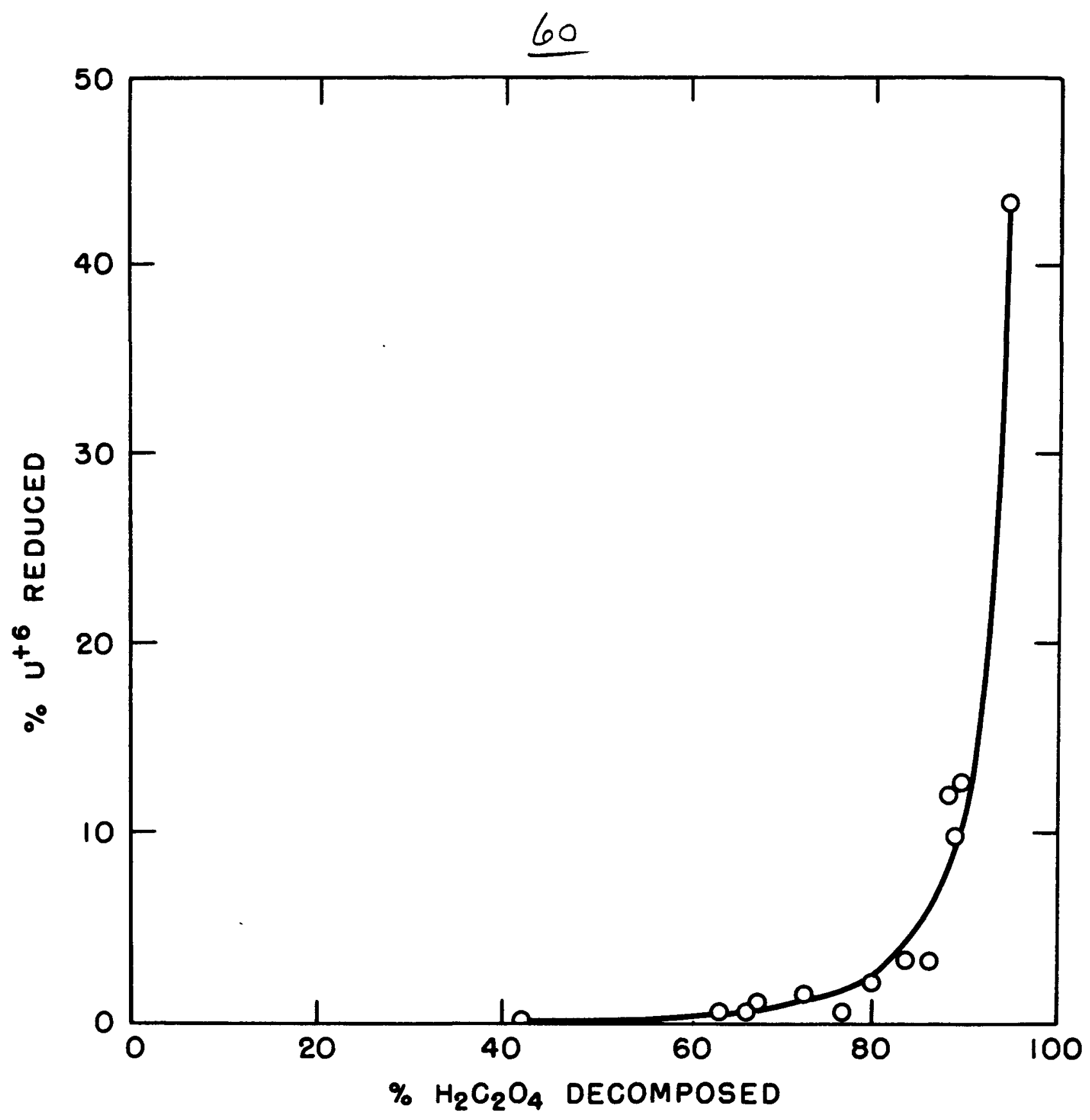

Fig. 4.Il. Reduction of $U(\bar{Z})$ as function of the fraction of $\mathrm{H}_{2} \mathrm{C}_{2} \mathrm{O}_{4}$ decomposed (ofter Pitzer, Gordon, and wilson, 1936). 


\section{1}

Protection of uranyl from reduction by excess oxalic acid is most easily understood if one assumes that light absorbed by uranyl-oxalate complexes causes sensitized decomposition of oxalate into $\mathrm{CO}, \mathrm{H}_{2} \mathrm{O}$, and $\mathrm{CO}_{2}$ (or $\mathrm{CO}_{2}$ and $\mathrm{HCOOH}$ ), with light absorbed by free $\mathrm{UO}_{2}^{++}$ions (or a different kind of complexes, cf. below) causes oxidation-reduction. (It will be recalled that in the case of acetate, we have reached the reverse conclusion, namely, that light absorption in a complex produces oxidation-reduction, and light absorbed in free ions produces sensitized decomposition. This reversal is not too credible, although there is no gainsaying that different anions and different complexes may behave in a different way.)

Pitzer et al. discussed the most probable composition of the reactive complex. Büchi had suggested $\mathrm{UO}_{2} \mathrm{C}_{2} \mathrm{O}_{4} \cdot \mathrm{H}_{2} \mathrm{C}_{2} \mathrm{O}_{4}$, dissociating into $2 \mathrm{H}^{+}+$ $\mathrm{UO}_{2}\left(\mathrm{C}_{2} \mathrm{O}_{4}\right)_{2}^{--}$. Leighton and Forbes assumed that neutral $\mathrm{UO}_{2} \mathrm{C}_{2} \mathrm{O}_{4}$ is the reaction carrier. The occurrence of complex U(VI) anions was demonstrated by Dittrich (1899), who showed that in solutions containing $\mathrm{Na}_{2} \mathrm{C}_{2} \mathrm{O}_{4}$, uranium moves towards the anode. Pitzer and co-workers followed Büchi in the assumption that the associated group is $\mathrm{UO}_{2} \mathrm{C}_{2} \mathrm{O}_{4} \cdot \mathrm{H}_{2} \mathrm{C}_{2} \mathrm{O}_{4}$, dissociating into $2 \mathrm{H}^{+}$and a complex anion, $\mathrm{UO}_{2}^{++}\left(\mathrm{C}_{2} \mathrm{O}_{4}^{--}\right)_{2}$, which can also be interpreted as the second association complex of $\mathrm{UO}_{2}^{+}$and $\mathrm{C}_{2} \mathrm{O}_{4}^{--}$ions. Since the ionic dissociation constant of $\mathrm{UO}_{2} \mathrm{C}_{2} \mathrm{O}_{4}$ is small [ $10 \%$ in saturated $(0.0156 \mathrm{M})$ solution, a value derived from the freezing point depression of water; a similar figure follows from Dittrich's conductivity measurements], "free $\mathrm{UO}_{2}^{++}$" must be present mostly - up to $90 \%$ - in the form of neutral $\mathrm{UO}_{2} \mathrm{C}_{2} \mathrm{O}_{4}$ molecules. If sensitized decomposition of oxalic acid, ascribed above to "complexes" in general, is attributed, more specifically, to complex anions, oxidation-reduction may perhaps be ascribed to neutral molecules, $\mathrm{UO}_{2} \mathrm{C}_{2} \mathrm{O}_{4}$, rather than to free uranyl ions. Such hypotheses are bound to remain guesses, until a systematic study of the products and the kinetics of the uranyl-oxalate reaction is coupled with the investigation of the composition of the reacting solutions by spectroscopic and electrochemical methods, leading to the know ledge not only of the relative concentration of the different molecular and ionic species, but also of their relative role in the absorption of light of different wavelengths. Such an investigation seems to be urgently needed.

In corroboration of their theory, Pitzer and co-workers quoted the observation that addition of uranyl oxalate increases the acidity of oxalic acid, instead of decreasing it (the usual effect of neutral salts on acids containing the same anion). The effect becomes understandable if a stronger complex acid is formed by association of $\mathrm{UO}_{2} \mathrm{C}_{2} \mathrm{O}_{4}$ with $\mathrm{H}_{2} \mathrm{C}_{2} \mathrm{O}_{4}$. Estimation of acid strength of the complex from the measured $\mathrm{pH}$ indicates complete dissociation $\left(0.02\right.$ moles $\mathrm{H}^{+}$from 0.1 mole $\left.\mathrm{UO}_{2} \mathrm{C}_{2} \mathrm{O}_{4}+0.1 \mathrm{M} \mathrm{H}_{2} \mathrm{C}_{2} \mathrm{O}_{4}\right)$. This gives (for $25^{\circ} \mathrm{C}$ ):

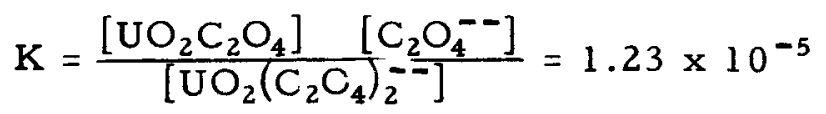




$$
62
$$

At very high values of the ratio $\left[\mathrm{H}_{2} \mathrm{C}_{2} \mathrm{O}_{4}\right] /\left[\mathrm{UO}_{2}^{++}\right]$(such as 10:1) a still higher complex may be formed; a potassium salt of the acid $\mathrm{H}_{6}\left(\mathrm{UO}_{2}\right)_{2}\left(\mathrm{C}_{2} \mathrm{O}_{4}\right)_{5}$ has been described in the literature.

Weiss (1938) discussed the uranyl-oxalate reaction from the point of view of the electron transfer theory. He pointed out that only this theory (as contrasted to the energy transfer theory) can account for the parallelism between the quenching of fluorescence and the inhibition of oxalate decomposition by ions described by Müller (cf. p.50). This consideration seems offhand to apply to kinetic encounter mechanisms only, but Weiss suggested that complex formation between sensitizer and substrate does not change the situation, since electron transfer phenomena can occur within the excited complex in the same way as between excited uranyl ions and other partners in an encounter. This, however, is not quite correct, because, as mentioned above, the time between excitation and electron transfer within a complex should be much shorter where transfer does not have to await a kinetic encounter. Furthermore, this time must be independent of the concentration of the electron donor (oxalate), so that the extent of inhibition should depend only on the concentration of the quenching ions. The effect of the concentration of oxalic acid on the yield, and (if the inhibitor acts by displacing the substrate from the complex, and not by kinetic encounters) also the effect of the concentration of the inhibitor, must be different in two mechanisms. Closer kinetic studies are needed to decide whether the quenching and inhibition phenomena can be brought into accord with the hypothesis of complexes as exclusive reaction carriers.

The mechanism of sensitized oxalate decomposition is, according to Weiss, as follows (neglecting the complex formation):

$$
\begin{aligned}
& \mathrm{UO}_{2}^{++*}+\mathrm{HC}_{2} \mathrm{O}_{4}^{-} \longrightarrow \mathrm{UO}+\mathrm{HC}_{2} \mathrm{O}_{4} \text { (electron transfer) } \\
& \mathrm{HC}_{2} \mathrm{O}_{4} \longrightarrow \mathrm{CO}_{2}+\mathrm{HCOO} \\
& \text { or } \quad \mathrm{HC}_{2} \mathrm{O}_{4} \longrightarrow \mathrm{CO}_{2}+\mathrm{CO}+\mathrm{OH} \\
& \left.\begin{array}{l}
\mathrm{HCOO}+\mathrm{UO}_{2}^{+} \longrightarrow \mathrm{HCOO}^{-}+\mathrm{UO}_{2}^{++} \\
\mathrm{OH}+\mathrm{UO}_{2}^{+} \longrightarrow \mathrm{UO}_{2}^{++}+\mathrm{OH}^{-}
\end{array}\right\} \text {back reactions }
\end{aligned}
$$

Net reaction: $\mathrm{HC}_{2} \mathrm{O}_{4}^{-} \longrightarrow \mathrm{CO}_{2}+\mathrm{HCOO}^{-}$

$$
\text { or } \quad \mathrm{HC}_{2} \mathrm{O}_{4}^{-} \longrightarrow \mathrm{CO}_{2}+\mathrm{CO}+\mathrm{OH}^{-}
$$

This scheme shows how sensitized decomposition, $(61)$ or $(61 \mathrm{~A})$, can result from an initial oxidation-reduction, $(61 \mathrm{a})$ : $\mathrm{U}^{+6}$ oxidizes the oxalate anion, $\mathrm{HC}_{2} \mathrm{O}_{4}^{-}$, to a radical, $\mathrm{HC}_{2} \mathrm{O}_{4}$; the latter decomposes (into $\mathrm{CO}_{2}$, and 
either the radical $\mathrm{HCOO}$, or the radical $\mathrm{OH}$ and the molecule $\mathrm{CO}$ ); the radicals re-oxidize $\mathrm{U}^{+5}$ to $\mathrm{U}^{+6}$, and are themselves converted into stable ions, $\mathrm{HCOO}^{-}$ and $\mathrm{OH}^{-}$.

[A similar scheme can be devised by assuming reversible reduction of $\mathrm{U}(\mathrm{VI})$ to the $\mathrm{U}(\mathrm{IV})$ instead of the $\mathrm{U}(\mathrm{V})$ level.]

Weiss suggested that the retardation of the oxalate decomposition by strong acids (p. 45) could be due to decreasing ionization of oxalic acid. He postulated that only the ions, $\mathrm{HC}_{2} \mathrm{O}_{4}^{-}$, and not the neutral molecules, $\mathrm{H}_{2} \mathrm{C}_{2} \mathrm{O}_{4}$, can serve as electron donors in reaction (61a),

In the presence of $\mathrm{I}^{-}$ions, the fluorescence of $\mathrm{UO}_{2}^{++}$may be completely quenched, but the photodecomposition of $\mathrm{H}_{2} \mathrm{C}_{2} \mathrm{O}_{4}$ still goes on (cf. below). Weiss attributed this to the capacity of iodine atoms (or iodine molecules) formed in the quenching process to carry out the chemical oxidation of oxalic acid (in competition with the back reaction, which is the re-oxidation of $\mathrm{U}(\mathrm{IV})$ by $\mathrm{I}_{2}$ ).

Carter and Weiss (1940) proceeded with an experimental reinvestigation of the reaction, especially of the influence of fluorescence quenchers on the ratio of the two products, $\mathrm{CO}$ and $\mathrm{HCOOH}$ (cf. Baur and Rebmann, p. 42). They suggested that such an influence would be incomprehensible from the point of view of the energy transfer theory (Schneider), as well as from that of the reaction in a stable complex (Buichi), but could be explained if mechanism $(61)$ is assumed. The same they also thought to be true of the explanation of the $\mathrm{pH}$ effect on the rate of decomposition.

In a series of measurements Carter and Weiss determined $\triangle C O$, $\triangle \mathrm{H}_{2} \mathrm{C}_{2} \mathrm{O}_{4}, \triangle \mathrm{U}(\mathrm{IV})$ and $\triangle \mathrm{HCOOH}$. Oxygen was excluded; oxalic acid was used (with or without $\mathrm{H}_{2} \mathrm{SO}_{4}$ addition), as well as $\mathrm{Na}_{2} \mathrm{C}_{2} \mathrm{O}_{4}(\mathrm{pH}$ 5).

The results obtained with oxalic acid in the presence of potassium iodide were similar to those of West (p. 50), but their meaning was somewhat clearer because West did not exclude oxygen.

Iodide concentrations of the order of $10^{-3} \mathrm{M}$, while decreasing considerably the yield of fluorescence, were without influence on the rate of sensitized decomposition of oxalic acid. In the presence of $0.033 \mathrm{M} \mathrm{H}_{2} \mathrm{C}_{2} \mathrm{O}_{4}$, as much as $0.1 \mathrm{M} \mathrm{KI}$ was found to be needed to reduce the rate of decomposition by $38 \%$; approximately the same is true of an equivalent $\mathrm{Na}_{2} \mathrm{C}_{2} \mathrm{O}_{4}$ solution. In the presence of $0.01 \mathrm{M} \mathrm{H}_{2} \mathrm{SO}_{4}$, the inhibiting effect is somewhat stronger $\left(26 \%\right.$ inhibition by $\left.0.05 \mathrm{M} \mathrm{I}^{-}\right)$. Table 4.14 shows the inhibitions by $0.01 \mathrm{M} \mathrm{I}^{-}$observed in oxalic acid solutions of different acidity. 
64

Table 4.14

INHIBITION OF URANYL-OXALATE REACTION BY IODIDE (AFTER CARTER AND WEISS, 1940)

\begin{tabular}{|l|c|c|c|c|}
\hline & \multicolumn{4}{|c|}{$\mathrm{H}_{2} \mathrm{SO}_{4}, \mathrm{M}$} \\
\cline { 2 - 5 } & 0 & 0.01 & 0.1 & 1 \\
\hline $\begin{array}{l}\text { Inhibition } \\
\text { by } 0.01 \mathrm{M} \mathrm{I}^{-}\end{array}$ & $-2.7 \%$ & $-4.6 \%$ & $-20 \%$ & $-19 \%$ \\
\hline
\end{tabular}

The results listed in Table 4.15 were found in the study of the effect of composition on the proportion of $\mathrm{CO}$ and $\mathrm{HCOOH}$ in the products:

Table 4.15

PRODUCTS OF URANYL OXALATE REACTION

(AFTER CARTER AND WEISS, 1940)

\begin{tabular}{|l|c|c|}
\hline Composition of the Photolyte & $\begin{array}{c}\Delta \mathrm{CO}_{\%}, \\
\mathrm{H}_{2} \mathrm{C}_{2} \mathrm{O}_{4}\end{array}$ & $\begin{array}{c}\Delta \mathrm{HCOOH}, \\
\mathrm{H}_{2} \mathrm{C}_{2} \mathrm{O}_{4}+\mathrm{I}^{-}(0.1 \mathrm{M})\end{array}$ \\
$\mathrm{H}_{2} \mathrm{C}_{2} \mathrm{O}_{4}+\mathrm{Br}-(0.1 \mathrm{M})$ & 42 & $44^{*}$ \\
$\mathrm{Na}_{2} \mathrm{C}_{2} \mathrm{O}_{4}$ & 44 & 42 \\
$\mathrm{Na}_{2} \mathrm{C}_{2} \mathrm{O}_{4}+\mathrm{I}^{-}(0.1 \mathrm{M})$ & 23 & 43 \\
$\mathrm{H}_{2} \mathrm{C}_{2} \mathrm{O}_{4}+\mathrm{H}_{2} \mathrm{SO}_{4}(0.01 \mathrm{M})$ & 18 & 72 \\
$\mathrm{H}_{2} \mathrm{C}_{2} \mathrm{O}_{4}+\mathrm{I}^{-}(0.1 \mathrm{M})$ & 56 & 56 \\
$\mathrm{H}_{2} \mathrm{C}_{2} \mathrm{O}_{4}+\mathrm{I}^{-}(0.01 \mathrm{M})$ & 38 & 38 \\
$\mathrm{H}_{2} \mathrm{C}_{2} \mathrm{O}_{4}+\mathrm{H}_{2} \mathrm{SO}_{4}(0.1 \mathrm{M})$ & 54 & 34 \\
$\mathrm{H}_{2} \mathrm{SO}_{4}+\mathrm{I}^{-}(0.01 \mathrm{M})$ & 76 & 36 \\
$\quad+\mathrm{H}_{2} \mathrm{SO}_{4}(1 \mathrm{M})$ & 75 & 14 \\
$\mathrm{H}_{2} \mathrm{C}_{2} \mathrm{O}_{4}+\mathrm{H}_{2} \mathrm{SO}_{4}+\mathrm{I}^{-}(0.01 \mathrm{M})$ & 53 & 11 \\
\hline
\end{tabular}

*The rest is $\mathrm{U}(\mathrm{IV})+\mathrm{CO}_{2}$ 


\section{5}

The two notable results of these experiments are, first, the wide discrepancy between the concentrations of $\mathrm{I}^{-}$which quench fluorescence, and the (much higher) concentrations of this anion needed to inhibit the reaction of uranyl ions with oxalic acid; and, second, the influence of composition (acidity, presence of iodide) on the proportion of the two reaction products, carbon monoxide and formic acid (rather than on the total yield of decomposition; cf, however, Fig. 4.8).

To explain the results, Carter and Weiss used scheme (61) complemented by the assumption of the acid-base equilibria

$$
\begin{aligned}
& \mathrm{UO}_{2}^{+}+4 \mathrm{H}^{+} \rightleftharpoons \mathrm{U}^{+5}+2 \mathrm{H}_{2} \mathrm{O} \\
& \mathrm{UO}_{2}^{+}+2 \mathrm{H}^{+} \rightleftharpoons \mathrm{U}^{+5}+2 \mathrm{OH}^{-}
\end{aligned}
$$

which stabilize the $\mathrm{UO}_{2}^{+}$ions and thus retard the backreactions (6ld) and (61e). As a consequence, the stationary concentration of the radicals $\mathrm{COOH}$ and $O H$ becomes higher with increasing acidity, and the probability of the reaction between them

$$
\mathrm{OH}+\mathrm{COOH}-\mathrm{CO}_{2}+\mathrm{H}_{2} \mathrm{O}
$$

increases. This reaction eliminates the partners with which $U(V)$ must react in the back reactions (6ld) or (6le) and leads to a net reduction $\mathrm{UO}_{2}^{++}$. This mechanism can explain why the relative yield of $\mathrm{UO}_{2}^{++}$reduction (compared to the yield of sensitized decomposition of oxalic acid) increases with increasing acidity (as found by Büchi).

The inhibiting effect of $\mathrm{H}^{+}$ions on the over-all yield of decomposition is understandable if $\mathrm{HC}_{2} \mathrm{O}_{4}^{-}$is the electron donor, as assumed in (6la), since the ionic dissociation of $\mathrm{H}_{2} \mathrm{C}_{2} \mathrm{O}_{4}$ declines with increasing $\left[\mathrm{H}^{+}\right]$.

The fact that $\mathrm{I}^{-}$ions can completely quench fluorescence without reducing the yield of sensitized decomposition was attributed by Carter and Weiss to capacity of the iodine atoms formed by the quenching reaction

$$
\mathrm{UO}_{2}^{++}+\mathrm{I}^{-} \rightleftharpoons \mathrm{UO}+\mathrm{I}
$$

to carry the reaction sequence further by themselves oxidizing oxalic acid [reaction (65)]. When the concentration of oxalic acid is low, the probability of the back reaction in (64) compared to that of the forward reaction

$$
\mathrm{I}+\mathrm{HC}_{2} \mathrm{O}_{4}^{-} \longrightarrow \mathrm{I}^{-}+\mathrm{HC}_{2} \mathrm{O}_{4} \longrightarrow \mathrm{I}^{-}+\mathrm{COOH}+\mathrm{CO}_{2}
$$


66

is high, and the yield of photoxidation is small. However, this does not explain why the yield of photoxidation increases at higher $\mathrm{I}^{-}$concentrations, since the latter should not change the relative probabilities of the two reactions. Furthermore, it seems from earlier experiments (cf., p. 63) that very high $\mathrm{II}^{-}$] concentrations inhibit the photochemical reaction of $\mathrm{I}^{-}$ with oxalate.

When [ $\left.\mathrm{I}^{-}\right]$is high, the yield of $\mathrm{CO}$ and $\mathrm{HCOOH}$ must decrease and more U(IV) must be produced, because the reactions

and

$$
\mathrm{COOH}+\mathrm{I} \longrightarrow \mathrm{CO}_{2}+\mathrm{HI}
$$

$$
\mathrm{C}_{2} \mathrm{O}_{4}^{-}+\mathrm{I}_{2} \longrightarrow 2 \mathrm{CO}_{2}+\mathrm{I}^{-}+\mathrm{I}
$$

which "snatch away" the radicals needed for regeneration of $\mathrm{UO}_{2}^{++}$, become important. The latter reaction is known from photoxidation of oxalate by iodine.

McBrady and Livingston (1946) investigated the formation of tetravalent uranium by reaction of uranyl ions with oxalate using Leighton and Forbes' actinometer. Under anaerobic conditions, this side reaction amounted to about $1 \%$ of the main one.

The determinations were made by measuring the absorption of a weak "scanning" beam of light at $650 \mathrm{m \mu}$ (where the absorption by $\mathrm{UO}_{2}^{++}$is negligible) while illuminating with strong light from a mercury arc at right angle to the scanning beam. The extinction curves of uranyl and uranous ions were determined over the range 400-700 $\mathrm{m} \mu$ by means of a Beckman spectrophotometer.

With $0.01 \mathrm{M} \mathrm{UO}_{2} \mathrm{SO}_{4}$ and $0.05 \mathrm{M}$ oxalic acid, in a vessel which was previously evacuated and filled with carbon dioxide, U(IV) was formed in light at a steady rate of $1.5 \times 10^{-7}$ moles/liter/sec. When the concentration of oxalic acid was lowered, the yield of U(IV) formation decreased (Table 4.16). The influence of acidity is shown by Table 4.17. It was found that the quantum yield of formation of U(IV) could be represented by the equation

$$
\gamma=\frac{0.0136\left[\mathrm{H}^{+}\right]}{0.0455+\left[\mathrm{H}^{+}\right]}+\frac{0.63\left[\mathrm{U}^{+4}\right]}{\left[\mathrm{H}^{+}\right]}
$$

When the concentration of oxalic acid is not smaller than that of uranyl sulfate $(x 21)$, the quantum yield of U(IV) formation is a function of [ $\left.\mathrm{H}^{+}\right]$(or of the total concentration of oxalic acid) represented adequately by the first term in Eq. (68), but when the concentration of oxalic acid is small, only the initial rate of reaction obeys the simplified formula, the rate becoming autocatalytically accelerated as U(IV) is formed. It increases approximately linearly with [U(IV)] [second term in Eq. (68)]. In this case the formation of $\mathrm{U}(\mathrm{IV})$ continues for a while in darkness. 


\section{7}

Table 4.16

QUANTUM YIELD, $\gamma$, OF U(IV) FORMATION IN

URANYL + OXALIC ACID REACTION

(AFTER MCBRADY AND LIVINGSTON, 1946)

$$
\left[\mathrm{UO}_{2} \mathrm{SO}_{4}\right]=0.1 \mathrm{M}
$$

\begin{tabular}{|c|l|}
\hline$\left[\mathrm{H}_{2} \mathrm{C}_{2} \mathrm{O}_{4}\right], \mathrm{M}$ & $\gamma \times 10^{3}$ \\
\hline 0.2 & 8.6 \\
0.1 & 7.7 \\
0.05 & $6.0(\mathrm{a})$ \\
0.025 & 4.3 \\
0.01 & $2.3(\mathrm{~b})$ \\
\hline
\end{tabular}

(a) Measured at two light intensities about $4 \times 10^{15}$ and $2 \times 10^{16}$ quanta absorbed per cc per sec.

(b) Initial rate, increasing autocatalytically with formation of U(IV).

Table 4.17

QUANTUM YIELD OF U(IV) FORMATION (AFTER MCBRADY AND LIVINGSTON, 1946)

$$
\left[\mathrm{UO}_{2} \mathrm{SO}_{4}\right]=0.01 \mathrm{M} \quad\left[\mathrm{H}_{2} \mathrm{C}_{2} \mathrm{O}_{4}\right]=0.05 \mathrm{M}
$$

\begin{tabular}{|c|c|}
\hline Medium & $\gamma \times 10^{3}$ \\
\hline $0.04 \mathrm{M} \mathrm{H}_{2} \mathrm{SO}_{4}$ & 7.4 \\
$0.02 \mathrm{M} \mathrm{NaOH}^{2}$ & $5.9 *$ \\
$0.04 \mathrm{M} \mathrm{NaOH}$ & $5.7 *$ \\
\hline
\end{tabular}

*Initial rate; autocatalytically accelerated.

When air is admitted, U(IV) is re-oxidized. An illumination of uranyl sulfate solution in the presence of air therefore causes only a passing appearance of the U(IV) bands.

Attempts were made to detect the presence of $U(V)$ in the irradiated solution by using green light (510-600 $\mathrm{m} \mu$ ) for scanning (it has been reported that $U(V)$ salts are red). However, no reversible increase in absorption in the green was noted during the illumination period. 


$$
48
$$

In the discussion of these results, McBrady and Livingston pointed out that in the experiments of Büchi, and of Leighton and Forbes, the quantum yield of $\mathrm{UO}_{2}^{++}$sensitized decomposition of oxalic acid was found to be practically independent of oxalic acid concentration if the latter was equal to or higher than, that of uranyl $(x<1)$. The (small) yield of U(IV) formation increased in the same region with increasing $\left[\mathrm{H}_{2} \mathrm{C}_{2} \mathrm{O}_{4}\right]$; this increase is forecast by Eq. (68) which, however, relates it to a change in $\left[\mathrm{H}^{+}\right]$, rather than in $\left[\mathrm{H}_{2} \mathrm{C}_{2} \mathrm{O}_{4}\right]$ (assuming the first dissociation of oxalic acid to be complete, the second negligible). This also permits a single equation to cover the results of experiments with $0.04 \mathrm{M} \mathrm{H}_{2} \mathrm{SO}_{4}$.

McBrady and Livingston assumed that the light-absorbing species is the complex $\left[\mathrm{UO}_{2}^{++}(\mathrm{COOH})_{2}\right]$, or, more exactly, its monopositive ion, $\left[\mathrm{UO}_{2}^{++}+\mathrm{COO}^{-}\right]$. Here again the assumption is made that the first acid ionization is complete, the second negligible; the alternative is to assume that the second ionization, too, is complete, because the complex probably is a much stronger acid than free oxalic acid. The first assumption is used because it fits the experimental results somewhat better (but not decisively so).

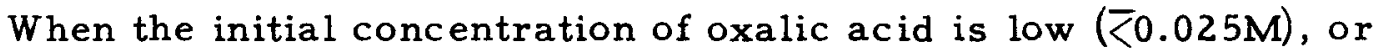
when the acid is neutralized by $\mathrm{NaOH}$, or $270 \%$ of the initial oxalic acid had been decomposed, the autocatalytic effect of U(IV) becomes apparent, and the addition of the second term in Eq. (68) becomes necessary. Under the same conditions an "after -effect" becomes notic eable - formation of U(IV) by a first-order dark reaction from a colorless "precursor" formed in light.

McBrady and Livingston gave a sequence of reaction which could account for the observed regularities. The essential steps are

$$
\begin{aligned}
& \mathrm{UO}_{2} \mathrm{C}_{2} \mathrm{O}_{4} \text { or }\left(\mathrm{UO}_{2} \mathrm{HC}_{2} \mathrm{O}_{4}^{+}\right) \frac{\mathrm{h} \nu}{\overline{\mathrm{dark}}, \mathrm{k}_{2}} \mathrm{UO}_{2} \mathrm{C}_{2} \mathrm{O}_{4} * \\
& \mathrm{UO}_{2} \mathrm{C}_{2} \mathrm{O}_{4} * \stackrel{\mathrm{k}_{3}}{-} \mathrm{X} \text { [metastable molecule, or two radicals } \\
& \text { such as } \left.\mathrm{UO}_{2}^{+} \text {and } \mathrm{C}_{2} \mathrm{O}_{4}^{-}\right] \\
& \mathrm{X}\left\{\begin{array}{c}
+\mathrm{H}_{2} \mathrm{O} \stackrel{\mathrm{k}_{4}}{\longrightarrow}-\mathrm{UO}_{2}(\mathrm{OH})_{2}+\mathrm{CO}_{2}+\begin{array}{c}
\mathrm{CO} \text { (sensitized decom- } \\
\text { position) }
\end{array} \\
+\mathrm{H}^{+} \stackrel{\mathrm{k}_{5}}{\longrightarrow} \mathrm{UOOH}^{+}+2 \mathrm{CO}_{2} \\
\stackrel{\mathrm{K}_{8}}{\longrightarrow} \mathrm{UO}_{2}+\mathrm{H}^{+}+2 \mathrm{CO}_{2} \text { (reduction to U(IV)) } \\
+\mathrm{UO}_{2} \stackrel{\mathrm{k}_{6}}{\longrightarrow} \mathrm{A} \longrightarrow 2 \mathrm{UO}_{2}+2 \mathrm{CO}_{2} \text { (U(IV) catalysis) }
\end{array}\right.
\end{aligned}
$$


The metastable intermediate $\mathrm{x}$ can react in (69c) either by decomposition of oxalate to $\mathrm{CO}_{2}$ and $\mathrm{CO}$ and regeneration of $\mathrm{U}(\mathrm{VI})$, or by $\mathrm{H}^{+}$catalysed internal oxidation-reduction, yielding $\mathrm{U}(\mathrm{IV})$ and $\mathrm{CO}_{2}$, or with $\mathrm{U}(\mathrm{IV})$ to bring about "autocatalytic" formation of more $\mathrm{CO}_{2}$ and U(IV).

The species of the molecules used in these equations are tentative. The reaction leading to $\mathrm{UO}_{2}$ is formulated so as to explain the stimulation of the oxidation-reduction by acidity.

Eqs. ( $69 a, b, c)$ give for the steady rate of the reaction (i.e., the rate established after the concentrations of all intermediates have become constant):

$$
\gamma_{\text {steady }} \simeq \frac{k_{3}}{\mathrm{k}_{3}+\mathrm{k}_{2}} \frac{\left[\mathrm{H}^{+}\right]}{\frac{\mathrm{k}_{4}}{\mathrm{k}_{5}}+\left[\mathrm{H}^{+}\right]}+\frac{\frac{\mathrm{k}_{6} \mathrm{k}_{8}}{\mathrm{k}_{4}\left[\mathrm{UOOH}^{+}\right]}}{\left[\mathrm{H}^{+}\right]}
$$

in formal agreement with the empirical Eq. (68).

The long-lived intermediate $A$ is introduced to account for the "after-effect" in the dark.

The mechanism suggested is also consistent with the results of Leighton and Forbes; it is still, however, general and uncertain in most details.

(b) Higher Dibasic Acids - Malonic Acid (COOH $\left.\cdot \mathrm{CH}_{2} \cdot \mathrm{COOH}\right)$. Fay (1896) attempted to study the photochemical decomposition of uranyl malonate but found that $\mathrm{UO}_{2}(\mathrm{OOC})_{2} \mathrm{CH}_{2} \cdot 3 \mathrm{H}_{2} \mathrm{O}$, which he prepared from hot concentrated solutions of malonic acid and uranyl nitrate, was almost insoluble in water. This compound dissolves, however, in malonic acid or potassium malonate solution. Both solutions proved to be stable in sunlight. A dilute solution of uranyl oxalate and malonic acid decomposed in sunlight, but very slowly.

The decomposition of malonic acid by uranyl ions in light was later noted by Berthelot and Gaudechon (1913).

Pierce, Leviton, and Noyes (1929) noted that addition of uranyl sulfate to a $0.05 \mathrm{M}$ malonic acid, in a quartz vessel exposed to the full light of a quartz mercury arc, increased considerably (e.g., from $12.6 \mathrm{cc}$ to $55 \mathrm{cc}$ ) the amount of liberated gas. (In the absence of the sensitizer, gas was produced by direct photochemical decomposition of malonic acid.) In both direct and sensitized decomposition, 95-96\% of the gas was carbon dioxide. Results were similar with Pyrex-filtered light $(\lambda>300 \mathrm{~m} \mu)$. Fig. 4.12 shows the effects on the rate of increased concentration of uranyl ions, observed at constant malonic acid concentration $(0.05 \mathrm{M})$, and of increased malonic 


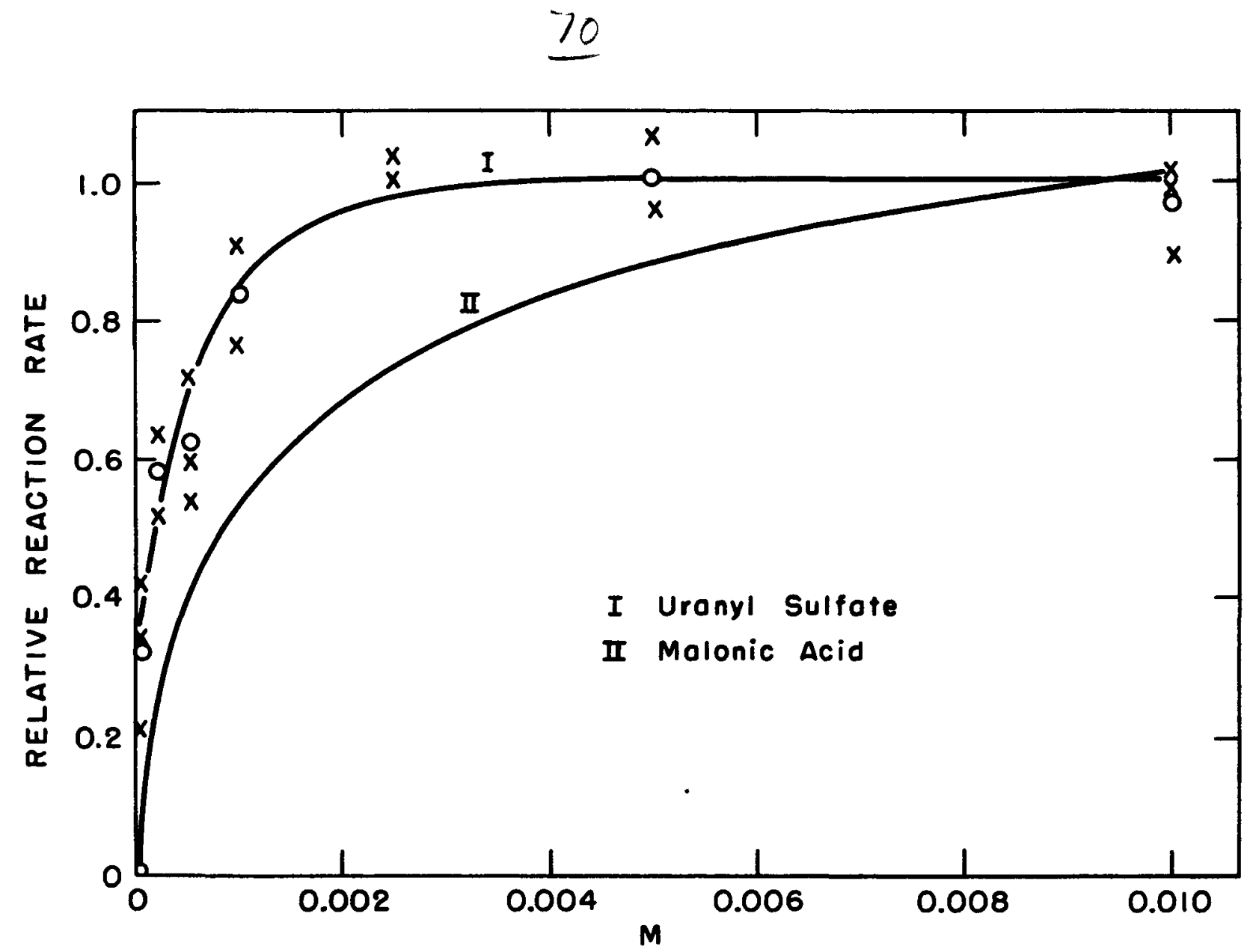

Fig. 4.12. Rate of decomposition of malonic acid in the presence of uranyl sulfate (after Pierce, Leviton, and Noyes, 1929). Curve I: Rate as function of $\left[\mathrm{UO}_{2}^{++}\right]$ot $0.05 \mathrm{M}$ molonic acid.

Curve III: Rate os function of [malonic ocid] at $0.01 \mathrm{M}$ $\mathrm{UO}_{2} \mathrm{SO}_{4}$. 
acid concentration observed at constant uranyl concentration (0.01M). Curve II will be further discussed below; curve I shows saturation with respect to [ $\mathrm{UO}_{2}^{++}$] to occur (in a vessel $5 \mathrm{~mm}$ deep, in $0.05 \mathrm{M}$ malonic acid) below $2.5 \times 10^{-3} \mathrm{M}$; above $5 \times 10^{-3} \mathrm{M}$, the yield of decomposition fell off slightly. This can hardly be attributed to complete absorption of incident light. With $\left[\mathrm{UO}_{2}^{++}\right]=2.5 \times 10^{-3} \mathrm{M}$, for the absorption in a $0.5 \mathrm{~cm}$ deep vessel to exceed $90 \%$, the average absorption coefficient, $\bar{\alpha}$, must be $>10^{3}$. According to Table 2.8, this is the case for the uranyl-malonic acid complex only below $270 \mathrm{~m} \mu$, while $\bar{\lambda}$ has been estimated by Pierce and co-workers to be, in their experiments, $290 \mathrm{~m} \mu$ without the Pyrex filter, and $320 \mathrm{~m} \mu$ with the Pyrex filter. It thus seems that "uranyl saturation" must be attributed in this case not to complete light absorption, but to energy dissipation by $\mathrm{UO}_{2}^{++*}+\mathrm{UO}_{2}^{++}$interaction. The decline of the yield above $10^{-2} \mathrm{M} \mathrm{UO}_{2}^{++}$is in agreement with this hypothesis.

In four runs, lasting 5-7 hours each, with no [ $\mathrm{UO}_{2}^{++}$] added ( $3 \%$ light absorption), the quantum yield of direct decomposition of malonic acid (0.5M) was found to be $0.68,0.71,0.73$, and 0.81 , respectively. In the presence of $5 \times 10^{-3} \mathrm{M}$ uranyl sulfate, the experimentally determined absorption was $27.6 \%$ (confirming the above estimate that it must be incomplete); the quantum yields (averaged for 3.5-7.3 hour runs) were 0.25-0.27 in quartz ultraviolet light $(\bar{\lambda}=290 \mathrm{~m} \mu)$ and $0.24-0.27$ in Pyrex-filtered light $(\bar{\lambda}=320 \mathrm{~m} \mu)$.

Addition of $5 \times 10^{-3} \mathrm{M} \mathrm{H}_{2} \mathrm{SO}_{4}$ had no effect on the quantum yield, indicating that acid dissociation of malonic acid was irrelevant.

According to Ghosh and Mitter, the concentration of the complex at $0.01 \mathrm{M} \mathrm{UO}_{2} \mathrm{SO}_{4}$ is $\mathrm{x}=80(0.01-\mathrm{x})(0.01-\mathrm{x})=0.0035$, corresponding to only $35 \%$ complexing. If this were the explanation of the fact that the maximum quantum yield is only 0.27 , further increase in malonic acid cancentration should increase the yield. Since this was not found to be the case, it appears that reaction can occur not only by light absorption in the complex, but also by absorption in a free uranyl ion and its subsequent encounter with a malonic acid molecule, and that the low quantum yield is due to causes other than incomplete complexing, such as primary recombination ("cage effect") (cf., however, the later results of Pierce, given below).

In an attempt to analyze the relation between $\mathrm{UO}_{2}^{++}$concentration and yield, Pierce et al. first used a simple equation

$$
-\frac{\mathrm{d}[\mathrm{malonic} \text { acid }]}{\mathrm{dt}}=\mathrm{k}_{1} \mathrm{I}_{0}\left(1-10^{-\mathrm{k}}\left[\mathrm{UO}_{2}^{++}\right] \mathrm{d}\right)+\mathrm{k}_{2} \mathrm{I}_{0} 10^{-\mathrm{k}}\left[\mathrm{UO}_{2}^{++}\right] \mathrm{d}
$$

where the first term represents the uranyl-sensitized, and the second term, the direct decomposition of malonic acid. The best approximation could be achieved by assuming $\mathrm{k}_{1} \mathrm{I}_{0}=1.00, \mathrm{k}_{2}=0.327$ and $\mathrm{kd}=0.64\left(\mathrm{~d}=2 \mathrm{~cm},\left[\mathrm{UO}_{2}^{++}\right]\right.$ in millimoles/liter). The value of $\mathrm{k}\left[320\right.$ (moles/liter) $\left.{ }^{-1} \mathrm{~cm}^{-1}\right]$ seems somewhat high (cf. Table 2.8), but much of the light used was $<330 \mathrm{~m} \mu$. 
72

Eq. (71) does not explain the decline of the rate at high [ $\mathrm{UO}_{2}^{++}$] values. To account for this it was assumed that uranyl-malonic acid complexes can be de-activated by collisions with $\mathrm{UO}_{2}^{++}$ions. The resulting equation required, however, a more rapid decline than was actually observed.

The effect of acid concentration on the rate could be explained by collision theory more satisfactorily than by the complex formation theory, but the simple collision formula [Stern-Volmer, Eq. (20)] did not fit the data exactly. The fit could be improved by adding a factor $\left[\mathrm{UO}_{2}^{++}\right] /\left(\left[\mathrm{UO}_{2}^{++}\right]+\right.$ [acid]) accounting for deactivation of excited $\mathrm{UO}_{2}^{++}$ions by encounters with non-excited uranyl ions.

Pierce (1929) found that, in contrast to the similar reaction with oxalate, the photodecomposition of malonic acid sensitized by uranyl sulfate has a marked temperature coefficient $\left(Q_{10}=1.13 \pm 0.02\right)$ between $3^{\circ}$ and $73^{\circ}$.

He corrected the statement of Pierce, Leviton, and Noyes that no enhancement of absorption is noticeable in uranyl-malonate mixtures; this is only true at the longer waves, while marked increase in absorption occurs at 220-320 $\mathrm{m} \mu$ [as noted in the earlier observations by Ghosh and Mitter (1928) (cf. Table 2.8).

Pierce also made new experiments on the dependence of rate on $\mathrm{UO}_{2}^{++}$concentration and confirmed the previous observation that (at $0.05 \mathrm{M}$ malonic acid, in the presence of $0.0528 \mathrm{M} \mathrm{NaOH}$, in a $1.5 \mathrm{~cm}$ deep vessel) the rate reached saturation at $\left[\mathrm{UO}_{2} \mathrm{SO}_{4}\right]>0.0025 \mathrm{M}$. New measurements also were made on the effect of variations in malonic acid concentration at constant $\left[\mathrm{UO}_{2}^{++}\right]$(Table 4.18).

Table 4.18

RATE OF SENSITIZED MALONIC ACID DECOMPOSITION

(AFTER PIERCE, 1929)

$\mathrm{UO}_{2}^{++}=0.0116 \mathrm{M} ; \mathrm{NaOH}=0.0528 \mathrm{M}$

\begin{tabular}{|c|l|l|l|l|}
\hline [malonic acid]: & $\begin{array}{l}0.0046 \\
0.45\end{array}$ & $\begin{array}{l}0.0092 \\
0.55\end{array}$ & $\begin{array}{l}0.023 \\
0.67\end{array}$ & $\begin{array}{l}0.046 \\
0.90\end{array}$ \\
\hline
\end{tabular}

Table 4.18 extends curve II in Fig. 4.12 and shows that saturation had been far from reached at $0.01 \mathrm{M}$ (the limit of the earlier experiments). It is, however, not clear whether the absolute rate (quantum yield) exceeded in this experiment the maximum value of 0.27 , found in the preceding investigation. 


\section{3}

The results can be interpreted on the basis of the complex theory by using the complexing constant $(K=80)$ given by Ghosh and Mitter. The practical equality of rates at $\left[\mathrm{UO}_{2}^{++}\right]=0.025 \mathrm{M}$ and $0.01 \mathrm{M}$, for $0.05 \mathrm{M}$ acid is then understandable, because $\mathrm{UO}_{2}^{++}$complexing is $87 \%$ complete in the first case and $83 \%$ complete in the second one, while absorption is practically complete in both cases. The effect of increased acid concentration can also be explained by progressive complexing, e.g., in Table 4.18 complexing (with $\mathrm{K}=80$ ) must have been $34 \%$ complete at [malonic acid] $=0.0046$ and $\sim 95 \%$ complete at [malonic acid] $=0.046 \mathrm{M}$.

Succinic Acid (COOH$\cdot \mathrm{CH}_{2} \mathrm{CH}_{2} \cdot \mathrm{COOH}$ ) - Seekamp (1865) noted that succinic acid decomposes in sunlight, in the presence of uranyl nitrate, into carbon dioxide and propionic acid; a green precipitate [U(IV) succinate?] also is formed. Fay (1896) attempted to prepare uranyl succinate to study its decomposition in light, but the compound obtained by evaporation of a solution of uranyl nitrate and acid sodium succinate proved to be insoluble in water; its solution in dilute succinic acid was photostable. The experiments were not pursued any further.

Neuberg and Peterson (1914) found no increase in alkalinity of a solution containing $1 \%$ potassium succinate and $0.1 \%$ uranyl sulfate upon a 17 day exposure to sunlight (while marked changes were observed in analogous experiment with malic, citric, lactic and tartaric acid).

The photodecomposition of succinic acid by uranyl ions was studied in some detail only in a system containing, in addition to uranyl ions as sensitizers, also methylene blue $(\mathrm{MB})$ as ultimate oxidant. Ghosh, Banerjee and Bhatta (1936) investigated the behavior of this system in ultraviolet light from a mercury arc ( $\lambda 366 \mathrm{~m} \mu$, isolated by filter). They found that no change in [MB] occurs upon exposure to this light of a mixture of $0.32 \mathrm{M}$ uranyl nitrate and $4 \times 10^{-4} \mathrm{M}$ methylene blue, or of a mixture $0.1 \mathrm{M}$ in succinic acid and $4 \times 10^{-4} \mathrm{M}$ in methylene blue, but that the dyestuff was bleached (i.e., presumably reduced to the leuko base) upon having been exposed to light under exclusion of air in the presence of both uranyl ions and succinic acid.

The rate of bleaching was found to be independent of acidity. Therefore, the observed effect of changes in the concentration of succinic acid could not be a pH effect. The reciprocal of the rate proved to be a linear function of the reciprocal of succinic acid concentration, (Fig. 4.13), as expected for competition between mono-molecular deactivation of excited uranyl ions and their bimolecular reaction with succinic acid:

$$
v=\frac{d[M B]}{d t}=\frac{k a[\text { succinic acid }]}{b+a[\text { succinic acid }]} \text {, or } \frac{1}{\mathrm{v}}=c_{1}+\frac{c_{2}}{[\text { succinic acid }]}
$$




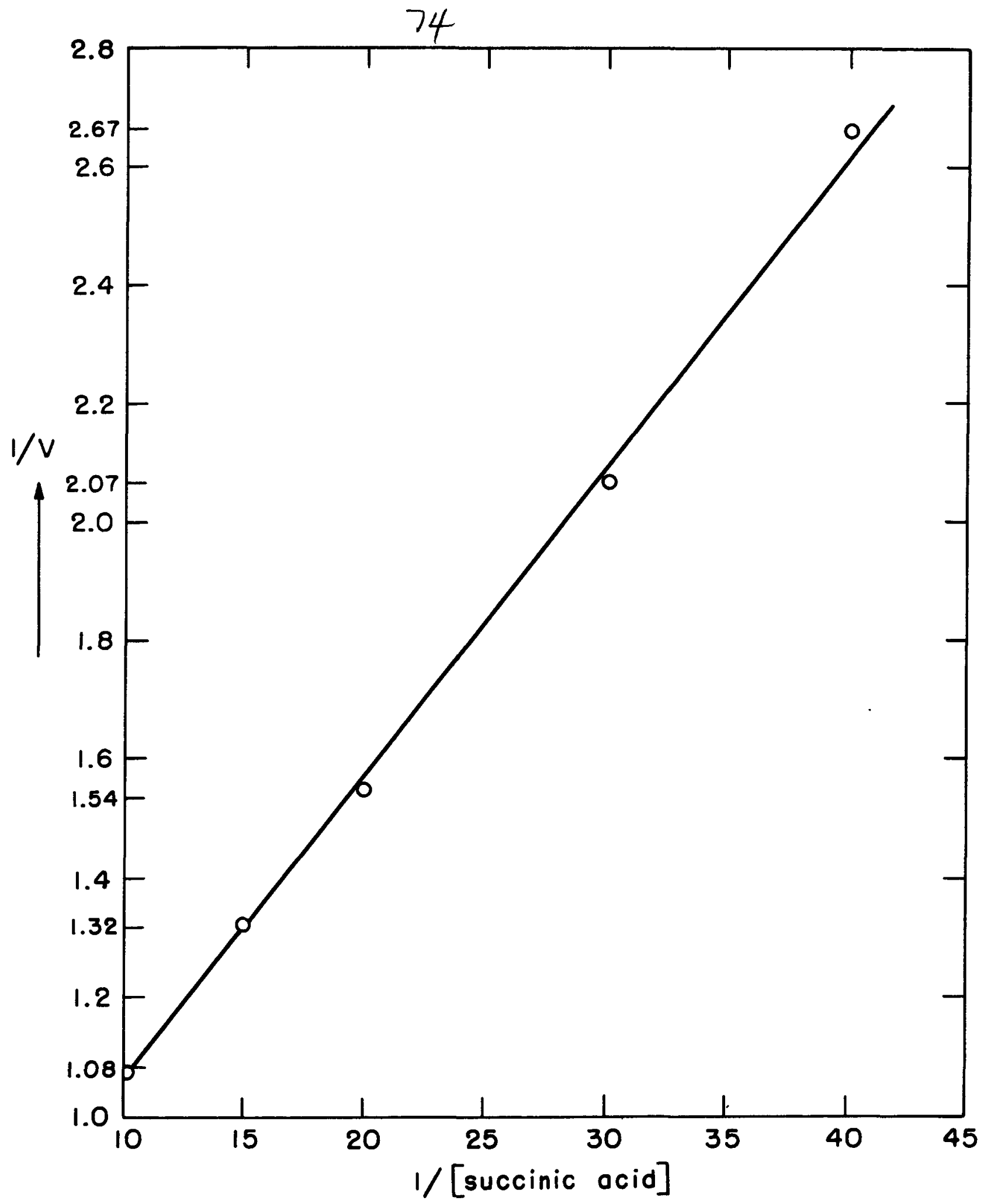

Fig. 4.13. Rate of bleaching of methylene blue in methylene blue--succinate--uranyl mixture as function of oxalate concentration (after Ghosh, Banerjee, and Bhatta, 1936). 
75

The observed dependence of the rate on uranyl concentration was attributed to the combined effects of changes in light absorption and of "self-deactivation," caused by encounters between excited and normal uranyl ions. The light absorption by uranyl ions is given approximately by the equation:

$$
A_{1}=I_{0}\left[1-e^{-\epsilon_{1} c_{1}+\epsilon_{2} c_{2}}\right] \frac{\epsilon_{1} c_{1}}{\epsilon_{1} c_{1}+\epsilon_{2} c_{2}}
$$

where the indices 1 and 2 refer to uranyl and methylene blue respectively (assuming that the acid does not absorb any of the light used). As an example, with $\bar{\epsilon}_{1}=17$ and $\bar{\epsilon}_{2}=2500,\left[\mathrm{UO}_{2}^{++}\right]=0.32$ and $[\mathrm{MB}]=4 \times 10^{-4} \mathrm{M}$, the absorption by the (mostly complexed) $\mathrm{UO}_{2}^{++}$was $85 \%$ of the total obsportion.

Eq. (74), which accounts for self-deactivation by the second term in the denominator, was found to fit the experimental data well (cf. Table 4.19):

$$
\mathrm{v}=-\frac{\mathrm{d}[\mathrm{MB}]}{\mathrm{dt}} \frac{2.08 \times 10^{-3} \mathrm{~A}_{1} \times 10^{-11}}{1+17\left[\mathrm{UO}_{2}^{++}\right]} \mathrm{moles} /(\mathrm{sec} . \mathrm{sq} . \mathrm{cm} .)
$$

here, $A_{1}$ is the energy absorbed by $\mathrm{UO}_{2}^{++}$, expressed in ergs $/\left(\mathrm{sec} . \mathrm{cm}^{2}\right)$.

\section{Table 4.19}

$$
\begin{aligned}
& \text { KINETICS OF BLEACHING OF METHYLENE BLUE IN } \\
& \text { MIXTURE WITH URANYL SALT AND SUCCINATE } \\
& \text { (AFTER GHOSH et al., 1936) } \\
& \begin{aligned}
\mathrm{k}_{0}= & 2.08 \times 10^{-3} ;[\text { succinic acid] }=0.1 \mathrm{M}: \text { [MB] } \\
= & 4 \times 10^{-4} \mathrm{M} ; \mathrm{I}_{0}=2732 \mathrm{ergs} /(\mathrm{sec} . \mathrm{sq} . \mathrm{cm} .)
\end{aligned}
\end{aligned}
$$

\begin{tabular}{|c|c|c|c|c|}
\hline & & \multicolumn{2}{|c|}{$\begin{array}{c}\Delta \mathrm{MB} / \Delta \mathrm{t} \times 10^{11} \\
\text { moles/(1iter x sec.) }\end{array}$} & $\begin{array}{c}\text { Quantum } \\
\text { yield, } \\
\text { observed }\end{array}$ \\
\cline { 3 - 4 } & ergs/(sec. sq. cm.) & observed & $\begin{array}{c}\text { calculated } \\
\text { (Eq. 74) }\end{array}$ & \\
\hline 0.16 & 1676 & 0.93 & 0.94 & 0.018 \\
0.12 & 1426 & 0.88 & 0.96 & 0.020 \\
0.08 & 1083 & 0.88 & 0.95 & 0.026 \\
0.04 & 624 & 0.77 & 0.77 & 0.040 \\
0.01 & 175 & 0.33 & 0.31 & 0.061 \\
\hline
\end{tabular}


76

Both the observed dependence on [succinic acid] [Eq. (72)] and that on $\left[\mathrm{UO}_{2}^{++}\right][\mathrm{Eq}$. (74)] agree with those to be expected on the basis of the reaction mechanism:

$$
\begin{aligned}
& \mathrm{UO}_{2}^{++}+\mathrm{h} \nu \frac{\mathrm{k}_{1}}{\mathrm{k}_{2}}\left(\mathrm{UO}_{2}^{++}\right)^{*} \text { (excitation and fluorescence) } \\
& \mathrm{UO}_{2}^{++} *+\left\{\begin{array}{l}
\mathrm{UO}_{2}^{++} \stackrel{\mathrm{k}_{3}}{-} 2 \mathrm{UO}_{2}^{++}(\text {self-quenching) } \\
\text { succinic acid } \stackrel{\mathrm{k}_{4}}{-} \mathrm{UO}_{2}^{+}+\text {oxidation products }
\end{array}\right. \\
& \mathrm{UO}_{2}^{+}+\mathrm{MB} \longrightarrow \mathrm{UO}_{2}^{++}+\text {reduced MB (restoration of the } \\
& \text { sensitizer) }
\end{aligned}
$$

which leads to theoretical Eq. (75), which includes (73) and (74) as special cases:

$$
-\frac{d[M B]}{d t}=\frac{A_{1} k_{4}[\text { succinic acid }]}{\left(k_{2}+k_{3}\right)\left[U_{2}^{++}\right]+k_{4}[\text { succinic acid }]}
$$

From Vavilov's self-quenching experiments on uranyl solutions, it appears that $k_{3}=99 k_{2}$. The ratio $k_{4} / k_{3}$ was assumed to be unity in a similar investigation with mandelic acid as reductant (p. 90), but had to be assumed to be about 0.5 to account for the empirical value of the constants in Eq. (75). At a given acid concentration, the quantum yields of the $M B$ reduction by mandelic acid were correspondingly higher (by a factor of 1.6). The ratio $k_{4} / k_{2}$ appeared to $b e \simeq 50$.

In the above discussion, as on several similar occasions, Ghosh discussed the kinetics of the photochemical process without reference to the complex formation from uranyl ions and the organic photolyte, although earlier measurements by Ghosh and Mitter had indicated the extent of this association. The application of the reaction system $(75 \mathrm{a}-\mathrm{d})$ to a largely associated system is somewhat doubtful - first, because it presumes that a complex, such as $\left\{\mathrm{UO}_{2}^{++}\right.$. succinic acid $\}$, only reacts if it encounters, after excitation, another molecule of the acid; and second, because the concentration of this acid is assumed to be equal to the total concentration added, while it may be that only the free, unassociated acid molecules should be counted. [It is, however, not impossible that for geometrical reasons the $\mathrm{UO}_{2}^{++*}$ ion in a complex can react with free acid molecules, and with acid molecules in other complexes, but not with the acid molecule in its own complex.] 


\section{7}

\section{SUBSTITUTED ALIPHATIC ACIDS}

3.1 Halogenated Acids - Uranyl salts of halogenated aliphatic and aromatic acids, first prepared by Lobanov, were studied by Křepelka and Résö (1938) for their reaction to light. In solution, all of them (uranyl $\alpha-$ chloropropionate, uranyl $\beta$-chloropropionate, uranyl $\alpha$-bromopropionate, uranyl $\beta$-bromopropionate, uranyl p-bromobenzoate) were found to decompose in ultraviolet and, more slowly, in visible light, showing changes in color, and precipitation. A little ether was added as a catalyst to accelerate the decomposition. The aliphatic compounds gave U(IV) and carbon dioxide; aromatic compounds liberated no carbon dioxide and formed no basic salts, but instead decomposed into the corresponding hydroxy compounds (salicylates) and hydrogen chloride. In visible light (in the presence of a little ether), the decomposition of the halogenated propionates was complete in 4-6 weeks; in ultraviolet light, it reached 50-70\% after 1-2 days but then appeared to stop. The chlorobenzoate was more stable in light than the aliphatic compounds; $\beta$-substituted compounds were more stable than the $\alpha$-substituted compounds.

Ghosh and Ray (1936a) investigated the oxidation of monochloracetic acid, $\mathrm{CH}_{2} \mathrm{Cl} \cdot \mathrm{COOH}$, by potassium permanganate in the presence of uranyl sulfate in monochromatic light $(436 \mathrm{~m} \mu$ and $366 \mathrm{~m} \mu \mathrm{Hg}$ lines isolated by filters). No reaction occurred in light with only two components present, or with all three components in the absence of light. The disappearance of $\mathrm{KMnO}_{4}$ was followed by observing the absorption at $540 \mathrm{~m} \mu$. In $366 \mathrm{~m} \mu$ light [2650 ergs $\left./\left(\mathrm{sec} . \mathrm{cm}^{2}\right)\right]$ at $30^{\circ} \mathrm{C}$ in a $5 \mathrm{~mm}$ thick vessel containing $5.1 \times 10^{-4} \mathrm{M}$ $\mathrm{KMnO}_{4}, 0.1 \mathrm{M} \mathrm{CH} \mathrm{CH}_{2} \mathrm{Cl} \cdot \mathrm{COOH}, 0.1 \mathrm{M} \mathrm{UO}_{2} \mathrm{SO}_{4}$, and $2.5 \mathrm{~N} \mathrm{H}_{2} \mathrm{SO}_{4}$, permanganate was bleached at a constant rate of $1.5 \times 10^{-11}$ (moles $/$ liter) $/\left(\sec \mathrm{cm}^{2}\right)$ for $2 \frac{1}{2}$ hours. At $\left.436 \mathrm{~m} \mu\left[930 \mathrm{ergs} /(\mathrm{sec} \mathrm{cm})^{2}\right)\right]$ in a solution containing $4.2 \times 10^{-4} \mathrm{M}$ $\mathrm{KMnO}_{4}, 0.03 \mathrm{M} \mathrm{CH}_{2} \mathrm{Cl} \cdot \mathrm{COOH}, 0.1 \mathrm{M} \mathrm{UO}_{2} \mathrm{SO}_{4}$ and $3 \mathrm{~N} \mathrm{H}_{2} \mathrm{SO}_{4}$, the rate of disappearance of permanganate was $0.33 \times 10^{-11}$ (moles $/$ liter) $/\left(\mathrm{sec} \mathrm{cm}^{2}\right)$. The rate in ultraviolet light remained constant even after over one half of the initial quantity of $\mathrm{KMnO}_{4}$ had disappeared, indicating that the reaction was sensitized by uranyl ions, and not brought about by direct excitation of $\mathrm{KMnO}_{4}$. (The amount of light available to the uranyl ions did not change with time because the reduction products of $\mathrm{KMnO}_{4}$ proved to have an unchanged absorption capacity in the ultraviolet.) The rate of light absorption by $\mathrm{UO}_{2}^{++}$, designated as $\mathrm{A}_{1}$, was calculated by multiplying the total absorption, A total, by the factor:

$$
\bar{\epsilon}_{\mathrm{UO}_{2}^{++}}\left[\mathrm{UO}_{2}^{++}\right] /\left(\epsilon_{\mathrm{MnO}_{4}^{-}}\left[\mathrm{MnO}_{4}^{-}\right]+\bar{\epsilon}_{\mathrm{UO}_{2}^{++}}\left[\mathrm{UO}_{2}^{++}\right]\right)
$$

where ${ }^{-} \epsilon_{\mathrm{UO}}^{++}$is the (natural) absorption coefficient of uranyl ions determined in the presence of chloracetic acid, i.e., complexed to a certain extent (See Chap. 2) with chloracetate anions or molecules $(\vec{\epsilon}=10$ at $366 \mathrm{~m} \mu$, $\bar{\epsilon}=6.5$ at $436 \mathrm{~m} \mu$ ). The (natural) absorption coefficients of $\mathrm{KMnO}_{4}$ at the same wave lengths are $2000(366 \mathrm{~m} \mu)$ and $10(436 \mathrm{~m} \mu)$. 
78

The effect on the yield of the substrate concentration, $\left[\mathrm{CH}_{2} \mathrm{Cl} \cdot \mathrm{COOH}\right]$, is shown by Table 4.20. It shows that the reaction rate is not "saturated" with respect to the substrate even at $0.2 \mathrm{M}$; at that concentration, the quantum yield is still below 0.1. According to Chap. 2, complexing of $\mathrm{UO}_{2}^{++}$should be practically complete under the conditions of Table 4.20; the reaction thus does not occur after each absorption act in the complex, but appears to require encounters of excited uranyl ions (or their complexes) with free acid anions.

Table 4.20

URANYL-SENSITIZED OXIDATION OF $\mathrm{CH}_{2} \mathrm{Cl} \cdot \mathrm{COOH} \mathrm{BY} \mathrm{KMnO}_{4}$ (After Ghosh and Ray, 1936a)

$\left[\mathrm{KMnO}_{4}\right]=4.2 \times 10^{-4} \mathrm{M} ;\left[\mathrm{UO}_{2} \mathrm{SO}_{4}\right]=0.087 \mathrm{M}$ $\left[\mathrm{H}_{2} \mathrm{SO}_{4}\right]=3 \mathrm{~N} ; \mathrm{t}=29^{\circ} \mathrm{C} ; \lambda=436 \mathrm{~m} \mu$ $\mathrm{I}_{0}=1030 \mathrm{ergs} /\left(\mathrm{sec} \mathrm{cm}^{2}\right)$, of which $250 \mathrm{ergs} /\left(\mathrm{sec} \mathrm{cm}^{2}\right)$ are absorbed by $\mathrm{UO}_{2} \mathrm{SO}_{4}$

\begin{tabular}{|c|l|l|l|l|}
\hline$\left[\mathrm{CH}_{2} \mathrm{Cl} \cdot \mathrm{COOH}\right], \mathrm{M}$ & 0.033 & 0.05 & 0.1 & 0.2 \\
\hline$\frac{\mathrm{d}\left[\mathrm{KMnO}_{4}\right]}{\mathrm{dt}} \times 10^{11}:$ & 0.34 & 0.43 & 0.57 & 0.66 \\
quantum yield : & 0.038 & 0.048 & 0.063 & 0.073 \\
\hline
\end{tabular}

The effect of the concentration of the sensitizer, [UOt+], was studied in the presence of $0.1 \mathrm{M} \mathrm{CH}_{2} \mathrm{Cl} \cdot \mathrm{COOH}$ and $4.2 \times 10^{-4} \mathrm{M} \mathrm{KMnO}_{4}$, in $3 \mathrm{~N} \mathrm{H}_{2} \mathrm{SO}_{4}$, at $29^{\circ} \mathrm{C}$. Table 4.21 gives the results.

The observed decrease in quantum yield with increasing [ $\mathrm{UO}_{2}^{+}{ }^{+}$] can be represented by the empirical equation

$$
\frac{\mathrm{d}\left[\mathrm{KMnO}_{4}\right]}{\mathrm{dt}}=\frac{\mathrm{k}_{0} \mathrm{~A}_{1}}{1+9.08\left[\mathrm{UO}_{2}^{+}\right]}
$$

where $A_{1}$ is the amount of light energy absorbed by uranyl ions. The cause of self-deactivation may be sought, as before, in deactivation by encounters of $\left(\mathrm{UO}_{2}^{++}\right)^{*}$ ions with normal $\mathrm{UO}_{2}^{++}$ions (or in the formation of dimeric uranyl ions).

Incident light intensity (at $366 \mathrm{~m} \mu$ ) was varied between 2650 and $4190 \mathrm{ergs} /\left(\mathrm{sec} \mathrm{cm}^{2}\right)$ and found to have no influence on the quantum yield. The temperature coefficient was slightly $>1\left(1.02\right.$ and 1.04 between $30^{\circ} \mathrm{C}$ and $40^{\circ} \mathrm{C}$, in 0.067 and $0.0335 \mathrm{M} \mathrm{UO}_{2} \mathrm{SO}_{4}$, respectively). 
Table 4.21

QUANTUM YIELD OF URANYL-SENSITIZED OXIDATION OF CHLORACETIC ACID BY PERMANGANATE

(After Ghosh and Ray, 1936a)

\begin{tabular}{|c|c|c|c|c|}
\hline \multirow{2}{*}{$\begin{array}{c}{\left[\mathrm{UO}_{2} \mathrm{SO}_{4}\right]} \\
\mathrm{M}\end{array}$} & \multirow{2}{*}{$\begin{array}{l}\text { No. of quanta } \\
\text { absorbed per } \\
\text { sec per } \\
\mathrm{cm}^{2} \times 10^{-13}\end{array}$} & \multicolumn{2}{|c|}{$\frac{\mathrm{d}\left[\mathrm{KMnO}_{4}\right]}{\mathrm{dt}} \times 10^{11}$} & \multirow{2}{*}{$\begin{array}{l}\text { Quantum yield } \\
\qquad \gamma\end{array}$} \\
\hline & & obs. & calc. & \\
\hline & \multicolumn{4}{|c|}{ Incident intensity $=1030 \mathrm{ergs} /\left(\mathrm{sec} \mathrm{cm}^{2}\right)$ at $\lambda=436 \mathrm{~m} \mu$} \\
\hline 0.0218 & 1.57 & 0.26 & 0.24 & 0.10 \\
\hline 0.0436 & 3.0 & 0.38 & 0.40 & 0.077 \\
\hline 0.0653 & 4.3 & $\begin{array}{l}0.47 \\
k=4.1\end{array}$ & $\begin{array}{r}0.49 \\
\times \quad 10^{-3}\end{array}$ & 0.067 \\
\hline 0.0871 & 5.5 & 0.57 & 0.57 & 0.063 \\
\hline 0.1511 & 8.3 & 0.68 & 0.65 & 0.05 \\
\hline 0.2267 & 11.9 & 0.70 & 0.70 & 0.036 \\
\hline & \multicolumn{3}{|c|}{ Incident intensity $=3360 \mathrm{ergs} /(\mathrm{sec}$} & $\left.\mathrm{cm}^{2}\right)$ at $\lambda=336 \mathrm{~m} \mu$ \\
\hline 0.0218 & 5.3 & 1.02 & 0.94 & 0.12 \\
\hline 0.0436 & 10 & 1.47 & 1.50 & 0.09 \\
\hline 0.0653 & 14 & $\begin{array}{l}1.89 \\
k_{0}=3.9\end{array}$ & $\begin{array}{c}1.88 \\
\times 10^{-3}\end{array}$ & 0.082 \\
\hline 0.0871 & 18 & 2.05 & 2.12 & 0.07 \\
\hline 0.1511 & 28 & 2.29 & 2.40 & 0.05 \\
\hline 0.2267 & 36 & 2.45 & 2.45 & 0.042 \\
\hline
\end{tabular}

As a probable mechanism of the sensitized reaction, Ghosh and Ray suggested - in agreement with the concepts used elsewhere in this chapter primary photoxidation of chloracetic acid by excited uranyl ions, followed by re-oxidation of reduced uranyl [in the U(IV) or U(V) state] by permanganate. To account for the decrease of the quantum yield at higher uranyl concentrations, a de-activation reaction between $\left(\mathrm{UO}_{2}^{++}\right)^{* *}$ and $\mathrm{UO}_{2}^{++}$was assumed. The set of reactions

$$
\begin{aligned}
& \mathrm{UO}_{2}^{+}+\mathrm{h \nu} \underset{\mathrm{k}_{2}}{\stackrel{\mathrm{k}^{*} \mathrm{I}}{\longrightarrow}}\left(\mathrm{UO}_{2}^{++}\right)^{*} \\
& \mathrm{UO}_{2}^{+*}+\mathrm{UO}_{2} \stackrel{\mathrm{k}_{3}}{\longrightarrow}-\mathrm{UO}_{2} \\
& \mathrm{UO}_{2}^{+*}+\mathrm{CH}_{2} \mathrm{Cl} \cdot \mathrm{COOH} \stackrel{\mathrm{k}_{4}}{\longrightarrow} \mathrm{U}(\mathrm{V})+\text { oxidation products } \\
& \mathrm{U}(\mathrm{V})+\mathrm{KMnO}_{4} \longrightarrow \mathrm{UO}_{2}^{++}+\text {reduction products }
\end{aligned}
$$

leads to the rate equation

$$
\frac{\mathrm{d}\left[\mathrm{KMnO}_{4}\right]}{\mathrm{dt}}=\frac{\mathrm{A}_{1} \mathrm{k}_{4}\left[\mathrm{CH}_{2} \mathrm{Cl} \cdot \mathrm{COOH}\right]}{\mathrm{Nh} \nu\left(\mathrm{k}_{2}+\mathrm{k}_{3}\right)\left[\mathrm{UO}_{2}^{+}\right]+\mathrm{k}_{4}\left[\mathrm{CH}_{2} \mathrm{Cl} \cdot \mathrm{COOH}\right]}
$$


where $1 / \mathrm{Nh} \nu$ is the number of einsteins in one erg of the light used ( $A_{1}$ was measured in ergs). From Vavilov's experiments on the self-quenching of uranyl fluorescence, the authors take $k_{3}=99 k_{2}$. If reactions $(77 b)$ and $(77 c)$ occur after the first, or, more generally, after the same number of collision, $k_{4} \simeq k_{3}$, and thus $k_{4}$ also $\simeq 99 k_{2}$. Transformation proves that the factor before $\left[\mathrm{UO}_{2}^{++}\right.$] must be equal to $\frac{\mathrm{k}_{4}}{\mathrm{k}_{2}+\mathrm{k}_{4} \text { [monochloracetic acid] }} \cdot$ With $k_{4} / k_{2}=99$ in $0.1 \mathrm{M}$ acid, the calculated value of this factor is 9.08 , in agreement with the empirical value. This indicates approximate validity of the assumption $\mathrm{k}_{4} \simeq \mathrm{k}_{3}$.

The explicit meaning of the empirical constant $k_{0}$ in (76) is $k_{0}=k_{4}[$ acid $] / N h \nu\left(k_{2}+k_{4}[\right.$ acid $\left.]\right)$.

3.2 Hydroxy and Thio Acids - Glycolic acid $\left(\mathrm{CH}_{2} \mathrm{OH} \cdot \mathrm{COOH}\right)$. The uranyl-sensitized decomposition of glycolic acid was first observed by Baur (1913). A mixture $0.3 \mathrm{M}$ in glycolic acid and $0.016 \mathrm{M}$ in $\mathrm{UO}_{2} \mathrm{SO}_{4}$ was illuminated for 15 hours with a quartz lamp. The uranyl salt was found to be reduced without gas evolution and glycolic acid oxidized to an aldehyde (possibly, glyoxalic acid, $\mathrm{CHO} \cdot \mathrm{COOH}$, or formaldehyde, $\mathrm{H}_{2} \mathrm{CO}$ ). When potassium glycolate was substituted for free acid, no U(IV) was formed, but the illuminated solution nevertheless gave the aldehyde reaction, indicating the formation of an aldehyde by sensitized decomposition of glycolate, e.g.,

$$
\mathrm{CH}_{2} \mathrm{OH} \cdot \mathrm{COOH} \frac{\mathrm{UO}_{2}^{++}}{\text {light }} \mathrm{HCOOH}+\mathrm{H}_{2} \mathrm{CO}
$$

In a second paper (1919) Baur interpreted the formation of formaldehyde from glycolic acid and the effect of mercuric chloride on this reaction by an "electrochemical" scheme:

$$
\left(\mathrm{U}^{+6}\right) \pm \pm\left\{\begin{array}{l}
+\mathrm{CH}_{2} \mathrm{OH} \cdot \mathrm{COO}^{-}+\mathrm{OH}^{-} \longrightarrow 2 \mathrm{HgCl}_{2}+2 \mathrm{Cl}^{-} \\
+2 \mathrm{COCl}_{2} \longrightarrow \mathrm{H}_{2} \mathrm{O}+\mathrm{H}_{2} \mathrm{CO}
\end{array}\right\}+\begin{aligned}
& \mathrm{U}^{+6} \\
& (80)
\end{aligned}
$$

This simultaneous reaction of a light-excited ion with an oxidant and a reductant can, of course, be replaced by two successive reactions, such as:

$$
\begin{aligned}
& \mathrm{U}^{+6 *}+\mathrm{CH}_{2} \mathrm{OH} \cdot \mathrm{COO}^{-}+\mathrm{OH}^{-} \longrightarrow \mathrm{U}^{+4}+\mathrm{CO}_{2}+\mathrm{H}_{2} \mathrm{O}+\mathrm{H}_{2} \mathrm{CO} \\
& \mathrm{U}^{+4}+2 \mathrm{HgCl}_{2} \longrightarrow 2 \mathrm{HgCl}+\mathrm{U}^{+6}+2 \mathrm{Cl}^{-}
\end{aligned}
$$

Courtois (1923) observed that, in sunlight, $\mathrm{UO}_{2}^{++}$ions reacted with glycolic acid, in the presence as well as in absence of air, with reduction to U(IV) compounds and formation of a precipitate which first was yellow and then 


\section{1}

became green. The illuminated solution smelled of formaldehyde; gas (carbon dioxide) was evolved. Courtois suggested that the green precipitate was uranous formate. The reactions of uranyl ions and glycolic acid can thus be tentatively summarized as follows:

$4 \mathrm{CH}_{2} \mathrm{OH} \cdot \mathrm{COOH} \stackrel{\mathrm{UO}_{2}^{+*}}{\longrightarrow} 4 \mathrm{H}_{2} \mathrm{CO}+4 \mathrm{HCOOH}$ (sensitized decomposition)
$\begin{aligned} & \mathrm{CH}_{2} \mathrm{OH} \cdot \mathrm{COOH}+\mathrm{UO}_{2}^{+*} \longrightarrow \\ & \mathrm{H}_{2} \mathrm{CO}+\mathrm{U}^{+4}+\mathrm{CO}_{2}+2 \mathrm{OH}^{-} \\ & \text {(oxidoreduction) }\end{aligned}$
$\begin{aligned} & \text { (82 } \mathrm{HCOOH}+\mathrm{U}^{+4} \longrightarrow \mathrm{U}(\mathrm{COOH})_{4}+4 \mathrm{H}^{+} \text {(precipitation) } \\ & 5 \mathrm{CH}_{2} \mathrm{OH} \cdot \mathrm{COOH}+\mathrm{UO}_{2}^{++*} \stackrel{\text { light }}{\longrightarrow} 5 \mathrm{H}_{2} \mathrm{CO}+\mathrm{CO}_{2}+\mathrm{U}(\mathrm{COOH})_{4}+2 \mathrm{H}_{2} \mathrm{O}+2 \mathrm{H}^{+}\end{aligned}$

It is noteworthy that no simple sensitized decarboxylation:

$\mathrm{CH}_{2} \mathrm{OH} \cdot \mathrm{COOH} \frac{\mathrm{UO}_{2}^{++}}{\text {light }} \mathrm{CH}_{3} \mathrm{OH}+\mathrm{CO}_{2}$

(similar to those observed in the case of acetic, oxalic, and other nonsubstituted acids) has been reported; it looks as if the hydroxyl group is too easily oxidizable to survive the oxidation of the carboxyl group to free carbon dioxide without being itself oxidized to a carbonyl group.

More recently, Baur (1936) gave Fig. 4.14 for the time course of decomposition of glycolic acid and glycolate by uranyl sulfate in the presence of mercuric chloride as "depolarizer."

Determination of the amounts of $\mathrm{Hg}_{2} \mathrm{Cl}_{2}$ and $\mathrm{H}_{2} \mathrm{CO}$ formed showed exact equivalency of the two products, indicating that in this case photochemical oxidation-reduction proceeded practically without interference by the sensitized decomposition.

It will be noted that the rate of reaction was much higher in sodium glycolate than in glycolic acid, indicating that the glycolate ion (rather than the glycolic acid molecule) may be the main reacting species.

Observations on the decomposition of thioglycolic acid by light in the presence of uranyl ions were made by Krepelka and Résö (1938); $\mathrm{SO}_{2}$ and $\mathrm{H}_{2} \mathrm{~S}$ were found to be liberated in this reaction.

Lactic acid $\left(\mathrm{CH}_{3} \cdot \mathrm{CHOH} \cdot \mathrm{COOH}\right)-$ The photodecomposition of lactic acid, sensitized by uranyl ions, was first noted by Bacon (1907). He said that it gives carbon dioxide and acetaldehyde; and that the products may also include formic acid $\left(\mathrm{CH}_{3} \cdot \mathrm{CHOH} \cdot \mathrm{COOH} \longrightarrow \mathrm{CH}_{3} \mathrm{CHO}+\mathrm{HCOOH}\right)$. 
82

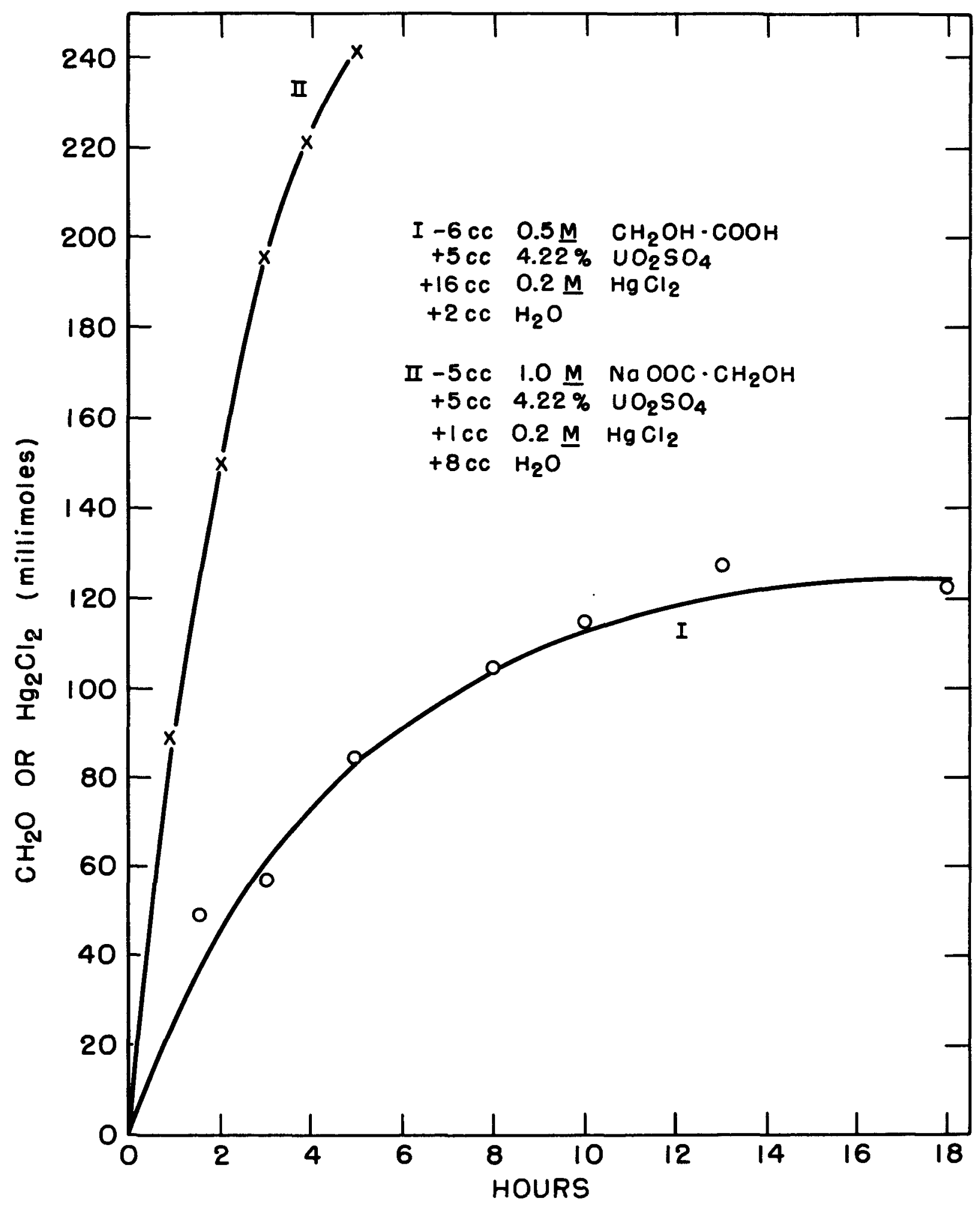

Fig. 4.14. Decomposition of glycolic acid by uranyl sulfate in light (Bour, 1936). 


\section{3}

Neuberg (1.908) also noted that acetaldehyde is formed in $\mathrm{UO}_{2}^{++}$solutions containing d, 1-lactic acid upon exposure to sunlight. Neuberg and Peterson (1914) found that 17 days of exposure to sunlight changed the reaction of a solution $1 \%$ in sodium lactate and $0.1 \%$ in uranyl sulfate from alkaline $\left(0.2 \mathrm{cc} 0.1 \mathrm{~N} \mathrm{H}_{2} \mathrm{SO}_{4}\right.$ required for neutralization of $5 \mathrm{cc}$ ) to acid $(1.2 \mathrm{cc} 0.1 \mathrm{~N}$ $\mathrm{NaOH}$ required for the same purpose).

Courtois $(1914,1923)$ stated that cold, saturated aqueous solutions of uranyl lactate are stable in darkness and diffuse light, but decompose in direct sunlight. If air is present, the solution becomes first green, then brownish, but no precipitate appears until after 4-5 days, when a violet hydroxide is formed, and the solution becomes almost colorless. In the absence of air the solution also becomes green, and some gas bubbles ap pear; basic U(IV) salt is precipitated in about 10 days. The gas evolution is small and consists of carbon dioxide, an aldehyde odor appears, and formic acid can be identified in the solution.

Bolin (1914) investigated the relation of oxidation-reduction to sensitized decomposition in the lactic acid photolysis by uranyl sulfate in light. To prevent the precipitation of basic uranium salts (carbonate, lactate, etc.) or U(VI) hydroxides, acid solutions were used (the natural acidity of uranyl sulfate was sufficient).

The aldehyde produced was titrated with sulfite and iodine, U(IV) with permanganate (after removal of lactic acid).

The rate of formation of U(IV) and aldehyde was found to be the same at $20^{\circ} \mathrm{C}$ and $30^{\circ} \mathrm{C}\left(0.87 \mathrm{~N}\right.$ lactic acid, $1.6 \mathrm{~g} \mathrm{UO} \mathrm{U}^{++}$sulfate, $60 \mathrm{~min} \mathrm{ex}-$ posure to carbon arc light).

No direct photodecomposition of lactic acid occurred in arc light in the absence of uranyl ions, and no thermal decomposition could be detected in the dark in 2 days in the presence of uranyl sulfate.

In solutions of free lactic acid, the quantity of U(IV) formed was 2-3 times larger than that of aldehyde. In sodium lactate solutions, on the other hand, the two products were formed in approximately equivalent quantities.

Fig. 4.15 shows dependence of the rate of decomposition on [ $\mathrm{UO}_{2}^{++}$] ( $\% \mathrm{UO}_{2} \mathrm{SO}_{4}$ in $0.87 \mathrm{~N}$ sodium lactate). The curve approaches saturation, at $>10 \%$ (complete absorption?).

The equivalency of $\triangle \mathrm{U}(\mathrm{IV})$ and $\triangle \mathrm{CH}_{3} \mathrm{CHO}$ indicates oxidation according to the equation

$$
\mathrm{CH}_{3} \cdot \mathrm{CHOH} \cdot \mathrm{COOH}+\mathrm{UO}_{2}^{++*}+2 \mathrm{H}^{+} \longrightarrow \mathrm{CH}_{3} \mathrm{CHO}+\mathrm{CO}_{2}+2 \mathrm{H}_{2} \mathrm{O}+\mathrm{U}^{+4}
$$




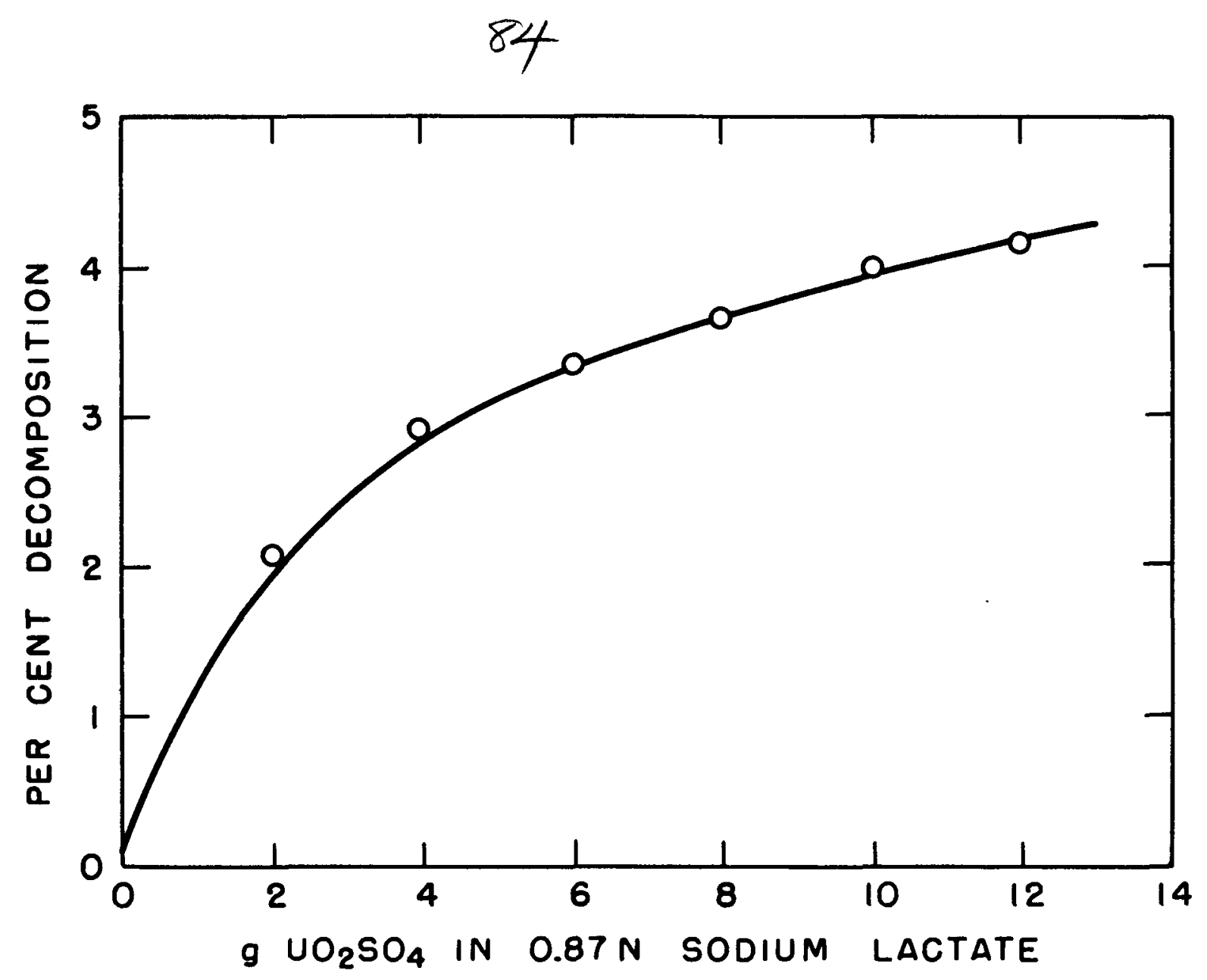

Fig. 4.15. Speed of decomposition of lactic acid by $\mathrm{UO}_{2} \mathrm{SO}_{4}$ in light in relation to $\left[\mathrm{UO}_{2}^{++}\right]$(ofter Bolin, 1914). 


\section{5}

As a check, the quantity of carbon dioxide also was determined and found to be about $5 \%$ in excess of that calculated from Eq. (84). In another experiment, in sunlight instead of arc light, the excess was $15 \%$.

The lactate concentration was without effect on the yield in the range 0.22 to $0.87 \mathrm{M}$.

The time course of the reaction (initial composition: $0.8 \mathrm{~g} \mathrm{UO}_{2} \mathrm{SO}_{4}$ in $40 \mathrm{cc} 0.87 \mathrm{~N}$ lactate) showed a gradual slowing down (at the end of 12 hours, to about $1 / 10$ of the initial rate). At that time about 0.8 mole lactic acid was decomposed for 1 mole $\mathrm{UO}_{2}^{++}$present. This result, too, indicates the practical absence of photocatalysis.

All these experiments were carried out in the absence of air. In the presence of oxygen, the $U(I V)$ is re-oxidized and the reaction is converted to sensitized autoxidation. The rate of the latter is approximately constant for 6 hours.

Müller (1926) measured the quantum yield of this reaction $(0.1 \mathrm{~N}$ $\mathrm{NaOH}$ neutralized lactic acid, $0.01 \mathrm{M} \mathrm{UO}_{2} \mathrm{SO}_{4}$ ) in a glass vessel, in the total light of a quartz mercury lamp, assuming $402.5 \mathrm{~m} \mu$ as average wave length. In $95 \mathrm{~min}, 4.47 \times 10^{19}$ quanta were absorbed and $4.24 \times 10^{19}$ acetaldehyde molecules were formed, indicating a quantum yield of $\gamma=0.95$. As a control, the measurement was repeated using an oxalate-uranyl sulfate mixture as actinometer; the comparison of the rate of the decomposition of the two systems (both in quartz vessels) led to a practical identity of the quantum yields. With Büchi's value (p. 48) of $\gamma \simeq 1.0$ for the uranyloxalate system, this appeared as confirmation of the above value of $\gamma$ for lactate, but we recall (cf. p.59) that subsequent investigations have given for the "actinometer" system a quantum yield of about 0.6 , rather than 1.0 .

Tartaric acid $(\mathrm{COOH} \cdot \mathrm{CHOH} \cdot \mathrm{CHOH} \cdot \mathrm{COOH})-$ Tartaric acid was first observed to decompose in light in the presence of uranium compounds by Seekamp (1894). He noted that a $5 \%$ solution of tartaric acid in which $1 \%$ "uranium oxide" had been dissolved evolves gas and becomes green upon exposure to light. After prolonged exposure (several months), aldehyde could be distilled from the illuminated solution; the residue had a characteristic smell and was found to contain malic and succinic acid and an undetermined $\mathrm{Cu}^{++}$reducing compound.

Fay (1896) also noted that when tartaric acid solution containing uranyl nitrate was exposed to sunlight, it turned green, and after some time a light-green salt precipitated out. He observed no gas evolution. The formation of the precipitate was strongly accelerated by heat; it formed most readily in an equimolar mixture of $\mathrm{UO}_{2}\left(\mathrm{NO}_{3}\right)_{2}$ and tartaric acid. Upon standing the green precipitate re-dissolved to an amber solution. An attempted analysis of the precipitate was inconclusive. 


\section{6}

Bacon (1907) said that carbon dioxide and pyruvic acid, $\mathrm{CH}_{3} \mathrm{COCOOH}$, are among the products of uranyl-sensitized photodecomposition of tartaric acid. The pyruvic acid was identified by the melting point of its phenylhydrazone.

Neuberg (1908) found that $d$-tartaric acid exposed to sunlight in the presence of uranyl ions gives glyoxalic acid and keto acids. The products reduced Fehling solution in the cold; they showed a very strong reaction with naphthoresorcin and had a mixed caramel and fruity odor.

Euler and Ryd (1913) noticed that the presence of uranyl ions accelerates the decomposition of tartaric acid by ultraviolet light.

Neuberg and Peterson (1914) measured the change in the alkaline titer of solutions of the salts of organic acids upon exposure to sunlight. A solution of $0.1 \%$ uranyl sulfate, containing $1 \% \mathrm{Na}-\mathrm{K}$-tartrate, showed, after 17 days exposure, a marked increase in alkalinity, probably because of the loss of $\mathrm{CO}_{2}\left(1.4 \mathrm{cc} 0.1 \mathrm{~N} \mathrm{H}_{2} \mathrm{SO}_{4}\right.$ were required to neutralize $5 \mathrm{cc}$ of the solution after exposure, in contrast to $0.05 \mathrm{cc}$ before exposure; a sample left in the dark showed no appreciable change).

Courtois $(1914,1923)$ observed that the photochemical decomposition of tartrate by uranyl ions proceeds differently in the presence and in the absence of air. Without air, the solution became troubled, acquired a yellowish-brown color and formed, in 3-4 days, a yellowish precipitate of basic salt; later, gas evolution began. In air, the basic salt transformed itself into a hydroxide, which was at first brown and then became violet $\left(\mathrm{U}_{3} \mathrm{O}_{8}\right.$ hydrate $)$.

According to Hatt (1918), acid solutions containing uranyl sulfate and tartaric acid become brown and develop gas in light; alkaline solutions also show reduction of $\mathrm{UO}_{2}^{++}$to $\mathrm{U}(\mathrm{IV})$ (color change and precipitation!), but liberate no gas.

Hakomori (1927), who first found spectroscopic evidence for the formation of a uranyl tartrate complex, also noted that uranyl tartrate solutions are light-sensitive, darkening in color (apparently due to the formation of a colloid) and forming a white precipitate in light; the presence of U(IV) could be proved in the product. Complexing was also indicated by an increase of the specific rotatory power of a sodium tartrate solution (e.g., from $30^{\circ}$ to $170^{\circ}$ ) by the addition of uranium sulfate. Rotatory power disappeared completely after prolonged exposure to light.

The uranyl tartrate complexing equilibrium was measured spectroscopically by Ghosh and Mitter (cf., Chap. 2). It was again confirmed by Rama Char (1942), who measured the optical rotation in uranyl nitratetartaric acid mixtures. Addition of uranyl nitrate hexahydrate to a solution 
of $d$ - or 1-tartaric acid enhanced the rotation; the maximum effect was reached at [ $\left.\mathrm{UO}_{2}^{+}\right]:$[tartaric acid] $=4$. Assuming that the observed average rotation, $R$, is additive:

$$
\bar{R}=R_{\text {complex }}[\text { complex }]+R_{\text {tartrate }}[\text { tartaric acid }]
$$

the complexing constant $K$

$$
K=\frac{[\text { complex }]}{\left[\text { UOt }^{+}\right][\text {free acid }]}
$$

can be calculated, e.g., from a set of $\bar{R}$ measurements at constant total tartrate concentration ([tartaric acid $]_{0}=[$ tartaric nitrate $]+[$ complex $]$ ). An average value of $K=10.2$ (individual values from 9.5 to 11.6 ) was derived from such measurements. This is not too different from $K=20$, the spectroscopic value of Ghosh and Mitter (Table 2.7). (It must be kept in mind that $\mathrm{K}$ must depend on ionic strength, as well as on $\mathrm{pH}-$ the latter because of ionic dissociation equilibria of the acid and of the complex.)

In light, Rama Char found $\mathrm{UO}_{2}^{++}$to be reduced to $\mathrm{U}^{+4}$ and tartaric acid to be oxidized. He observed this reaction by $U(I V)$ determination with permanganate. At all the wave lengths studied $(313,406$, and $436 \mathrm{~m} \mu$ ), the rate was found to obey the equation

$$
+\frac{\mathrm{d}[\mathrm{U}(\mathrm{IV})]}{\mathrm{dt}}=20.52 \times 10^{-8} \times \frac{\mathrm{I}_{\mathrm{a}}[\text { tartrate }]_{0}}{0.2+[\text { tartrate }]_{0}}
$$

where $I_{a}$ is absorbed energy in ergs. The conditions were:

$$
\left[\mathrm{UO}_{2}^{+}\right]_{0}: 0.125-0.500 ;\left[\text { tartaric acid] }: 0.063-0.500 ; \mathrm{t}=28^{\circ} \mathrm{C} ; \mathrm{pH} \simeq 1\right.
$$

No difference was found between $\mathbf{r}-, \mathrm{l}-$ and $\mathrm{d}$-acids; there was no effect of circular polarization (d or 1) of the light.

The quantum efficiencies, $\gamma$, are shown in Table 4.22. The form of Eq. (86) indicates a simple competition between monomolecular deactivation of excited $\mathrm{UO}_{2}^{++}$ions (or, rather $\mathrm{UO}_{2}^{++} \mathrm{A}^{-}$complexes) and an oxidation-reduction reaction, with a ratio of 0.2 between the two rate constants. The absolute quantum yields found (up to $\sim 5$ ) seem to indicate a chain reaction (it is assumed that complexing is complete which should not be correct for the lower $A$ values, and that the reaction requires the encounter of an excited complex with a second acid molecule). The effect of wave length (decreasing yield with increasing wave length) is in the direction explicable by the "cage effect" (greater probability of escape from primary back reaction within the "cage" when the excess energy of the photochemical products is higher). 


\section{8}

Table 4.22

QUANTUM YIELD OF THE URANYL-TARTRATE REACTION

(After Rama Char, 1942)

$28^{\circ} \mathrm{C}, \mathrm{pH}=0.9$ to 1.2

\begin{tabular}{|c|l||c|c|c|}
\hline \multicolumn{2}{|c||}{ Conc., moles/liter } & \multicolumn{3}{c|}{$\gamma$ of U(IV) formation at $\lambda$} \\
\hline$[$ tartaric acid] & {$\left[\mathrm{UO}_{2}^{++}\right]$} & $313 \mathrm{~m} \mu$ & $406 \mathrm{~m} \mu$ & $436 \mathrm{~m} \mu$ \\
\hline 0.50 & 0.50 & 4.7 & 3.6 & 3.4 \\
0.25 & 0.25 & 3.6 & 2.8 & 2.6 \\
0.125 & 0.125 & 2.5 & 2.1 & 1.8 \\
\hline
\end{tabular}

Malic Acid ( $\left.\mathrm{COOH} \cdot \mathrm{CH}_{2} \cdot \mathrm{CHOH} \cdot \mathrm{COOH}\right)$. Bacon (1907) said that uranyl-induced photodecomposition of malic acid yields carbon dioxide and acetaldehyde, together with unknown products; he suggested that the first reaction step is the decarboxylation of malic acid to lactic acid, followed by the decomposition of the latter into acetaldehyde and (perhaps) formic acid.

Neuberg (1908) observed that, in sunlight, a mixture of uranyl sulfate and malic acid gave a product which reduced Fehling's solution in the cold. The reaction with naphthoresorcin was first positive, later negative. Phenylhydrazine gave a small amount of osazone of hydroxy pyruvic acid (or of the half-aldehyde of mesoxalic acid).

The same reaction was also observed by Neuberg and Peterson (1914). A solution of $0.1 \%$ uranyl sulfate and $1 \%$ potassium lactate, which required for its neutralization $0.4 \mathrm{cc} 0.1 \mathrm{~N} \mathrm{H}_{2} \mathrm{SO}_{4}$ per $5 \mathrm{cc}$, became more alkaline after eight days exposure to sun ( $\left.1.9 \mathrm{cc}_{2} \mathrm{SO}_{4}\right)$ and after 17 days required as much as $2.3 \mathrm{cc}_{2} \mathrm{SO}_{4}\left(\mathrm{CO}_{2}\right.$ loss!). In the darkened control sample, the alkalinity was practically unchanged.

Citric acid $\left(\mathrm{COOH} \cdot \mathrm{CH}_{2} \cdot \mathrm{COH} \cdot \mathrm{COOH} \cdot \mathrm{CH}_{2} \mathrm{COOH}\right)$. Seekamp (1894) found that citric acid behaves in the presence of uranyl similarly to tartaric acid; gas evolution sets in in sunlight, the solution becomes green and acquires a peculiar odor. After several months, acetone could be obtained by distillation; the following decomposition equation

$$
\mathrm{C}_{6} \mathrm{H}_{8} \mathrm{O}_{7} \frac{\left[\overline{\mathrm{UO}}{ }_{2}^{+}\right]}{\text {light }} \quad \mathrm{CH}_{3} \mathrm{COCH}_{3}+\mathrm{HOOC} \cdot \mathrm{COOH}+\mathrm{CO}_{2}
$$

was tentatively suggested. 
Neuberg (1908) noted that citric acid solutions containing uranyl ions produce, in sunlight, a substance which reduces Fehling's solution and acquire a fruity odor. Neuberg and Peterson (1914) found that 17 days of exposure to sunlight increased somewhat the alkalinity of a solution, $0.1 \%$ in potassium citrate and $0.01 \%$ in uranyl sulfate, so that $2.2 \mathrm{cc} 0.1 \mathrm{~N} \mathrm{H}_{2} \mathrm{SO}_{4}$ were required for neutralization of $5 \mathrm{cc}$ instead of the initial $1.3 \mathrm{cc}$.

Courtois $(1914,1923)$ found that cold, saturated $20 \%$ solutions of uranyl citrate are somewhat unstable even in the dark, giving, after some time, a yellow precipitate of basic salt. In sunlight, one observes first (in 2-3 days) a yellow precipitate; then the solution becomes brown, and the precipitate slowly transforms itself into violet $\mathrm{U}_{3} \mathrm{O}_{8}$ hydrate. After one day in the sun, considerable amounts of carbonic acid begin to be evolved.

Hatt (1918) noted that acid solutions of uranyl sulfate and citric acid become brown in light and develop a gas which is probably $\mathrm{CO}_{2}$ (since no gas is evolved in alkaline solution). Concentrated alkaline solutions of UOt ${ }^{+}$ and citric acid cannot be obtained because of insolubility of complex salts; dilute, almost colorless alkaline solutions are stable in the dark but form a white precipitate in light.

3.3 Keto Acids. Glyoxylic acid (CHO . COOH) - Baur (1936) observed the photodecomposition of glyoxylic acid sensitized by uranyl sulfate with mercuric chloride as "depolarizer" (ultimate oxidant) in sunlight and in incandescent light. He measured the progress of reaction for 10 hours in a system consisting of $10 \mathrm{cc} 1.6 \% \mathrm{Na}$ glyoxylate, $5 \mathrm{cc} 4.22 \% \mathrm{UO}_{2} \mathrm{SO}_{4}$, $8 \mathrm{cc} 0.2 \mathrm{M} \mathrm{HgCl}_{2}$, and $5 \mathrm{cc}$ water, by $\mathrm{Hg}_{2} \mathrm{Cl}_{2}$ determinations. The reaction showed initial inhibition, which could be represented by the equation $\Delta\left[\mathrm{Hg}_{2} \mathrm{Cl}_{2}\right]=\mathrm{A}\left(1-\mathrm{e}^{-\mathrm{bt}}\right)$, where $\mathrm{t}$ is time and $\mathrm{A}(=108)$ and $\mathrm{b}(=0.425)$ are constants. The gas evolved was pure carbon dioxide, so that the net reaction appeared to be

$$
\mathrm{CHO} \cdot \mathrm{COOH}+4 \mathrm{HgCl}_{2}+\mathrm{H}_{2} \mathrm{O} \frac{\mathrm{UO}_{2} \mathrm{SO}_{4}}{\text { light }} 2 \mathrm{CO}_{2}+\mathrm{HCl}+2 \mathrm{Hg}_{2} \mathrm{Cl}_{2}
$$

No formaldehyde was found among the products.

Pyruvic acid $\left(\mathrm{CH}_{3} \mathrm{COCOOH}\right)$. Bacon (1907) observed that solutions of uranyl acetate containing pyruvic acid decompose in light, evolving carbon dioxide and forming $n$-butyric and isobutyric acid.

3.4 Aromatic Acids - Very little work has been done on uranyl sensitized photodecomposition of aromatic acids, with the exception of mandelic acid. 


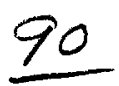

Benzoic acid, $\mathrm{C}_{6} \mathrm{H}_{5} \mathrm{COOH}$, and Salicylic acid, $\mathrm{C}_{6} \mathrm{H}_{4}(\mathrm{OH}) \mathrm{COOH}$. Courtois (1923) found that uranyl benzoate solutions are not decomposed by exposure to sunlight. A yellow basic salt precipitate is formed very slowly, both in light and in the dark.

Uranyl salicylate solutions, according to Courtois (1923), also are stable in sunlight. It will be recalled that, according to Krepelka and Résö (1938), para-brombenzoic acid, too, is more stable against uranyl-sensitized photoxidation than the corresponding aliphatic acids.

Courtois found that uranyl benzoate can be decomposed by light if it is dissolved in ethanol. A violet precipitate of hydrated $\mathrm{U}_{3} \mathrm{O}_{8}$ is formed; it becomes yellow (i.e., is converted to $\mathrm{UO}_{3} \cdot 2 \mathrm{H}_{2} \mathrm{O}$ ) by washing with cold water. Uranyl salicylate, however, proved to be stable in sunlight even in alcoholic solution.

Mandelic acid (phenylglycolic acid) $\mathrm{C}_{6} \mathrm{H}_{5} \cdot \mathrm{CHOH} \cdot \mathrm{COOH}$. Bacon (1907) found that mandelic acid decomposed rapidly when exposed to sunlight in the presence of uranyl acetate. Benzaldehyde and benzoic acid were produced in considerable amounts, the latter perhaps as a secondary product of photochemical oxidation of the former.

Ghosh and co-workers $(1935,1936)$ investigated the photoxidation of mandelic acid sensitized by uranyl sulfate in the presence of methylene blue (MB) or bromine as ultimate oxidant.

Ghosh, Narayanmurti and Roy (1935) used methylene blue. It was added to a mixture of uranyl nitrate and mandelic acid. Upon exposure of the mixture, without methylene blue, to monochromatic mercury arc light $(\lambda 436,366,313+334$, or $254 \mathrm{~m} \mu$, isolated by filters), uranous salt was formed and benzaldehyde odor appeared. Addition of methylene blue (MB) led to re-oxidation of U(IV) to U(VI), leaving sensitized oxidation of mandelic acid by $M B$ as the net result of irradiation. The bleaching of $M B$ could be followed spectrophotometrically at $540 \mathrm{~m} \mu$ without marked interference by uranyl.

No change of $[\mathrm{MB}]$ was observed upon irradiation of uranyl nitrate $(0.1 \mathrm{M})+\mathrm{MB}\left(4 \times 10^{-4} \mathrm{M}\right)$ or mandelic acid $(0.1 \mathrm{M})+\mathrm{MB}\left(4 \times 10^{-4} \mathrm{M}\right)$ or upon mixing all three ingredients in the dark. Upon illumination of the ternary system, no reaction was observed in six hours at $546 \mathrm{~m} \mu$ (where MB alone absorbs); at the other wavelengths, the bleaching proceeded rapidly after an initial induction period. The rate of disappearance of MB continued increasing for several hours. This was found to be due not to autocatalytic effect of the product, benzaldehyde, but probably to the presence of oxygen; removal of oxygen made the rate uniform and shortened (but not entirely suppressed) the induction period. 
91

The observed extinction coefficients are shown in Table 4.23.

Table 4.23

EXTINCTION COEFFICIENT OF UO ${ }_{2}^{++}+$MANDELIC ACID MIXTURES (After Ghosh et al., 1935)

\begin{tabular}{|c|c|c|c|c|}
\hline$\lambda(\mathrm{m} \mu)$ & 436 & 365 & $313+334$ & 254 \\
\hline$\epsilon^{(*)} \mathrm{UO}_{2}^{++}$nitrate : & 6.5 & 6.6 & & high \\
\hline $\begin{array}{l}\text { (same }+ \text { excess } \\
\text { mandelic acid): }\end{array}$ & 15 & 20 & 50 & 1200 \\
\hline$\epsilon_{\mathrm{MB}}:$ & $\begin{array}{l}\text { very } \\
\text { low }\end{array}$ & 2500 & 9,000 & 13,000 \\
\hline
\end{tabular}

(*) natural, not decadic extinction coefficients; whether or not these values, similarly and those of Ghosh and Mitter, require the correction noted is not clear.

In the calculations of the light absorbed by uranyl ions, the higher values found in the presence of excess mandelic acid were used; these values presumably correspond to complete complexing. The kinetic mechanism was discussed as if no complexing occurred.

The constancy of the rate with time $\left(\mathrm{d}[\mathrm{MB}] / \mathrm{dt}=0.127 \times 10^{-5}\right.$ in the first 44 minute period, with $[\mathrm{MB}]_{0}=37 \times 10^{-5} \mathrm{M} ; \mathrm{d}[\mathrm{MB}] / \mathrm{dt}=0.135 \times 10^{-5}$ during the third 45 minutes with $[\mathrm{MB}]_{0}=27 \times 10^{-5}$ ) was taken as implying that the absorption (at $365 \mathrm{~m} \mu$ ) was the same for $\mathrm{MB}$ and the leuco base (so that the amount of light apportioned to uranyl remains unchanged by the bleaching of the $\mathrm{MB}$ ), a conclusion which disagrees with the actual relationships (cf. Epstein, Karush and Rabinowitch, 1941).

The rate was found to be independent of acidity (addition of $0.1 \mathrm{~N} \mathrm{HNO}_{3}$ had no effect). The effect of mandelic acid concentration was therefore not a $\mathrm{pH}$ effect. The reciprocal rate constant was a linear function of reciprocal acid concentration ( $F$ ig. 4.16). The rate was proportional to light intensity. Its dependence on uranyl nitrate concentration could be expressed by the equation

$$
\frac{\mathrm{d}[\mathrm{MB}]}{\mathrm{dt}}=\frac{\mathrm{k}_{0} \mathrm{I}_{\mathrm{abs}}}{\mathrm{l}+17\left[\mathrm{UO}_{2}^{++}\right]}
$$

with $k_{0}$ values of $\sim 4.0 \times 10^{-3}$ at 436 and $366 \mathrm{~m} \mu, 7.6 \times 10^{-3}$ at $334+313 \mathrm{~m} \mu$, and $2.36 \times 10^{-3}$ at $254 \mathrm{~m} \mu$. 
92

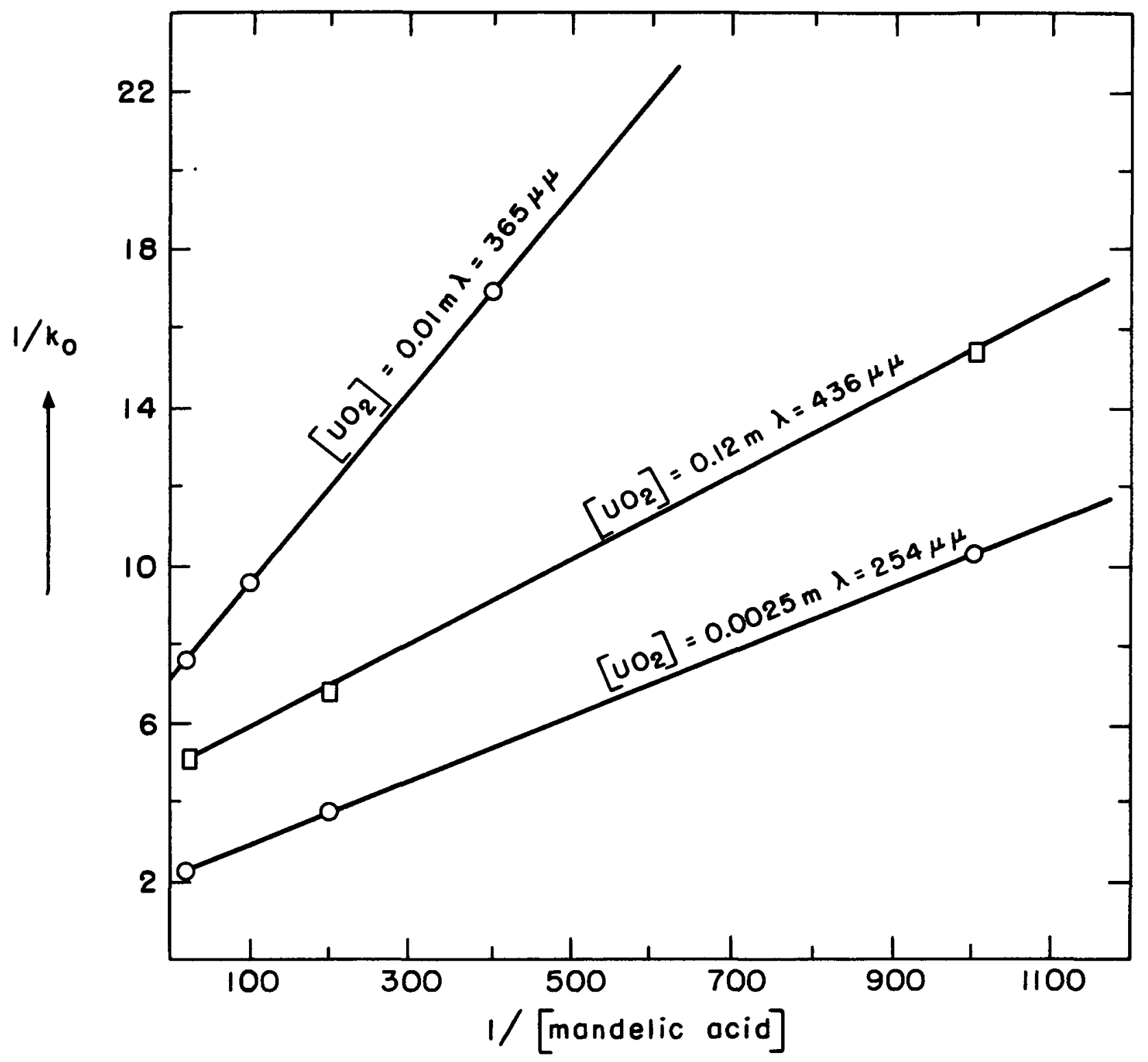

Fig. 4.16. Reciprocal rate constant of bleaching of methylene blue in mixture with uranyl salt and mandelic acid, as function of reciprocal concentration of mandelic acid (after Gnosh et al., 1935). 


\section{3}

All these results were explained in terms of the following reaction sequence:

$$
\begin{aligned}
& \mathrm{h \nu}+\mathrm{UO}_{2}^{++} \frac{\mathrm{k}_{1}}{\mathrm{k}_{2}} \mathrm{UO}_{2}^{++^{*}} \\
& \mathrm{UO}_{2}^{++^{*}}+\mathrm{UO}_{2}^{++} \stackrel{\mathrm{k}_{3}}{\longrightarrow} 2 \mathrm{UO}_{2}^{++} \text {(self-quenching) } \\
& \mathrm{UO}_{2}^{++^{*}}+\text { mandelic acid } \stackrel{\mathrm{k}_{4}}{\longrightarrow} \mathrm{U}(\mathrm{IV})+\text { benzaldehyde } \\
& \mathrm{U}(\mathrm{IV})+\mathrm{MB} \stackrel{\mathrm{k}_{5}}{\longrightarrow} \mathrm{UO}_{2}^{++}+\text {leucobase }
\end{aligned}
$$

This mechanism, which neglects complexing, leads to a rate equation

$$
\frac{\mathrm{d}[\mathrm{MB}]}{\mathrm{dt}}=\frac{\mathrm{A}_{\mathrm{UO}}^{+}+}{\mathrm{Nh} \nu} \frac{\mathrm{k}_{4}[\text { mandelic acid }]}{\mathrm{k}_{2}+\mathrm{k}_{3}\left[\mathrm{UO}_{2}^{++}\right]+\mathrm{k}_{4}[\text { mandelic acid }]}
$$

where $\mathrm{AUO}_{2}^{++}$is the light energy absorbed by $\mathrm{UO}_{2}^{++}$. This equation agrees with the above-given empirical relationships between the rate and the concentrations of 'mandelic acid and uranyl ions.

Fluorescence measurements give for the self-quenching (Vavilov's data) $k_{3} / k_{2}=99$. The values of $k_{4}$ and $k_{3}$ can be assumed to be equal (both reactions may occur by first encounter, cf. above) without contradicting the empirical value of the constant in Eq. (91).

The quantum yield, extrapolated to excess mandelic acid and high concentration of uranyl ions, appears to approach 1 at 436,366 , and $254 \mathrm{~m} \mu$, where the equation $\frac{\mathrm{d}[\mathrm{MB}]}{\mathrm{dt}}\left(1+17\left[\mathrm{UO}_{2}^{++}\right]\right)=\mathrm{A}_{\mathrm{UO}_{2}^{++}}+\mathrm{Nh} \nu$ is obeyed within $\pm 15 \%$, but to be much higher than 1 at $334+313 \mathrm{~m} \mu$.

A similar investigation was made by Ghosh and Ray (1936b) with bromine as ultimate oxidant; the advantage of the latter as compared to methylene blue is the absence of absorption $<300 \mathrm{~m} \mu$, so that experiments at 256 and $313 \mathrm{~m} \mu$ can be made with practically all absorption accounted for by the uranyl salt. The rate of reduction was found to be independent of $\left[\mathrm{Br}_{2}\right]$ between $\left[\mathrm{Br}_{2}\right]_{0}=0.08$ and $0.16 \mathrm{M}$ (at [mandelic acid] $=\left[\mathrm{UO}_{2}^{++}\right]=0.02 \mathrm{M}$ ). The inverse rate was a linear function of inverse mandelic acid concentration. It appeared to be proportional to the square root of light intensity (comparison of rates at 829 and $1444 \mathrm{ergs} /\left(\mathrm{sec} . \mathrm{cm}^{2}\right)$ at $\left[\overline{\mathrm{UO}_{2}^{++}}\right]=0.02$ and $\left.0.0566 \mathrm{M}\right)$. The rate was compared to light absorption by $\mathrm{UO}_{2}^{++}+$mandelic acid, using a value of $\epsilon=50$ (Ghosh and Mitter, Table 2.8). Between [ $\left.\mathrm{UO}_{2}^{++}\right]=0.01$ and $0.1 \mathrm{M}$, at $I_{0}=829 \mathrm{ergs} /\left(\mathrm{sec} . \mathrm{cm}^{2}\right)$, the rate was found to be proportional to the square root of light energy absorbed by uranyl ions. The quantum yield appeared very high; e.g., at $\left[\mathrm{Br}_{2}\right]_{0}=0.1263 \mathrm{M},\left[\mathrm{UO}_{2}^{++}\right]=0.01 \mathrm{M}$, [mandelic 


$$
94
$$

acid $]=0.0614 \mathrm{M}, \mathrm{AUO}_{2}^{++}=183.4 \mathrm{ergs} /\left(\mathrm{sec} . \mathrm{cm}^{2}\right)$, and $\lambda=313 \mathrm{~m} \mu$, the average yield in $120 \mathrm{~min}$ was about 32 .

The mechanism suggested to explain these results was based on a chain reaction initiated by $\mathrm{Br}$ atoms:

$$
\begin{array}{lr}
\mathrm{UO}_{2}^{++*}+\mathrm{Br}_{2} \stackrel{\mathrm{k}_{1}}{\longrightarrow} \mathrm{UO}_{2}^{++}+\mathrm{Br}+\mathrm{Br} & (92 \mathrm{a}) \\
\mathrm{Br}+\mathrm{Br} \longrightarrow \mathrm{Br}_{2} & (92 \mathrm{~b}) \\
\mathrm{Br}+\mathrm{Br}_{2} \longrightarrow \mathrm{Br}_{3} & (92 \mathrm{c}) \\
\mathrm{Br}_{3}+\text { mandelic acid } \longrightarrow \text { oxidation product }+2 \mathrm{HBr}+\mathrm{Br}(92 \mathrm{~d}) & (92 \mathrm{e}) \\
\mathrm{Br}_{3}{ }^{*} \longrightarrow \mathrm{Br}_{2}+\mathrm{Br} &
\end{array}
$$

giving the rate equation

$$
\frac{\mathrm{d}\left[\mathrm{Br}_{2}\right]}{\mathrm{dt}}=\left[\mathrm{Br}_{2}\right] \mathrm{k}_{3}\left(\frac{\mathrm{I}}{\mathrm{k}_{2}} \frac{\mathrm{A}_{\mathrm{UO}}++}{\mathrm{Nh} \nu}\right)^{\frac{1}{2}} \frac{\mathrm{k}_{4}[\text { mandelic acid }]}{k_{5}+\mathrm{k}_{4}[\text { mandelic acid }]}
$$

This equation indicates first order reaction in respect to $\left[\mathrm{Br}_{2}\right]$, proportionality to $\sqrt{\mathrm{I}}$, and linear relation between inverse rate and inverse mandelic acid concentration. 


\section{5}

\section{REFERENCES}

1842 L. L. Bonaparte, J. chim. med., 8.

1842 J。J. Ebelmen, Ann., 43: 286, 294.

1843 L。L. Bonaparte, J。prakt. Chem., 30: 308.

1860 Nièpce de Saint-Victor and L. Corvisart, Ann., 113: 112.

1862 W. Seekamp, Ann., 122: 113.

1865 W. Seekamp, Ann., 133: 253.

1866 C.Bolton, J. prakt. Chem., 99: 269.

1891 G. Wisbar, Ann., 262: 232.

1893 A.Bach, Compt. rend., 116:1147.

1894 A. Bach, Ber., 27: 341 .

1894 W.Seekamp, Ann., 278: 373.

1896 H. Fay, Am. Chem. J., 18: 265.

1898 A. Bach, Arch. phys。nat., [4] 5: 408.

1899 C.Dittrich, Z. physik. Chem., 29: 449-90。

1900 J. Aloy, Bull, soc. chim. Paris, [3] 23: 368.

1900 J. Zehenter, Montsh, 21: 237.

1901 J.Aloy, Ann. chim. et phys., [7] 24: 418.

1904 A. Bach, Ber., 37: 3985.

1904 H. Euler, Ber., 37: 3411-18.

1906 A。Bach, Ber., 39: 1673.

1907 R. F. Bacon, Philipp. J. Sci., 2: 129-37.

1908 E. Baur, Z. physik, Chem., 73: 683-710.

1908 R. Luther and A. C. Michie, Z. Elektrochem., 14: 826-9.

1908 C. Neuberg, Biochem. Z., 13: 305-20.

1909 H. N. McCoy and H。H. Bunzel, J. Am. Chem. Soc., 31: 367-73.

1910 R.F. Bacon, Philipp。J. Sci., 5: 281-303.

1910 E. Baur, Z, physik. Chem., 72: 232-37.

1911 L. Bruner and J. Kozak, Z. Elektrochem., 17: 354-60。

1912 H. Schiller, Z. physik. Chem., 80: 641-69.

1913 E。Baur, Ber., 46: 852-63. 


\section{6}

\section{REFERENCES}

1913 D. Berthelot and H. Gaudechon, Compt. rend., 157: 333-5.

1913 M. Boll, Compt. rend., 156: 1891 $\circ 4$.

1913 G. Courtois, Bull. soc. chim。, 13: 449-54.

1913 H. Euler and S. Ryd, Biochem. Z., 51: 97-106.

1913 J.H. Mathews and L. H. Bewey, J. Phys. Chem., 17: 211-8.

1914 I. Bolin, Z. physik. Chem., 87: 490-506.

1914 G. Courtois, Compt. rend., 158: $1511-4,1688-9$.

1914 V. Henri and M. Landau, Compt. rendo, 158: 181-183.

1914 C. Neuberg and W. H. Peterson, Biochem. Z., 67: 69.

1915 A。Müller, Z. anorg。Chem., 93: 267-70。

1915 G. Trumpler, Z, physik。Chem., 90: 385-457.

1916 K.A. Hofmann and K. Schumpelt, Ber., 49: 303-17.

1918 E. Baur, Helv. Chim。Acta, 1: 186-201.

1918 E. C.Hatt, Z. physik. Chem., 92: $513-62$.

1919 E. Baur, Z. Elektrochem., 25: 102-9。

1920 J. Aloy and E. Rodier, Bull。 soc. chim. France, 27: 101.

1922 J. Aloy and E. Rodier, Bull。 soc. chim. France, 31: 246。

1922 E. Baur, Z. physik。Chem,, 100: 36-41.

1922 E. Baur and A. Rebmann, Helv。Chim. Acta, 5: 221-239。

1922 A. Rosenheim and G. Trewendt, Ber。, 55B: 1957-60.

1923 J. Aloy and A.Valdiguie', Bull. soc. chim., 33: 572-6; Compt. rend., 176: $1229-31$.

1923 G. Courtois, Bul1, soc。chim。, 33: 1761-73, 1773-85.

1924 E. Baur, Z physik。Chem., 111: 315-8.

1924 P。F。Büchi, Z. physik. Chem。, 111: 269-314.

1925 J. Aloy and A.Valdiguie', Bull, soc。chim., 37: 1135-40.

1925 W. T. Anderson and F。W. Robinson, J。Am. Chem. Soc, 47: 71 8-25。

1925 G。 Berger, Rec。trav. chim。, 44: 47-67。

1926 E. J. Bowen and H. G. Watts, J. Chem. Soc., 1926: 1607-12.

1926 R. H. Müller, Biochem。Z., 178: 77-8.

1927 S. Hakomori, Sci。Repts。Tôhoku Imp. Univ., 16: 841-59. 
97

REFERENCES

1928 J。C. Ghosh and B. N. Mitter, Quart, J. Indian Chem, Soc。, 4: 353-366.

1928 R。H. Müller, Proc. Roy. Soc. London, Al21: 313-7.

1928 W. West, R. H. Müller, and E. Jette, Proc. Roy. Soc。London, A121: $294 \circ 8$ 。

1929 E. Baur, Helv. Chim. Acta, 12: 793-806.

1929 W. C. Pierce, J. Am. Chem. Soc。 51: 2731-8。

1929 W.C. Pierce, A. Leviton, and W. A. Noyes, J。Am。Chem.Soc., 51: $80-9$.

1930 W.G. Leighton and G.S. Forbes, J. Am. Chem. Soc。, 52: 3139-52.

1931 C.Ouellet, Helv. Chim. Acta, 14: 936-66.

1932 E. Baur, Z. physik. Chem., B16: 465-70.

1932 L。 J. Heidt and F. Daniels, J. Am.Chem. Soc., 54: 2384-91.

1933 F. P.Brackett, Jr., and G. S. Forbes, J. Am. Chem, Soc, 55: 4459-66.

1934 F. Diénert and F。Villemaine, Compt. rend., 199: 1113-4。

1934 G。S. Forbes and L。J。Heidt, J。Am. Chem。Soc., 56: 2363-5.

1935 J. C. Ghosh, D. S. Narayanmurti, and N. K. Roy, Z physik. Chem., B29: 236-46.

1935 E. Schneider, Z。 physik. Chem。, B28: 311-22.

1936 E. Baur, Helv. Chim. Acta, 19: 234-46。

1936 J.C.Ghosh, T. Banerjee and B.Bhatta, Z. physik,Chem., B32: 163-7.

1936a J. C. Ghosh and B. B. Ray, J. Indian Chem。Soc., 13: 1-10。

1936b J. C。Ghosh and B. B。Ray, Z. physik。Chem., B32: 158-62.

1936 E. C. Pitzer, N. E. Gordon, and D。A. Wilson, J. Am,Chem. Soc., 58: 67-70.

1937 P. Pringsheim, Physica, 4: 733-45.

1938 J。H。Křepelka and Z。Résö, Collection Czechoslov. Chem. Commun., 10: 559-81。

1938 E. Montignie, Bull. soc. chim. France, 5: 564.

1938 J.Weiss, Trans。Faraday Soc., 34: 451-6。

1940 A. H. Carter and J.Weiss, Proc. Roy. Soc. London, Al 74: 351-70.

1941 L. F. Epstein, F. Karush, and E。 Rabinowitch, J. Optical Soc. Am., $31: 77-84$ 。 
1942 D. Lipkin and S. I. Weissman, Columbia Report A-520, Dec. 17, 1942。

1942 T. L. Rama Char, J. Indian Chem.Soc。, 19: 369-76.

1942 G. M. Schwab and A. Is sidoridis, Ber., 75B: 1048-51.

1946 J. J. McBrady and R. Livingston, J. Phys. Chem., 50: 176-90.

1951 S. Ahrland, Acta Chem. Scand., 5: 199-219.

1951 J. J. Katz and E. Rabinowitch, "The Chemistry of Uranium," National Nuclear Energy Series, Division VIII, Volume 5, McGraw॰Hill Book Co., Inc., New York. 